\title{
The Development and Psychometric Analysis of an Instrument to Measure a Woman's Experience of Childbirth
}

\author{
Elizabeth Viens Rini
}

Follow this and additional works at: https://researchrepository.wvu.edu/etd

\section{Recommended Citation}

Rini, Elizabeth Viens, "The Development and Psychometric Analysis of an Instrument to Measure a Woman's Experience of Childbirth" (2014). Graduate Theses, Dissertations, and Problem Reports. 6507. https://researchrepository.wvu.edu/etd/6507

This Dissertation is protected by copyright and/or related rights. It has been brought to you by the The Research Repository @ WVU with permission from the rights-holder(s). You are free to use this Dissertation in any way that is permitted by the copyright and related rights legislation that applies to your use. For other uses you must obtain permission from the rights-holder(s) directly, unless additional rights are indicated by a Creative Commons license in the record and/ or on the work itself. This Dissertation has been accepted for inclusion in WVU Graduate Theses, Dissertations, and Problem Reports collection by an authorized administrator of The Research Repository @ WVU.

For more information, please contact researchrepository@mail.wvu.edu. 
The Development and Psychometric Analysis of an Instrument to Measure a Woman's Experience of Childbirth

\author{
Elizabeth Viens Rini, RN MSN
}

Dissertation submitted to

School of Nursing at West Virginia University

in partial fulfillment of the requirements for the degree of

Doctor of Philosophy in Nursing

\title{
Committee
}

Kari Sand-Jecklin, Ed.D., Chair Janet Bryanton, Ph.D.

Ilana Chertok, Ph.D.

Leslie Cottrell, Ph.D.

Stacey Culp, Ph.D.

Department of Nursing

Morgantown, West Virginia

2014

Keywords: instrument, psychometric, childbirth, childbirth experience

Copyright 2014 Elizabeth Viens Rini 


\begin{abstract}
The Development and Psychometric Analysis of an

Instrument to Measure a Woman's Experience of Childbirth
\end{abstract}

\title{
Elizabeth Viens Rini, RN MSN
}

This paper describes the development and testing of the Women's Experience in Childbirth Survey (WECS). Although many qualitative and quantitative studies of the childbirth experience have been published, there is no comprehensive instrument that measures the physical, emotional, cognitive, and social aspects of the experience. Forty nine Likert-type items were generated from review of the literature and feedback from mothers participating in two pilot studies. Content validity was analyzed with both pilot studies. For this study, the WECS was administered to 305 inpatient post-partum women at two community hospitals. A sub sample of women completed the WECS at least two weeks after discharge for test-re-test reliability analysis. Data analysis identified four sub-scales that aligned with the conceptual framework: Support during Childbirth, Physical and Emotional Responses to Childbirth, Transformative Experience of Childbirth, and Handling Pain. The number of items was reduced to 42 based on factor analysis. Validity of the WECS was supported by comparison to known groups: age, parity, length of labor, support, and medical interventions. Reliability of the WECS was measured by an alpha coefficient $=.87$; alpha coefficients for the subscale scores ranged between .66 and .82 . Test-retest analysis found no significant difference between inpatient WECS scores and post-discharge scores, although three of the subscale scores were significantly different from time to time. Overall, the WECS appears to be a sufficiently valid and reliable instrument that would benefit from further development. A fully developed WECS could be used to determine the most significant aspects of a multidimensional experience in order to improve care and assist the woman in her transition to becoming a mother. 


\section{TABLE OF CONTENTS}

Abstract

List of Tables

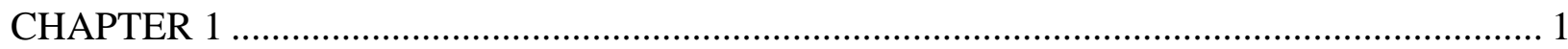

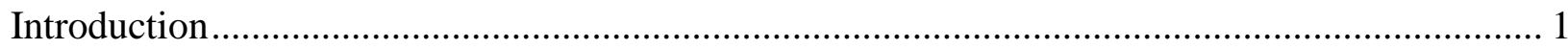

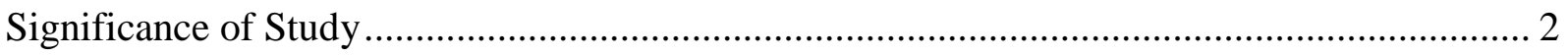

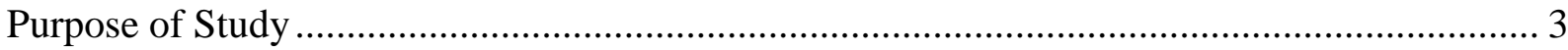

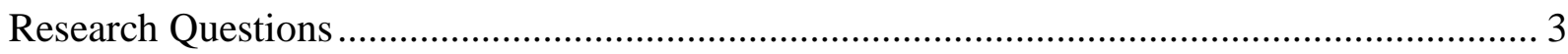

Method of Study …..................................................................................................... 3

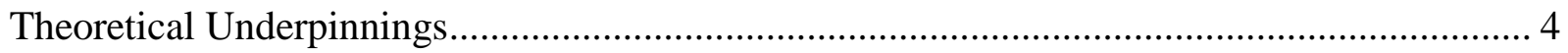

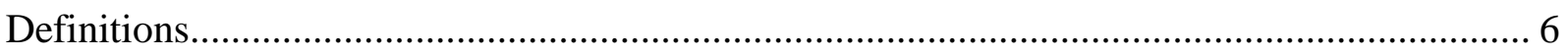

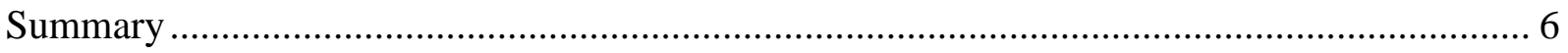

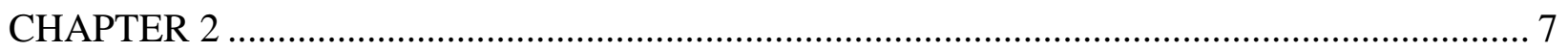

Perceptions of Childbirth Experiences.................................................................... 7

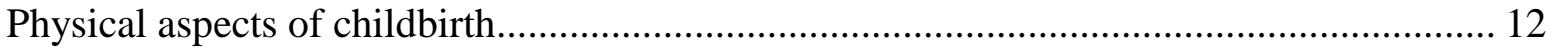

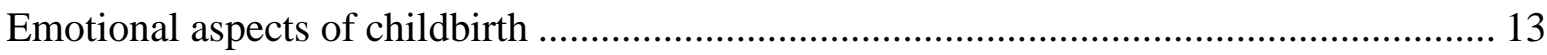

Cognitive aspects of childbirth ......................................................................... 14

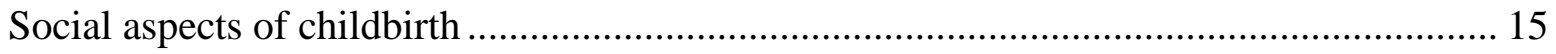

Existing Measures of the Childbirth Experience ............................................................... 16

The Questionnaire Measuring Attitudes about Labor and Delivery............................... 18

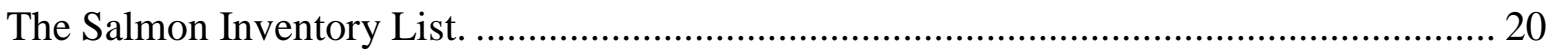


The Cognitive Schema Scale ............................................................................... 23

The Childbirth Experience Questionnaire ................................................................. 24

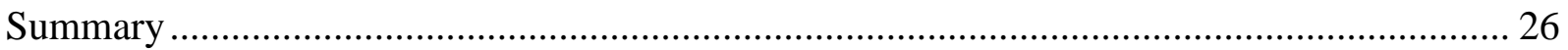

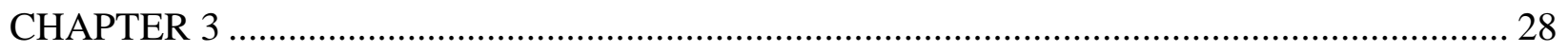

Instrument Development Phase One ........................................................................ 29

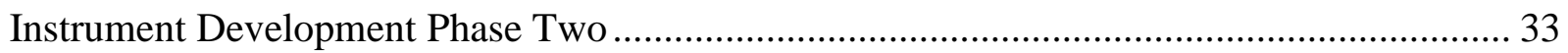

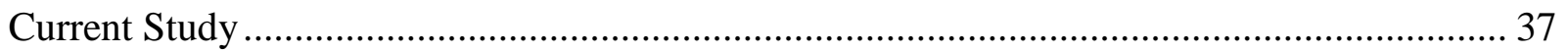

Human rights considerations.......................................................................... 38

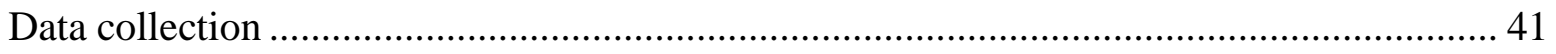

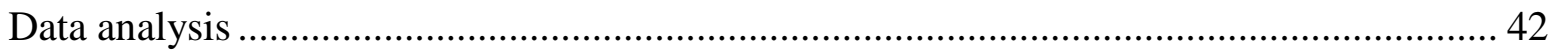

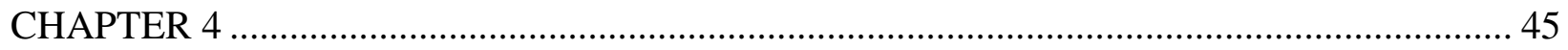

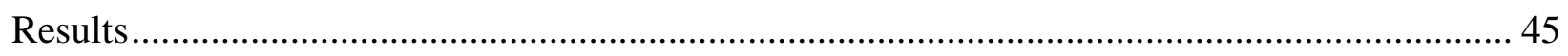

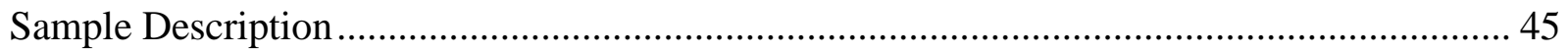

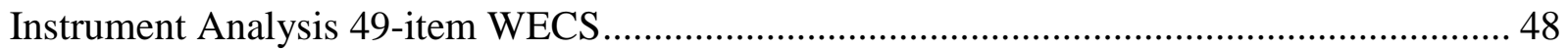

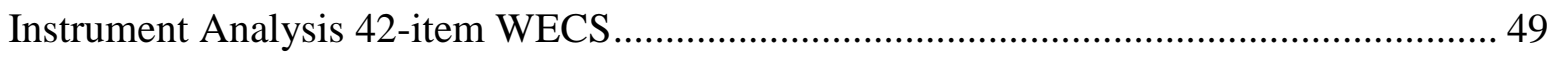

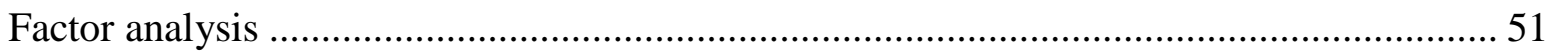

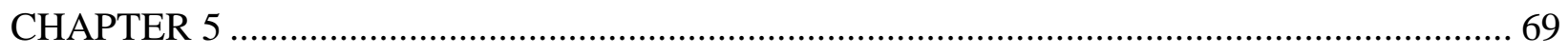

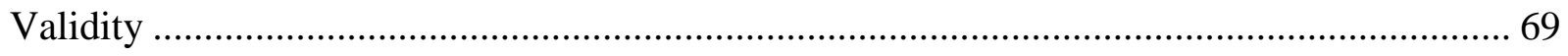

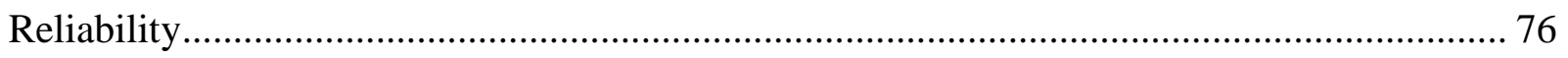

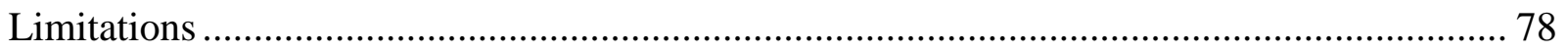

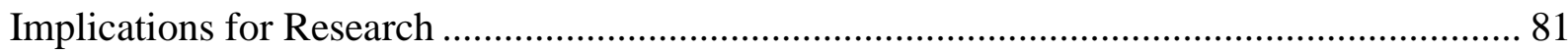


References 85

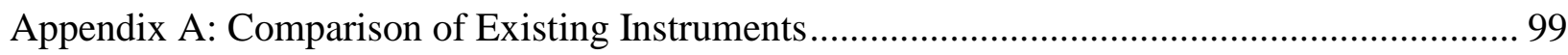

Appendix B: Comparison of Existing Instruments to Conceptual Framework ....................... 101

Appendix C: WECS Phase 1 Content Validity Scores ...................................................... 106

Appendix D: Progression of Item Development for WECS ............................................ 108

Appendix E: WECS Phase 2 Content Validity Scores ..................................................... 115

Appendix F: Instrument and Data Collection Forms ................................................... 117

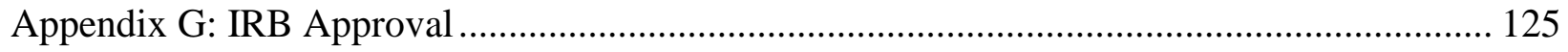

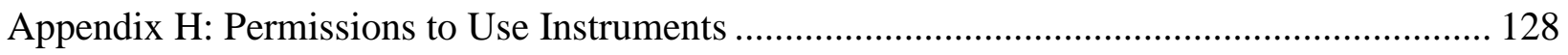




\section{List of Tables}

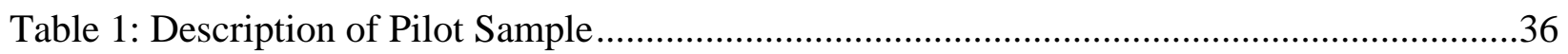

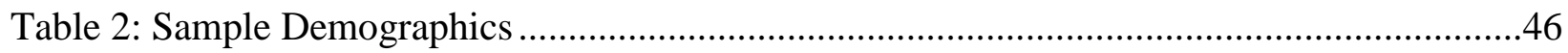

Table 3: Items and Factor Loadings Support during Childbirth Subscale.................................52

Table 4: Items and Factor Loadings Physical and Emotional Responses to

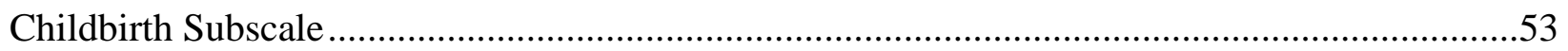

Table 5: Items and Factor Loadings Transformative Experience Subscale...............................54

Table 6: Items and Factor Loadings Handling Pain Subscale .................................................55

Table 7: Significant ANOVA Results for 42-item WECS .................................................56

Table 8: Significant Correlation Results for Subscale Scores .............................................57

Table 9: Significant ANOVA Results for Support during Childbirth .....................................58

Table 10: Significant ANOVA Results for Physical and Emotional Response...........................59

Table 11: Significant ANOVA Results for Transformative Experience ..................................60

Table 12: Significant ANOVA Results for Ability to Handle Pain ..........................................62

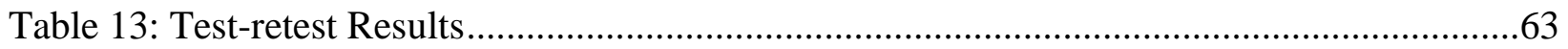

Table 14: Paired t-test Results for Subscales .....................................................................66 


\section{ACKNOWLEDGEMENTS}

To borrow from John Donne, no man is an island. I could not have thrived and succeeded in this endeavor without the support of many people. The first and most consistent is Guy Rini, my husband. He was not only encouraging but supportive throughout the entire six years. Thank you for the cups of coffee during long hours, missing social events so I could write or study, and driving back and forth so I would not be a driving hazard.

On the first day of classes I was embraced by a wonderful cohort of fellow students who listened thoughtfully as I talked through concepts and methods and offered constructive feedback. Thank you and best wishes to Vera Barton-Caro, Kristi Childers, Mariann Harding, and Crystal Sheaves. You all have made the journey pleasant and it has been an honor to work with you. A warm thank you to Dr. Mary Jane Smith; from the first day in program she directed me toward flow consciousness. I was then able to name the optimal experiences I had observed during childbirth.

Thank you to all the members of my committee for the diverse contributions and supportive roles you played in this project. You have provided a vision of possibilities beyond my usual spectrum. Special thanks go to Dr. Kari Sand-Jecklin who did not waiver when I told her I wanted to pursue instrument development for my dissertation. I would not have taken the path toward measuring perception of the childbirth experience except for the published research of Janet Bryanton. She provided encouraging feedback in communications prior to joining my committee and is a terrific proof reader for manuscripts. 
Thanks to the nursing staffs at Jefferson Memorial, Warren Memorial, and Winchester Medical Center for allowing me to enter your busy work space and gather the data for this study. Thanks also to the nursing faculty and college administration at Blue Ridge Community and Technical College for allowing me the flexibility of scheduling work around optimal data collection times.

Of course this study wouldn't have been possible if it hadn't been for the generosity of all the mothers who participated in this study. Even when they were tired, hurting, or distracted; they were willing to take time and talk about their births, hoping what they shared would help future birthing women. That is my hope also.

This study was funded in part by an internal grant from the Office of Research and Graduate Education at the Health Sciences Center, West Virginia University. 


\section{CHAPTER 1}

\section{Introduction}

The day a woman labors and gives birth provides life long memories that influence her identity as a woman and as a mother. The significance of this day is reflected whenever women talk about childbirth and share their stories. Research has shown these memories and their meanings are persistent and may be stable for decades following the birth (Simkin, 1991). This chapter will provide an overview of the significance of the childbirth experience as it relates to the development and analysis of a new instrument to quantify women's experiences in childbirth.

Childbirth is a significant event in the process of becoming a mother. Research has identified multiple complex interrelated factors affecting the birth experience. Women reporting a positive birth experience describe feeling empowered, masterful in their ability to cope, and confident in their ability to meet future challenges. An early study (Mercer, 1985) identified a positive relationship between women's perceptions of their birth experience and observed mothering. Subsequent studies have not replicated this relationship (Bryanton, Gagnon, Hatem, \& Johnston, 2009; Fawcett, Pollio, \& Tully, 1992; Pridham, Lytton, Chang, \& Rutledge, 1991). Women with negative birth experiences are more likely to suffer from depression (Lemola, Stadlmayr, \& Grob, 2007; Noriko, Megumi, Hanako, \& Yasuko, 2007), post-traumatic stress disorder and poor mother-infant attachment, have less desire for subsequent pregnancies (Fairbrother \& Woody, 2007; Leeds \& Hargreaves, 2008; Soderquist, Wijma, Thorbert, \& Wijma, 2009; Waldenstrom, Hildingsson, Rubertsson, \& Radestad, 2004), or request a cesarean birth rather than experience a similar event (Avasarala \& Mahendran, 2009).

Childbirth research mirrors the history of general nursing research, beginning with a positivistic approach and maturing to current standards for both qualitative and quantitative 
studies (Polit \& Beck, 2008). Through the 1980's, nursing research about childbirth was prolific, although quantitative instruments used to measure the overall birth experience were not able to demonstrate the theoretically proposed relationships between a positive birth experience and positive emotional and parenting outcomes. Researchers expanded their studies to related topics such as postpartum depression, post-traumatic stress disorder, and patient satisfaction related to childbirth. In Europe and other developed countries where midwives provided intrapartum care, qualitative studies expanded the knowledge about the childbirth experience. It was not until 2009 that a concept analysis of the experience of childbirth was published (Larkin, Begley, \& Devane, 2009).

\section{Significance of Study}

Intrapartum nursing care in the United States follows the medical model focused on maternal-infant safety through the use of technology and interventions (McCool \& Simeone, 2002). This intrapartum focus on technology continues despite findings that it contributes to women's lower satisfaction of the birth experience (Alfirevic, Devane, \& Gyte, 2006). A review of available instruments has identified a significant lack in the ability to measure the full breadth of a woman's perception of childbirth. Current instruments do not capture birth experiences from negative to transformative and prevents nurses from understanding the effects of this important life transition and nursing's role in supporting the childbearing woman through the transition. The availability of a valid and reliable instrument to measure the childbirth experience will contribute to nursing knowledge and ultimately could improve nursing practice. Initially, nursing knowledge will be advanced by the ability to measure a significant life transition, its influencing factors, and the relationships to physical and psychosocial outcomes. Nursing 
practice will be informed by research identifying interventions associated with positive and negative birth experiences, as well as outcomes resulting from these experiences.

\section{Purpose of Study}

The purpose of this study was to develop and test an instrument designed to measure a woman's perception of her childbirth experience. The instrument is called the Woman's Experience of Childbirth Survey (WECS).

\section{Research Questions}

The research questions were based on processes and outcomes of instrument development (Streiner \& Norman, 2008). They were:

1. Is the WECS a valid measurement of a woman's childbirth experience?

2. Is the WECS a reliable measurement of a woman's childbirth experience?

3. What are the psychometric properties of the WECS?

\section{Method of Study}

This study used the process of instrument development as presented by Streiner and Norman (2008): (a) developing items, (b) determining response scales, (c) reducing bias, (d) assessing validity, (e) establishing scoring and (f) assessing administration procedures. The WECS was administered to new mothers during the postpartum hospitalization period using a cross-sectional design. Data analysis included descriptive statistics of the study sample, calculation of WECS scores, associations of WECS to variables known to influence the childbirth experience, analysis of reliability coefficients, and factor analysis of the instrument. 


\section{Theoretical Underpinnings}

Life transitions such as childbirth are vulnerable times that can either result in mastery of a new role and enhanced health, or potential illness and unhealthy coping mechanisms (Meleis, Sawyer, Im, Messias \& Schumaker, 2010). Childbirth is the most frequently studied developmental transition and is a critical event in the transition state labeled Becoming a Mother (Mercer, 2004). Transitions are characterized by the process, a sense of disconnectedness and insecurity, perception of the event, awareness of the transition, and patterns of response. Perception of the event is defined as the meaning of the event to that person. The perception can influence reactions and responses to the transition. Meleis notes that while most transitions are positive, they are not uniformly experienced, and thus are times of increased vulnerability.

The perception of the transition event is influenced by factors such as expectations, existing level of knowledge and coping skills, level of planning for the transition, and the person's emotional and physical well-being. These personal factors interact with the environment of social support and societal or cultural norms. The description of a transitional life event is closely aligned with a conceptual analysis of the childbirth experience as "an individual life event, incorporating interrelated subjective, psychological and physiological processes, influenced by environmental, organizational and policy contexts" (Larkin et al., 2009, p. e49). Transitions theory, research, and subsequent content analysis suggest organizing the instrument content according to physical, emotional, cognitive, and social aspects.

The physiologic process of giving birth is universal; however the perception of the childbirth experience is by definition, unique to each woman (Larkin et al., 2009). Perception is a neurophysiological process by which an organism gathers sensory information from the internal and external environments, becomes aware of what is happening, and stores this 
information in memory (Solms \& Turnbull, 2002). The authors note the purpose of perception is to generate actions in response to changes in the internal or external environments in order to maintain the integrity of the organism and provide an evolving sense of self. Sensory and somatic information is received, analyzed, and stored to provide information about the body in the external world. The sensory input from the internal environment is moderated by neurotransmitters and hormones that are expressed as emotions, driving behaviors toward a homeostatic equilibrium.

Perception of the birth experience is related to a woman's satisfaction of the experience, but different in its focus (Larkin et al., 2009). Larkin notes that satisfaction and perception of the experience are often used interchangeably. Satisfaction is more related to an evaluation of the care provided and requires the person distance themselves from the event (Hodnett, 2002). Perception is gathering the woman's interpretation of physiological activity during childbirth. In Hodnett's (2002) systematic review of studies on childbirth satisfaction; personal expectations, support from caregivers, quality of the patient-caregiver relationship and decision-making control were found to be the most influential factors in determining satisfaction.

During labor, the externally focused sensory perceptions of sight, sound, taste, smell, and touch provide less meaningful information to the laboring woman than the internally focused perceptions generated by the brain's monitoring of the physiologic functions of the body in labor. A woman's perception of the childbirth experience, which includes the gathering of both internal and external sensory perceptions, and her continually adaptive responses to those perceptions, affect the transition process and result in a change to her sense of self. The change to the woman's sense of self could be positive or negative. 


\section{Definitions}

The preceding theoretical underpinnings provide the basis for the definition of the woman's perception of the childbirth experience: the subjective appraisal of the physical, emotional, cognitive and social processes of giving birth are derived from the unique sensory information of her internal environment, her immediate external environment, and her responses to those stimuli.

\section{Summary}

Childbirth is an important transition period in a woman's life. Transition theory predicts that successful transitions result in an enhanced sense of mastery and role attainment; whereas unsuccessful transitions can result in illness and impaired coping. A key facilitator of a successful transition is the woman's perception of the transition event. Perception provides critical internal and external information that drives continual adaptive responses that are stored in memory. The memory of the experience changes the sense of self. Qualitative research about the childbirth experience supports the differing outcomes of both successful and unsuccessful transitions during childbirth; current quantitative studies have not consistently demonstrated the same. A valid and reliable instrument developed from both qualitative and quantitative research is needed to provide a comprehensive and predictive measure of a woman's perception of the childbirth experience. This new instrument has the potential to provide a better understanding of the perception of childbirth and its influence on maternal and neonatal outcomes. 


\section{CHAPTER 2}

\section{Literature Review}

This chapter provides a synthesis of the extant literature concerning the concepts related to the birth experience, an analysis of existing instruments used to measure a woman's perception of childbirth, and the processes used to develop a new instrument to quantify perceptions of the birth experience.

A search of the literature was performed using the online databases CINAHL and Medline with the following key words individually and in combination: childbirth, perception, positive experience, negative experience, and pregnancy outcomes. Item retrieval was limited to English language and female human subjects; there were no date limits. Additional articles were identified by retrograde review of published references and selected author searches. Studies were included that focused on the woman's subjective experience. Because of the focus on the subjective nature of the maternal experience, studies related to labor nurses or nursing assessment of quality of care were eliminated. Instruments for consideration were included if they reported to measure multidimensional factors of childbirth or an overall appraisal of the birth experience. Instruments measuring specific factors associated with childbirth such as control, labor support, or focused on psychopathology such as fear and worry, were reviewed but not included for analysis.

\section{Perceptions of Childbirth Experiences}

Despite common characteristics for many childbirth experiences, there are differences between women, differences from pregnancy to pregnancy in the same woman, as well as differences during each phase of childbirth as the woman progresses in labor (Halldorsdottir \& Karlsdottir, 1996a). Perceptions of the childbirth experience have been evaluated as a 
dichotomous variable, either positive or negative (Waldenstrom et al., 1996; Waldenstrom, 1999; Waldenstrom, 2003; Waldenstrom et al., 2006). A single item measurement such as this does not allow for an understanding of the factors of a multidimensional experience such as the birth experience, nor can it identify which factors are more important for predicting a positive experience (Streiner \& Norman, 2008).

While the majority of women report a positive experience in childbirth, two European studies report a prevalence of a negative experience between 7-15\% (Stadlmayr et al., 2006; Waldenstrom et al., 2004). Negative childbirth experiences have been associated with posttraumatic stress disorders and depression (Beck, 2004a; Beck, 2004b; Soet, Brack, \& Dilorio, 2003), impaired maternal infant attachment (Davies, Slade, Wright, \& Stewart, 2008; Weisman et al., 2010), increased demand for future elective cesarean sections, and decreased desire for future pregnancies (Gottvall \& Waldenstrom, 2002).

Demographic and obstetrical factors have been associated with a perception of the birth experience. Older and multiparous women are more likely to report a positive birth experience (Ayers \& Pickering, 2005; Baston, Rijnders, Green, \& Buitendijk, 2008; Waldenstrom, 1999). Shorter labors, vaginal births, fewer medical interventions, and giving birth in a homelike environment are associated with more positive experiences (Creedy, Shochet, \& Horsfall, 2000; Dencker, Taft, Bergqvist, Lilja, \& Berg, 2010; Hodnett, Edwards, \& Walsh, 2005; Mackey, 1995; Seguin, Therrien, Champagne, \& Larouche, 1989).

Childbirth education has varying effects on the perception of the childbirth experience. A meta-analysis of childbirth education was performed to assess the effects of classes on knowledge, anxiety, control, support, early parenting abilities and psychological adjustment (Gagnon \& Sandall, 2007). Reviewers were unable to identify effects of education and 
recommended further research. A review of the various educational models for childbirth identified at least three educational models and numerous certifying organizations for educators (Walker, Visger, \& Rossie, 2009).

Socioeconomic variables such as income level, educational achievement, race and ethnicity affect maternal-infant health (U.S. Department of Health and Human Services, 2014). Poverty can affect a woman's health directly as well as limit access to healthcare. It is known that women without adequate prenatal care are likely to have less satisfactory birth experiences (Waldenstrom et al., 2004). Educational achievement has been shown to predict a persons perception of her health status (Delpierre et al., 2009). Higher educational achievement is associated with better health status. Minority groups also have poorer health status; this in part may be due to lower educational achievement and income that are associated with being in a minority group. Black women are more likely to have poor pregnancy outcomes than White women (Tucker, Berg, Callahan \& Hsia, 2007).

Psychosocial factors influencing a positive experience include increased maternal selfesteem, decreased stress and anxiety, maternal expectations being met, increased perception of control, decreased fear of pain, and participation in decision making (DiMatteo, Kahn, \& Berry, 1993; Green \& Baston, 2003; Waldenstrom, 1999; Waldenstrom et al., 2006). Support during labor, specifically a positive perception of her partner, nurse, midwife, and doula is associated with a positive birth experience (Halldorsdottir \& Karlsdottir, 1996a; Hodnett, Gates, Hofmeyr, \& Sakala, 2007). One study (Bryanton, Gagnon, Johnston, \& Hatem, 20008) found that for women having a vaginal birth; being together with the infant, the degree of maternal awareness helpfulness of the partner's support, degree of relaxation, and degree of control were the five most significant predictors of a woman's' perception of the childbirth experience. A woman's 
expectations for birth are highly predictive of how she will perceive the event (Fenwick, Gamble and Hauck, 2006; Hauck, Fenwick, Downie, \& Butt, 2007). Studies have shown a positive maternal experience is related to desirable maternal-newborn outcomes. Hodnett and colleagues (2007) reported higher Apgar scores in newborns and fewer neonatal intensive care admissions. Simkins (1991) found women with a positive birth experience reported enhanced maternal selfesteem. Similarly, a study of early parenting self-efficacy (Bryanton, Gagnon, Hatem \& Johnston, 2008) found a significant positive correlation between women's parenting self-efficacy 12-48 hours after giving birth and their perception of the birth experience, their general selfefficacy, and their perception of their relationship with their partner.

Each social group has a definition of pregnancy and childbirth that includes the culturally proper way to prepare for childbirth, who will attend and support the mother during birth, where the birth will occur, what medications and technology are appropriate and when they are appropriate, and finally who controls the decision-making during the birth process (Jordan, 1993). This is important since many of the studies in the childbirth literature were conducted in Europe and Australia where midwifery is the predominant care model for hospital and home births. The social context influencing birth in the United States is a medical process with more than $95 \%$ of all births occurring in hospitals where invasive medical procedures are common and the physician often controls the decision-making (McCool \& Simeone, 2002).

For some women childbirth is more than just a positive experience; it is transcendent. Several authors have noted the similarities between women's description of a transcendent birth experience and the optimal experiences known as "flow consciousness" (Humenick, 1998; Humenick, 2006; Walsh, 2008). Flow is a state of consciousness occurring in a variety of situations whenever a person is fully engaged in an activity to the exclusion of all other 
sensations (Csikzentmihalyi, 1990). Any activity that is intrinsically rewarding to the person can result in flow. Flow studies have been conducted with exceptional athletes, musicians and artists, and persons surviving extreme environmental conditions. The basic construct of flow is a balance between perceived ability and the challenge of a situation that has clear goals and provides unambiguous feedback. Flow is accompanied by a loss of the sense of awareness of self, a feeling of being at one with the universe, a sharing of the harmony of a transpersonal experience, and a sense of timelessness except for the rhythm of the activity. Flow provides a sense of control or mastery of the experience that persists after the event. A recent qualitative study of laboring women identified several aspects of the childbirth experience that are similar to flow consciousness: the challenge of labor, an enhancement of the woman's sense of self, a loss of self during labor, an altered sense of time, and being one with the activity (Parratt \& Fahy, 2003). This is the only research of the childbirth experience relating to flow, although the themes were not labeled as such.

Csikszentmihalyi (1989) developed a specific qualitative method, "Experience Sampling Method" to study flow states, opining that flow should only be studied using qualitative methods less it be trivialized (personal communication, June 26, 2008). However, a quantitative instrument to measure flow was developed for use in athletic studies (Jackson \& Marsh, 1996). Jackson noted the need to study flow in larger samples where it is not always feasible to interrupt the event to collect data about flow consciousness. The Flow State Scale however, did not include items related to the characteristics of transpersonal harmony or being at one with the world.

Transitions theory, research, and subsequent content analysis suggest a conceptual framework for the instrument according to physical, emotional, cognitive, and social aspects of 
the birth experience. The following sections will introduce the literature to support the framework.

Physical aspects of childbirth. The two most prominent physical aspects of the labor experience are pain and the physical work of labor. Pain is related to, but separate from the progress of the contractions (Lowe, 1996). Longer labors with more medical interventions are more likely to be associated with negative experiences of birth than labor pain (Lavender, Walkinshaw, \& Walton, 1999; Waldenstrom et al., 1996). While pain in childbirth is independent of feelings of fulfillment or achievement (Salmon, Miller, \& Drew, 1990), women who feel overwhelmed by labor and pain may view themselves as failures and feel powerless (Schneider, 2009). Cultural beliefs about childbirth pain, pain management, and behavior during labor provide a basis for a woman's self-confidence to manage the pain of childbirth (Callister, Khalaf, Semenic, Kartchner, \& Vehvilainen-Julkunen, 2003). The memory of experienced pain from childbirth does not completely fade over time, but can provide a woman with a sense of accomplishment and strength upon which she may continue to draw (Niven \& Murphy-Black, 2000).

Because pain during childbirth is a common, pain management strategies for labor are an important aspect of the birth experience. Successful management of pain may result in a woman's sense of mastery and accomplishment (Callister, 2006), empowerment (Halldorsdottir \& Karlsdottir, 1996b), and a change to her sense of self (Parratt \& Fahy, 2003). In one study, a woman's self-confidence in her ability to manage pain was the most significant predictor of her pain perception (Lowe, 1989). A meta-analysis of pain management strategies identified methods that provide effective pain relief and the associated risks to their use in labor (Jones, Othman, Dowell, Alfirevic, Gates, Newburn, et al., 2012). Pharmacological pain interventions, 
such as epidural analgesia are associated with higher rates of instrumental births. Nonpharmacologic pain strategies may provide pain relief and are also associated with higher levels of satisfaction with the birth experience. Hidaka and Callister (2012) found that for the women who used epidural analgesia in their study, there were ambivalent feelings about the birth; even when they made they reported satisfaction with the analgesia and felt joy at the birth.

The average length of labor is 12 hours, with strong muscular contractions of the uterus occurring every 2 to 5 minutes during active labor (Perry, Hockenberry, Lowdermilk, \& Wilson, 2010). The involuntary work of the uterus is followed by the additional effort of bearing down to expel the newborn. In many hospitals, a laboring woman is not permitted food or oral fluids to meet the metabolic requirements of labor. Reports of fatigue or exhaustion are common, and some women report feelings of impending death (Halldorsdottir \& Karlsdottir, 1996a). In addition to the work of labor, women often experience unpleasant physical sensations of nausea, vomiting, diarrhea, chills, and shaking; no studies have been identified that include these symptoms and their effects perceptions of the birth experience.

Emotional aspects of childbirth. Women experience a wide range of emotions during labor that may change from one phase of labor to another, or they may experience two seemingly conflicting emotions at the same time (Halldorsdottir \& Karlsdottir, 1996a; Parratt \& Fahy, 2003). Feelings of fulfillment and achievement are independent of other emotions that may be experienced during childbirth (Salmon \& Drew, 1992; Schneider, 2009). It is culturally expected that women will experience positive emotions such as joy and excitement; however women also report negative emotions such as anxiety, depression, and fear (Salmon \& Drew, 1992; Peirce, 1994). In a Swedish study, almost $75 \%$ of the women having a positive experience reported some sense of panic throughout labor (Waldenstrom, 2003). Fear and anxiety are predictive of a 
negative birth experience (Ayers \& Pickering, 2005; Bryanton et al., 2008b; Green, Coupland, \& Kitzinger, 1990; Green \& Baston, 2003; Soderquist, Wijma, Thorbert, \& Wijma, 2009).

Cognitive aspects of childbirth. The increasing strength and frequency of labor contractions result in a woman becoming internally focused as labor progresses. Women use visualization or focusing on the baby as some of the cognitive strategies to maintain self-control and self-manage pain (VandeVusse, 1999). Women without a cognitive sense of what is happening may feel helpless (Nilsson \& Lundgren, 2009).

Women also report an altered sense of time during labor, it either moving slowly or quickly (Peirce, 1994; Salmon et al., 1990). Beck's (1983) study of time perception in the latent and active phases of labor quantified a significant difference in women's ability to accurately assess time intervals during those phases. Maher's (2008) study of laboring women's perception of time found they were so intensely focused on labor that they could not accurately recognize the passing of time unless others marked significant milestones for them.

A woman's sense of control during childbirth has been extensively studied and is in itself a multidimensional concept. Control during childbirth consists of internal and external factors. Internal factors include the woman's perception of her ability to control her own behavior, control her emotions, and cope with the contractions in order to self-manage pain (Ford, Ayers, \& Wright, 2009; Green \& Baston, 2003; O'Hare \& Fallon, 2011). Beliefs about control are often socially and culturally derived. Women gain their understanding of the female's body and childbirth expectations from their own mothers, other women in their social group, or childbirth education classes; these may have either a positive or negative influence on their sense of control during birth (Green \& Baston, 2003; Schneider, 2009). Several studies identified a seemingly paradoxical relationship, where women expressed a need to relinquish mental control of the birth 
process in order for their bodies to be free to give birth (Lundgren, 2004; Parratt \& Fahy, 2003).

The decision to follow the physical sensations provided a sense of control. Generally, a high sense of control is correlated with a positive birth experience (Goodman, Mackey, \& Tavakoli, 2004).

External factors of control focus on the birthing environment and the people around the laboring woman (Ford et al., 2009; O'Hare \& Fallon, 2011). Aspects of external control related to the environment include being allowed to change position and receive other physical comfort measures. The people sharing the birth environment include spouses, partners, friends, and health care providers, each with various roles to play. Control over the people in the birth environment is related to the degree of respect and caring provided by those supporting the laboring woman. Extending from control of the environment is the idea of being involved in decision-making about medical interventions. The need for control varies from woman to woman, as well as for each woman during differing stages of labor. Women identify the need to trust those caring for them during labor so they can focus on their body's responses to labor. The lack of a sense of control leaves a woman feeling powerless (Schneider, 2009) and is a predictor of post-traumatic stress disorder (Beck, 2004b; Creedy et al., 2000).

Social aspects of childbirth. Women in labor need to feel supported by the people they determine are important to their wellbeing (Bruggemann, Parpinelli, Osis, Cecatti, \& Carvalhinho, 2007; Polomeno, 1998). A concept analysis of labor support identified four aspects of labor support: emotional support, physical support, provision of information, and partner support (Burgess, 2014). A meta-analysis investigating the effects of continuous labor support found that with continuous support, women had shorter labors, fewer medical interventions, received less pain medication, and had more positive experiences than women without 
continuous support (Hodnett et al., 2013). Several authors commented that control and support are closely linked, and relinquishing one factor in favor of another may not improve the experience for women (Ayers, 2007; Ford et al., 2009; Wright, McCrea, Stringer, \& MurphyBlack, 2000).

The person providing support is the critical determinant in achieving the optimal outcomes. In the hospital births of North America, labor support may be provided by a registered nurse, the woman's partner, family member, friends, or a doula. Hodnett and colleagues (2013) determined that a female who was not related to the birthing woman, the doula, is critical to achieving desirable birth outcomes. Women choose the people who will be present for the birth carefully. While it is often presumed that the father will be present, some women will ask others to attend on the basis of common values about how the birth will be conducted, for family bonding, or for the comfort that they will provide (Price, Noseworthy \& Thornton, 2007). The presence of the father of the baby during labor was associated with more positive birth experiences than those of women who did not have partner support (Gungor \& Beji, 2007).

\section{Existing Measures of the Childbirth Experience}

The following section will compare and critique four instruments and a single item scale that have been used to measure a woman's overall perception of her birth experience. The purpose and conceptualization of the instrument, methodology for development, samples, validity and reliability measures, and scales as available in publication will be discussed. A summary of the analysis of the four instruments including the purpose of each instrument, number of items, type of response scale, sample characteristics, timing of administration, factor analysis, and reliability measures is presented in Appendix A. 
The simplest method used to measure a woman's perception of childbirth is a single scale with positive and negative as anchor terms (Waldenstrom et al., 1996; Waldenstrom, 1999; Waldenstrom, 2003; Waldenstrom et al., 2006). This scale rates the overall experience, combining all dimensions of the birth experience into one score, and does not allow for an understanding of which factors in the multidimensional experience are more important in predicting a positive or negative experience. As with all semantic scales, the choice of anchor terms must be clear to all respondents or the results are not reliable (Streiner \& Norman, 2008). A reliability co-efficient cannot be calculated from a single item. Waldenstrom's studies used either a 5-point or 7-point differentiation between anchor words, and then categorized the responses as positive or negative depending on the effect being studied. Most results in these Swedish samples were overwhelmingly positive, with a median score of 6.5 on a 7 point scale. Negative appraisals ranged from 3.2 to $10.4 \%$ of the samples.

In addition to the overall perception of birth experience item, Waldenstrom and colleagues (1996) used a series of questions about the labor experience concerning pain intensity, attitude to pain, anxiety in labor, participation in birth process, satisfaction with self, mental coping, support from partner, and the attending midwife's sensitivity. These were not considered a unified instrument; rather they were individual items using a 7-point scale with opposite word anchors. Each scale was used as a variable for regression models comparing primiparas and multiparas. Waldenstrom did not find any significant differences in perceptions between primiparas and multiparas in this study. However, a subsequent study using the same scales did identify multiparity as a significant predictor of satisfaction with the birth experience (Waldenstrom, 1999). In addition to rating the overall birth experience, this method was used to determine the woman's perception of time passing, missing pieces of the labor process, feelings 
of panic, the need to groan or scream, the need for contact, and decision making during labor. Six variables were found to explain a positive perception of the birth experience: support by midwives, duration of labor, pain, expectations of labor, involvement and participation with the birth process, and fewer surgical procedures.

The Questionnaire Measuring Attitudes about Labor and Delivery. The Questionnaire Measuring Attitudes about Labor and Delivery (QMAALD), also known as the Perception of Birth Scale, was originally developed to measure the difference between women having a vaginal birth and an emergency cesarean birth (Marut \& Mercer, 1979). The original version contains 29 items with a 5-point Likert type scale. Fifteen of the items were taken from a previously published instrument used to measure the hypnotic susceptibility of women using the Lamaze method (Samko \& Schoenfeld, 1975). Fourteen items were added by the authors based on qualitative interviews with women having primary cesarean births (Marut, 1978). An alternative version of the QMAALD was developed in order to measure the differences between women having a vaginal birth, a planned cesarean birth, or an emergency caesarean birth (Cranley, Hedahl, \& Pegg, 1983). The alternate instrument, for use with women having planned cesarean births, replaces items related to the labor experience with items related to perioperative care.

The QMAALD has been used the United States and Canada for studies with primiparous and multiparous women (Bennington, 2010; Bryanton et al., 2008a; Bryanton et al., 2008b; Bryanton et al., 2009; Cranley et al., 1983; Fawcett \& Knauth, 1996; Fawcett \& Weiss, 1993; Marut \& Mercer, 1979; Mercer, Hackley, \& Bostrom, 1983; Mercer, 1985). The overall reliability coefficient has been reported between .76 and .87. The QMAALD provides one score 
by summing the responses. Potential scores range from 29 to 145, with a higher score indicating a more positive experience; the actual reported range from the cited studies is 61 to 137.

The majority of studies do not report a mean score for the entire sample; instead means among different subgroups are reported. Bennington (2010) did report a mean QMAALD score of $107.07(\mathrm{SD}=18.92)$ for her study of 300 women. A report of the sample means in these studies would have provided an understanding of the distribution of scores in the samples, in light of findings by Waldenstrom that the perception of birth is predominantly positive (Waldenstrom et al., 1996; Waldenstrom, 1999; Waldenstrom, 2003; Waldenstrom et al., 2006).

Fawcett and Knauth (1996) performed factor analysis on the QMAALD in a study of 345 women, as a method to support the validity of the instrument. Using exploratory factor analysis, nine factors were initially identified, but four barely met an eigenvalue of 1.0 and accounted for less than $5 \%$ of the variance. All items were forced on a 5-factor solution and accounted for $54.5 \%$ of variance in scores. Four items were eliminated because of inadequate loading or ambiguity, resulting in a 24-item instrument. The factors were labeled: delivery experience, labor experience, delivery outcomes, partner participation, and awareness.

Despite the designed purpose of the instrument to measure the difference between women having vaginal and cesarean births, it has been used by other researchers as a global measure of the experience of giving birth. Mercer used the instrument for additional studies related to development of the concept of becoming a mother, but could not consistently identify a relationship between the birth experience as measured by the QMAALD and observed mothering behaviors (Mercer et al., 1983; Mercer, 1985). Bryanton and colleagues (2009) used the instrument in a study of predictors of parenting behaviors, and found the birth experience was not a significant predictor of the Nursing Child Assessment Satellite Training (NCAST) Feeding 
Scale total score that was used to measure maternal attachment and responsive care in mother's at 1 month following birth. The QMAALD was recently used in a correlational study of women's birth experience, spirituality, and maternal-infant attachment (Bennington, 2010). A significant correlation was found between the birth experience and spirituality, but this did not remain a significant variable when included in a regression model with maternal-infant attachment.

When the QMAALD is compared to the conceptual blueprint for physical, emotional, cognitive, and social aspects of the childbirth experience, multiple aspects are not represented. In the physical component, there are not items for the work of labor, timing of contractions, and unpleasant physical sensations. Emotional aspects represented include fear and worry. Two items referred to a "feeling state." The cognitive aspect focused on Lamaze strategies for coping with labor, expectations, having a sense of control, and being able to have choices about examinations during labor. Altered sense of time, enhanced sense of self, and flow consciousness were not represented. For the social aspects, the work of the labor coach was the primary focus. The physical or emotional support from the healthcare team or satisfaction with choices was not assessed in this instrument. Appendix B provides a comparison of the items on the QMAALD with the conceptual blueprint.

The Salmon Inventory List. The Salmon Inventory List (SIL) was developed to identify the multidimensional aspects of childbirth (Salmon et al., 1990). The SIL uses a 7-point semantic differential scale. Semantic differential scales are intended to provide differentiation of the qualities and intensity of a concept by using a series of bipolar scales (Osgood, Suci, \& Tannenbaum, 1957). 
The items were developed by interviewing pregnant women and new mothers in the hospital following birth. A female assistant asked women to describe the birth experience. She recorded only the adjectives, which were subsequently reviewed by the researchers. Obviously redundant words were eliminated, but words that were considered "idiosyncratic or ambiguous" were also eliminated without any attempt to clarify their meaning.

The instrument was administered to two separate groups: 106 pregnant women and 82 postpartum mothers. Demographic information about marital status, age, parity, and type of birth were reported; however scores were not provided for these groups. Principal component analysis of the instrument identified two factors that accounted for $50 \%$ of variance. The factors were labeled achievement and pleasantness. The item labeled painful/not painful did not load onto either factor. The authors remarked that the instrument should produce a score for each factor, since the childbirth experience is a multidimensional concept. The mean score for postpartum women for the achievement factor was 3.4; the mean score for pleasantness was 3.8. Reliability coefficients were not published (Salmon et al., 1990).

Originally the SIL consisted of 14 bipolar word pairs, which were revised to 20 word pairs. The authors stated that they wanted to clarify that the polar terms were true opposites and that all items were measured, so they separated 6 of the 14 word pairs to measure the attribute in only one direction per item (Salmon \& Drew, 1992). The revised scale was also subjected to principal component analysis and produced three factors with alpha coefficients: fulfillment/delight ( $\alpha=.83)$, distress $(\alpha=.54)$, and difficulty $(\alpha=.64)$, explaining $44 \%$ of variance. The items did not load cleanly in several circumstances. Three items: enthusiastic, happy, and good experience loaded onto both the fulfillment/delight and distress scales. Time going slowly loaded onto the difficulty and distress scales, but was determined to be a distinct item. 
Changes in the sampling methods were used in the second study of the SIL with mixed results. The authors chose to exclude non-White women from the study in order to "minimize heterogeneity." This sample included primigravidae in order to minimize the effect of a previous experience on the scores (Salmon \& Drew, 1992).

The original instrument was developed in England and has been translated into German (SIL-GER) and used in two Swiss studies generating multiple publications (Stadlmayr et al., 2001; Stadlmayr, Schneider, Amsler, Bergin, \& Bitzer, 2004; Stadlmayr et al., 2006; Lemola et al., 2007). The SIL-GER was administered to 251 women, both primigravidae and multiparae. The items were subjected to a principal component analysis resulting in four factors accounting for $55 \%$ of variance. The factors were labeled: fulfillment $(\alpha=.83)$, physical discomfort $(\alpha=.63)$, good emotional adaptation $(\alpha=.83)$, and negative emotional experience $(\alpha=.63)$. Three items did not load and were treated as distinct factors: control, anxiousness, and time going slowly. A complex cluster analysis of scores derived from the SIL-GER, the Berne-Basel Childbirth Inventory, the Edinburgh Postpartum Depression Scale, and the Impact of Event Scale were used to evaluate women rated at risk for persistent negative memories of childbirth (Stadlmayr et al., 2006). The findings of this study showed that $15.5 \%$ of the sample was at great risk of a persistent negative memory of the birth experience. It was also determined that a score below 70 on the SIL-GER is the cut score for a negative birth experience. As opposed to the scoring method established by Salmon, this study used a total score derived from summing the items with an overall reliability coefficient of .87 .

Lemola and associates (2007) used the German SIL with a sample of 374 Swiss women at 6 weeks postpartum. The instrument was reorganized in order for the women to complete the subscales related to distress and discomfort in relation to their labor experiences, and the 
subscales related to fulfillment and emotional experience to the time following birth. The subscale of discomfort was shortened to three items $(\alpha=.69)$; and the distress scale was reduced to four items $(\alpha=.78)$. Fulfillment and emotional evaluation were combined into a new dimension containing seven items $(\alpha=.88)$ based on a significant correlation between the two subscales $(\mathrm{r}=-0.67, \mathrm{p}<.001)$. This new subscale was labeled "postnatal emotional evaluation."

When the SIL is compared to the conceptual blueprint of the childbirth experience, the emotional aspect is represented by word pairs associated with fear, anxiety, and excitement. Pain and degree of work are included; however the rhythm of contractions, unpleasant physical sensations, and comfort provided by healthcare professionals are not assessed. Aspects related to flow consciousness and enhanced sense of self are not included in the instrument. Control is only measured by the anchor "in control;" specific types of control are not explored. Appendix B provides a comparison of the items on the SIL with the conceptual blueprint.

The Cognitive Schema Scale. Another semantic differential scale was developed by Peirce (1994) as part of a dissertation regarding schema development related to stressful events. The item development process included open ended interviews with pregnant and postpartum women, both primigravidae and multiparae. An initial list of 240 words and phrases was generated and redundant terms were eliminated. Naturally occurring opposite words were paired as the anchors. The Childbirth Schema Scale (CSS) has 17 paired words or short phrases. Seven of the word pairs are identical to the anchors used by Salmon, adding to the stability of those aspects of the childbirth experience. The CSS is designed to give a single score by summing the items; reverse scoring of some word pairs is required. A higher score reflects a more positive experience. Analysis of pilot study data from 30 women demonstrated an instrument alpha coefficient of .70. Content validity was supported through review of the tool by experienced 
childbirth education nurses. One hundred seventy six women participated in the larger study. Exploratory factor analysis identified four subscales: emotions of outcome (.73), sensations of the work of childbirth (.70), time (.84), and preparation for control (.65). Only the item, "shared/lonely" did not load onto one of the factors. An additional item, "scary/not scary" did not meet acceptable levels for item-total correlation but was not eliminated because the removal did not change the alpha coefficient. Construct validity was assessed by comparing CSS scores to pre and post schema differences using the Event Review Scale. There was a significant difference in CSS scores for those women whose schemas were less similar. Research has not been published with further use of the instrument beyond initial development.

A comparison of the items in the CSS with the conceptual blueprint are similar to those in the SIL; all aspects of the physical, emotional, cognitive, and social aspects of childbirth are not represented. Appendix B provides a comparison of the items on the CSS with the blueprint.

The Childbirth Experience Questionnaire. The Childbirth Experience Questionnaire (CEQ) (Dencker et al., 2010) is the most recently developed instrument to measure the birth experience and has only been tested in primigravidae. The purpose of the CEQ is to measure different dimensions of childbirth experience in first time mothers. Content validity of the instrument has been assessed through literature review, discussions with experienced midwives, a senior obstetrician, and a group of postpartum women. Content areas include a sense of security, experience of labor pain, partner's support, midwifery care and support, memories of childbirth, and experience of own performance.

The CEQ is a 28 item instrument using a 4-point Likert type scale of agreement for most of the items. The degree of pain experienced, sense of security, and control are measured with a 100-point visual analog scale that is converted into a 4-point categorical score to be included 
with the other items. A single score is obtained by summing the individual items once negatively worded items are reversed. A higher score indicates a more positive experience. The instrument was administered as part of a larger study about labor progress and oxytocin augmentation. The sample consisted of 920 primiparous women.

Initial review of the item ratings revealed two items with extreme ceiling effects; these were eliminated from further analysis. Although six items about professional care also had high ceiling effects, they were considered to be clinically important and were included in analysis. Exploratory factor analysis of 25 items identified four subscales: own capacity $(\alpha=.82)$, professional support ( $\alpha=.88$ ), perceived safety ( $\alpha=.78)$, and participation ( $\alpha=.63)$, accounting for $54 \%$ of total variance. Two items, pain in second stage and memory lapses, did not load adequately and were eliminated. The item "care given by midwife" lowered the alpha coefficient for perceived safety and was also eliminated. Item-scale correlations exceeded 40 for the capacity, professional support, and perceived safety scales. Construct validity was assessed by comparing the subscale scores between groups known to have different birth experiences: longer labors, augmentation, and operative interventions. Women in all three subgroups scored significantly lower scores than women with shorter labors, no augmentation or operative interventions. This instrument has not been used beyond initial psychometric evaluation.

Comparing items from the CEQ to the conceptual blueprint reveals similarities with the other published instruments. Pain and fatigue are assessed in the CEQ, but the rhythm and timing of contractions or any other physical symptoms are not assessed. The emotional aspects include the presence of happiness and fear. One item assessed memories and whether they made the women feel depressed. A cognitive interview study for the development of the WECS found 
that using the term "depressed" was very undesirable, and women avoided agreement with the statement. Cognitive aspects include self-confidence to manage labor, but nothing related to alteration of time or flow consciousness. For the social aspects of childbirth, the CEQ focuses on the care and support provided to the woman and her partner during labor; the support by the partner is not assessed. Appendix B provides a comparison of the items on the CEQ with the blueprint.

\section{Summary}

A conceptual framework or blueprint is an essential element of the research process, whether developing a new instrument or selecting an appropriate measurement tool (Waltz, Strickland, \& Lenz, 2005). The framework ensures that all aspects of the concept are represented and measured by the tools. Appendix B provides a comparison of the four existing instruments with the blueprint used in the development of the WECS. The comparison of existing instruments with the conceptual framework, as part of this review, identified gaps in what is measured. Pain and pain control have been well developed and are present in some way in all instruments. The work of labor is present in all except the QMAALD. None of the instruments include the timing and rhythm of contractions, or other unpleasant physical sensations that are commonly experienced.

All the instruments explore positive and negative emotional aspects of childbirth. Cognitive aspects, such as altered sense of time and cognitive strategies to cope with pain, are not present in all instruments, but all instruments have at least one item relating to preparation or anticipation for childbirth. There are a few loosely related items to the concept of flow; the SIL has two word pairs about the process being rewarding and satisfying and the CEQ has an item about feeling strong. The remaining aspects of flow are not included. The CEQ has items 
related to professional support during labor and a sense of security; the QMAALD has several items about help from the coach; the SIL and CSS do not have any items for how support is perceived to help or hinder the woman.

There are clear gaps in the content structure of existing instruments reported to measure a woman's experience in childbirth experience that are reflective of the purpose or method of their development. The WECS builds on existing measurements of the childbirth experience and explores new aspects that contribute to a woman's resulting sense of self and mastery of her transition to motherhood. Many of these aspects have only been reported in qualitative studies and are not generalizable to the larger population. There is a clear need for an instrument that quantifies the breadth of the childbirth experience and allows for meaningful comparison of the perception with the relationship to maternal and neonatal outcomes. 


\section{CHAPTER 3}

\section{Methods}

This chapter will present the processes used for the development of the WECS and the methodology for the study to evaluate the psychometric properties of the instrument. The development of a new instrument requires an organizing framework or blueprint of the concept, generation of items, a measurement scale, and methods to assess the reliability and validity of the instrument (Streiner \& Norman, 2008). Each phase of development provides multiple opportunities to assess the psychometric properties. The phases and timing of development are listed as follows:

1. Instrument Development Phase 1, Academic Year 2011-2012
a. Generate 29 items for prototype instrument using literature review
b. Subject prototype instrument to content expert validity assessment
c. Increase number of items to 49 based on feedback from content experts
d. Pilot 49 item instrument using cognitive interviewing
e. Increase number of items to 50 based on results of pilot study

2. Instrument Development Phase 2, Academic Year 2012-2013

a. Subject 50 item instrument to content expert validity assessment

b. Pilot administration of 50 item instrument

c. Reduce number of items to 49 based on reliability coefficient analysis

3. Phase 3, Academic Year 2013-2014

a. Dissertation study 


\section{Instrument Development Phase One}

The prototype of the WECS used an initial organizing framework from the concepts in the literature: (a) pain, (b) the work of labor, (c) support, (d) control, (e) emotions, (f) the meaning of the birth experience, and (g) flow consciousness. Items were generated to align with these concepts resulting in a 29 item prototype instrument. The content validity of the prototype was assessed by two methods. The first method was by expert review and the second through a pilot study of the prototype using cognitive interviewing.

An expert review of the prototype was conducted by a maternal-infant nurse, nurse midwife, and an instrument development specialist. Each of the items was evaluated for clarity, sufficiency, and relevance to a woman's experience in childbirth using a 5-point scale (Waltz et al, 2005). A score of at least 3 meant the item met the criteria. Items not having a score of 3 were identified and modified based on feedback from the content experts. Most of the items were deemed adequate but four items related to preparation for birth, unrealized anxieties, aspects of control, and support were rated lower, indicating a need for further revision. The items related to support did not differentiate who was providing support and the adequacy of the support to the mother. In a similar manner, items related to control required further definition as to whether the control related to self-control or control of the environment. Additional items were generated, resulting in a 42-item instrument. Results of the initial content validity assessment of the 29-item prototype are provided in Appendix C.

Following item revision, the 42-item instrument was piloted in a cognitive interviewing study to determine the clarity and sufficiency of the prototype, as well as the preferred scaling methods. Cognitive interviewing is the administration of a survey or questionnaire while collecting feedback about the items and determining the quality of the responses (Willis, 2004). 
A probing questions' method of cognitive interviewing was used. In this method, a semistructured interview was conducted immediately after the participant completed the questionnaire. In addition to responding to the prototype, the participants also completed the QMAALD and a combined version of the SIL and CSS. The inclusion of the other instruments served as a comparison for follow-up questions about what information was missing from the prototype, or was not reflective of their birth experience. The interviewer also followed up on nonverbal clues or direct questions that occurred during the administration of the instrument. The interviews were recorded, transcribed verbatim, and analyzed to determine a need for item modification.

Eleven women participated in this pilot study of the WECS prototype. The study was approved for human research by the Institutional Review Board of West Virginia University (H23082). The ages of participants ranged from 22 to 40 years with a mean of 30 years. Nine women had vaginal births; two had primary cesareans following labor. The births had occurred between 3 months and 12 years before the interview. The primary ethnicity of the sample was White, with one Black woman participating. One woman gave birth with a nurse midwife, one with a family practice physician, and the remaining by obstetricians. Nine of the women used epidural analgesia/anesthesia, one used IV medication only, and one woman did not use labor analgesia.

The results obtained from this study revealed the Likert-type scaling method was strongly preferred by 10 of the women. Women commented that the Likert-type items provided more contextual information about the complex and interrelated aspects of labor than the semantic differential scales. A Likert-type scale with five steps to measure the degree of agreement or disagreement with the subjective statement was chosen for the WECS. The choice of scale is 
based on what is being assessed and whether the intended response could be unipolar or bipolar (Streiner \& Norman, 2008). Too few numbers of steps in the scale can lower the reliability coefficient because there is not enough discrimination between the response options. On the other hand, there is little enhancement to the reliability coefficient if more than eight steps are provided. To support a reliability coefficient between 0.4 and 0.9 , it is recommended there be between five and seven steps. Either option is commonly used, but the 5-point scale is more useful in determining absolute judgment of response (Lietz, 2010).

The interview data about the clarity and sufficiency of the instrument resulted in further modification to the items and instrument. Women using epidural analgesia expressed difficulty answering items related to labor pain and concentration during contractions that is commonly noted by women not using regional analgesia. One woman who received an epidural before she experienced any pain viewed the term "being internally focused" as not being engaged with those around her. Likewise "being alone within myself" caused several women to focus on the word "alone" and correlate it to loneliness. In response to a statement about feeling overwhelmed by labor, one mother selected she "strongly agreed", but went on to say that this was a euphoric experience rather than a negative connotation.

The continually changing and sometimes conflicting physical and emotional experiences during labor were represented in one item. Several women focused on the word conflict and either related it to discord in the birth environment or tried to place a value on the "good or bad" emotions. An item asking about being oversensitive during labor elicited comments as to whether this was emotional or physical sensitivity. When answering an item about trusting her caregiver to make the best decision for herself and her baby, one woman discussed that while she 
agreed with her caregiver at the time, she later had regrets. She commented that if asked a follow-up question about regretting the decision, she would have answered differently. The conceptual framework was also evaluated as part of the revision process. Transition theory was used to organize the previous aspects of the childbirth experience extracted from the literature. According to transition theory, the perception of a critical event such as childbirth; can either facilitate or inhibit the transition process to becoming a mother (Meleis et al., 2010). Transition theory uses a biological, psychological, and social view of the person in transition. This is aligned with the concept analysis of the birth experience (Larkin et al., 2009). The physical domain includes the somatic sensation of pain, methods of pain relief and their effectiveness, the work of labor, and physical symptoms that accompany labor. The psychological domain includes emotions, the effect of the emotions as well as support to moderate negative emotions. However, the mind is more than emotions; cognitive functioning is another aspect of the psychological domain. The cognitive processes include thoughts, interpreted meanings, and altered consciousness that can occur during labor. The social domain includes the people interacting with the woman during childbirth and their effect on her perception of support and control.

Because perception of an event is the result of the individual's interaction and response to the external world, items were worded to express the subjective view of the respondent. New items for the instruments were generated using representative statements of themes from qualitative research. Additional items were also identified in existing instruments (Streiner \& Norman, 2008). Published instruments related to self-confidence in dealing with labor pain (Lowe, 1993), control (Ford et al., 2009), and social support (Sauls, 2004) were reviewed for subjective statements that aligned with the blueprint. Items from the Flow State Scale (Jackson 
\& Marsh, 1996) were modified to represent flow consciousness during childbirth instead of athletic endeavors.

As a result of the validity assessment and pilot study data during phase one, the instrument was expanded from the 29-item prototype to a 50-item instrument aligned on physical, psychological, and social domains. In the social domain, support from friends and family was differentiated from support from health care providers. Items related to control were modified to reflect self-control, involvement in decision-making, and whether the mother was satisfied with the decision. Appendix D provides information about the continued development of the WECS based on data collected throughout the development process. The instrument was developed to a point where it could be subjected to the second phase of psychometric assessment.

\section{Instrument Development Phase Two}

The revised 50-item instrument was subjected to a second content expert review. This assessment was performed by the same instrument specialist and nursing instructor. A different nurse midwife and two additional maternal-infant nurses also participated. The same scoring method was used. The average score for each quality was at least 3 among all experts. Cronbach's alpha coefficient for the content experts' scaling was 0.63 (Waltz et al., 2005) The results of the second phase validity assessment are provided in Appendix E.

The primary psychometric evaluation in Phase Two was a second pilot study to identify potential administrative errors (Waltz et al, 2005, p. 137) and to determine the feasibility of using the WECS in the intended population. Additional research objectives for the second pilot were to determine how much time was needed to complete the instrument and if there was adequate evidence of the reliability of the instrument using Cronbach's alpha coefficient. 
The second pilot study was approved for human research by the Institutional Review Board of West Virginia University (H-24248). The second pilot was conducted at two hospitals; each site provided obstetrical services with varying levels of acuity and types of providers that would allow for a heterogeneous sample. Women were identified at each location using the same inclusion and exclusion criteria. Participants needed to be at least 18 years of age, able to speak and write in English, had a vaginal birth between 37 and 42 weeks gestation, and gave birth to a live newborn. Women were excluded if there had been any episodes of preterm labor, vaginal bleeding in the second or third trimester, maternal diabetes, pregnancy induced hypertension, previous cesarean birth, or known fetal anomalies. Potential participants were identified through collaboration with postpartum nurses and the researcher. The postpartum nurses provided room numbers of mothers meeting the inclusion criteria. The women were approached by the researcher who determined if they were eligible for participation. The researcher remained in the room during administration of the instrument and timed the process using a stopwatch.

Because this pilot focused on the administrative procedures, demographic information about participants was self-reported on the last page of the instrument instead of being extracted from the medical records by the researcher. The women were asked to provide their age, race or ethnicity, educational achievement, parity, type of pain control methods used during labor, the type of care provider, estimated date of birth, and whether they had attended childbirth classes. Following administration of the instrument, each participant was asked about the burden of answering a 50-item instrument, if there were any statements that were not clearly phrased, if any aspect of their birth experience was not included, and if there were any ways the process of completing the instrument could be improved. 
Thirty four women agreed to participate in the study; four respondents were eliminated due to incomplete data. The age of women in the sample ranged from 18 to 35 years; the median age was 23.5 years. Table 1 contains the remaining descriptive statistics of the pilot sample. WECS scores were calculated for the sample and ranged from 131 to 213 from a possible 50250. The mean score was 184 ( $\mathrm{SD}=23)$. Cronbach's alpha coefficient for the pilot testing was .91.

Participants were timed during administration of the instrument. Respondent time ranged from 3 minutes and 49 seconds to 12 minutes and 1 second. The mean time to complete the instrument was 6 minutes and 18 seconds ( $\mathrm{SD}=1$ minute 56 seconds). Two women thought the instrument took too long to answer. One of the initial participants found it difficult to complete while writing on the over bed table. Following this observation, the researcher provided participants with a clipboard, and no further difficulties were expressed or observed.

The time to complete the instrument was highly dependent on what else was happening in the postpartum room. Participants often conversed with their visitors or the researcher while completing the survey. Likewise, if the newborn required attention, the participant was distracted from answering.

When asked if there were any items on the instrument that were not clear, 10 participants provided feedback. The most frequent comments were from five of the women who had not used analgesia. They expressed confusion with the wording about choice of pain management strategy. Two women related the items were understandable but required careful reading before responding. The item concerning staff taking control of the experience took several readings by one participant before answering. Another participant objected to the use of "higher power" instead of God. The third comment was related to having to answer globally about the entire 
Table 1

Description of Pilot Sample

\begin{tabular}{lll}
\hline & Number & Percent \\
\hline Race/Ethnicity & 26 & 86.75 \\
Non-Hispanic White & 2 & $6.7 \%$ \\
Hispanic & 1 & $3.3 \%$ \\
Native American & 1 & $3.3 \%$ \\
Non-Hispanic Black & & \\
Educational Achievement & 9 & $30 \%$ \\
Did not complete high school & 12 & $40 \%$ \\
High school graduate & 3 & $10 \%$ \\
Some college & 3 & $10 \%$ \\
At least college graduate & & \\
Attending Provider & 25 & $83.3 \%$ \\
OB-GYN & 3 & $10 \%$ \\
CNM & 1 & $3.3 \%$ \\
Family Practice & 1 & $3.3 \%$ \\
L\&D Staff Nurse & & \\
Analgesia & 7 & $23.3 \%$ \\
No analgesia & 5 & $16.7 \%$ \\
IV medication only & 12 & $40 \%$ \\
Epidural only & 6 & $20 \%$ \\
Epidural and IV medication &
\end{tabular}

labor process, when the experience was different in various phases of childbirth. The last specific response was to the item about the baby being the only positive aspect of childbirth.

One woman had difficulty differentiating the response to this single item and her responses to the overall instrument. The only aspect that respondents thought was not included in the instrument was if they had poor analgesic control with their epidural; four women related this concern.

Except for the need to stop and attend to crying newborns during administration of the instrument, participants did not offer any improvements to the way they were approached about the study, the information letter, or the construction and readability of the instrument.

While most items on the instrument were understandable, there were several items that were revised as a result of this second pilot study. Participants who did not use medication 
consistently expressed problems understanding that choosing not to use medication is a pain management strategy. In the subsequent version, phrasing about choice not to use pain medication was included. Although no one commented on the item related to being internally focused during contractions, this item was identified as being possibly incorrectly scored during reliability analysis. Because the construct of internal focus was represented with items related to flow consciousness, and mothers from the cognitive interviewing study also had difficulty with the wording, it was eliminated following the second pilot. Removal of the item did not affect the reliability coefficient $(. \alpha=.91)$.

The second pilot study confirmed the appropriateness of methods for identifying and recruiting participants. Most women were eager to answer questions about their experiences and did not find the length of the instrument burdensome. Recruitment for the second pilot study was performed over a 2-month period, according to the researcher's work schedule. The WECS for the dissertation study (Appendix F) contained 49 Likert-type items reflecting the physical, emotional, cognitive, and social aspects of a woman's childbirth experience.

\section{Current Study}

This study used a quantitative, cross-sectional design to test the reliability and validity of the WECS with postpartum inpatient women having vaginal births.

Readability of WECS. The Joint Committee on Standards for Educational and Psychological Testing (American Educational Research Association, 1999) recommends reading demands for instruments are kept to a minimum if reading ability is not the purpose for the instrument. Keeping the reading level below the American average of seventh and eighth grade level helps prevent non-responses and missing data in survey administration (Koume, 2010). The Flesch-Kincaid, Flesch Reading Ease, and the FORCAST are three readily available 
methods to assess reading ease or grade level (Burke \& Greenberg, 2010). The Flesch-Kincaid and the Flesch Reading Ease are available in Microsoft Word ${ }_{\odot}$. Both assess sentence length and the number of letters or syllables in words to reflect difficulty. The higher the score on the Flesch Reading Ease, the easier the content is to read. The Flesch-Kincaid converts the Reading Ease score to a grade level. The Flesch-Kincaid often provides lower than actual grade level reading analysis by as much as 2 years (Burke \& Greenberg, 2010). The items in the WECS scored 81.8 on the Reading Ease Scale, which translates to a grade level of 4.4. The FORCAST, named after the authors who developed the formula for the U.S. Army (Sticht, 1975), measures functional literacy by counting the number of one syllable words in the sample, and is recommended for use on questionnaires or lists. The WECS reading level according to this measure was grade level 9.9. A review of the multi-syllable words that increased the reading level above the eighth grade included childbirth and contractions at several points. These terms and meanings would not be unfamiliar to the participants, so further attempts to lower the reading level were not pursued.

Human rights considerations. Informed consent was obtained by following requirements established by the Institutional Review Boards (IRB) at West Virginia University and the selected study agencies. Copies of IRB approval letters are available in Appendix G. The researcher provided an information sheet with inclusion and exclusion criteria to the nursing staff to determine the women who were eligible for inclusion in the study. Written consent was required according to the Health Information Portability and Accountability Act of 1996. All informed consent and data collection procedures were done by the doctoral student researcher. The researcher approached the women to determine interest in participating in the study. Participants were also asked if they would agree to future contact for assessing test-retest 
reliability of the instrument. If interest was expressed, the researcher verbally validated eligibility for participation before obtaining informed consent. Participation criteria were again validated during data extraction from the maternal medical record. The informed consent form and test-retest contact form were the only documents recording the woman's name. The informed consent and contact forms were maintained by the researcher in a separate secure file from the other research documents. An alphanumeric code was used to link demographic and instrument data.

Sample selection. Participants in the study were solicited on the postpartum units of two community hospitals. The average hospital stay for childbirth in the United States is 2.7 days (Centers for Disease Control, 2010). Several studies have identified the perception of the childbirth experience as being stable for years (Simkin, 1991; Waldenstrom, 2003). A systematic review of literature found no conclusive evidence that the time of measurement of the childbirth experience affects the response (Hodnett et al., 2002). However, in order to assure comparability of responses, women in this study were approached for inclusion when physiologically stable within the first 48 hours after birth, as determined by consultation with the nursing staff.

Hospital A is a community hospital with an obstetrical unit having less than 500 births annually. Maternity care is provided by board certified obstetricians, family practice physicians, and family practice medical students and residents. Hospital B is a suburban, regional referral hospital with an obstetrical unit and Level II neonatal intensive care unit recording an average of 2,500 births annually. Maternity care is provided by board certified obstetricians and a certified nurse midwife. 
Women included in the study were at least 18 years old, able to read and write English, at least 37 weeks gestation, and had a vaginal birth of a single, living newborn. Women were excluded if they had a history of vaginal bleeding in pregnancy, previous fetal demise, previous cesarean birth, known fetal anomalies, pregnancy induced hypertension, or diabetes. Women who were known substance abusers or who planned to relinquish their newborn were also excluded from the study. Inclusion and exclusion criteria were established to obtain participants with generally uneventful pregnancies, since anticipation of poor pregnancy outcomes can have a negative effect on the perception of the childbirth experience (Green et al., 1990). Intrapartum events that occurred unexpectedly were not used as exclusion criteria.

Prior to data collection, in-service education about the study was provided to the charge nurses on the two postpartum units used in the study. Handouts listing the inclusion and exclusion criteria were provided in order for the charge nurses to identify potential participants. The doctoral student researcher approached potential participants to determine if there was interest in participation.

A power calculation is not applicable to determine sample size when using factor analysis, but statistical textbooks offer general guidelines that a sample size of 300 is considered good, 500 very good, and 1000 excellent. Tabachnick and Fidell, (2007) provide several rules of thumb for determining adequate sample size: either 10 participants per item, or a minimum of 300 participants.

The study forms included the instrument with instructions, a demographic and obstetrical data form, and two copies of the information and consent. In some cases, the participants asked to complete the WECS at a later time, but before discharge from the hospital. If so requested, the researcher provided an envelope marked with her name and instructions that the participants 
seal the WECS in the envelope and give it to their nurse, who would lock it in the nurses' station. The researcher collected the envelopes the following day.

Data collection. Independent variables were identified to support the validity of the instrument. These sources included variables used in other studies of the childbirth experience (Baston et al., 2008; Bryanton et al., 2008b; Waldenstrom et al., 1996; Waldenstrom, 1999) and characteristics to represent the culture of the sample. Demographic and obstetrical data were provided by the participant on the questionnaire forms, obtained by verbal questioning of the participant, or extracted by the researcher from the maternal medical records (Appendix G). Information provided by the participant on the questionnaire form or by verbal questioning included: relationship status, religious affiliation, race/ethnicity, country and state of birth, income, persons present with them during labor, whether the mother attended childbirth classes, and her planned feeding method. Participants were also asked whether family, friends or the newborn were in their postpartum room while they were completing the instrument. The participant also completed a 10-point visual analog scale (VAS) at the end of the instrument. This scale asked them to rate the overall birth experience, and was used to correlate the VAS rating to the WECS score. The anchor terms for the VAS were "worst experience of my life" and the "best experience of my life". The data collection forms are located in Appendix F along with the WECS.

Independent variables related to the obstetrical and childbirth experience were extracted from the medical record after obtaining consent included: age, parity, estimated date of birth, length of labor, use of medical interventions, type of fetal monitoring used, use of forceps, vacuum extraction, episiotomy, delivering health care provider, and the type of pain medication used. All medical interventions during labor and birth were recorded. The most invasive level 
of fetal monitoring used during labor was identified and recorded as the fetal monitoring method. The gender, estimated age, and the 1 and 5 minute Apgar scores of the neonate were also obtained.

Test-retest reliability was assessed at 2 to 4 weeks after birth (Waltz et al., 2005). Participants providing contact information during consent were mailed a copy of the WECS with their case number and a stamped return envelope. The goal for test-retest participation was $30 \%$ of the inpatient sample, or at least 90 responses.

Three hundred thirty five postpartum inpatients consented to participate in the study. Twenty eight of the participants did not return the questionnaire and two asked to be withdrawn after initial consent, leaving 305 eligible participants for final analysis. Because data collection of the demographic, obstetrical, and neonatal variables was completed once consent was given, it was possible to compare some characteristics of the group who did not return the questionnaire but had not withdrawn from the study. One-way analysis of variance was conducted to explore the differences in age, educational achievement, parity, length of labor, and entry to prenatal care between the women who completed the survey and those who did not. No significant differences were found between the women who completed the questionnaire and those who did not.

Data analysis. Prior to data entry, 13 items that were negatively worded were reverse coded. Data were entered into Statistical Package for the Social Sciences (SPSS) 16.0 Graduate Package. The cases were reviewed for missing responses and patterns of non-response to the WECS items. Seventy items $(0.4 \%)$ were not answered. Of these, three cases had more than $5 \%$ of the responses unanswered and were eliminated from the study. This reduced the overall nonresponse rate to $0.3 \%$. After elimination of the three cases, the pattern of non-response was evaluated. Items 3 and 6 were not completed by six respondents. The other missing responses 
were randomly scattered throughout the instrument. The missing data were imputed using the participant's mean score per item. Using the mean is the most conservative method for imputing data and does not affect the mean for the score (Tabachnick \& Fidell, 2007). This decision to impute item scores was based on the overall minimal percent of missing responses on the instrument compared to the total number of items in the questionnaire.

Following imputation, the WECS score was calculated by summing the item scores. A higher score indicated a more positive birth experience. A distribution of scores, mean score, and standard deviation for the total sample were calculated. Differences in WECS scores between characteristic groups of birthing mothers previously identified as having differing childbirth perceptions (maternal age, education level, healthcare provider, length of labor, medical interventions, and parity) were analyzed. Categorical variables such as healthcare provider, parity, and medical interventions were compared to the WECS score using ANOVA. Continuous variables such as maternal age, education level, and length of labor were correlated to WECS scores, as well as grouped into categories. The WECS score was correlated with the overall rating of the 10-point VAS global experience scale. It was expected for there to be a modest correlation (less than .8) between the two scores.

Exploratory factor analysis using principal component analysis was performed to examine the construct validity of the instrument. Principal component analysis (PCA) is used in instrument development to identify clusters of variables independent of each other (Tabachnick \& Fidell, 2007). While items for the WECS were generated using a physical, emotional, cognitive, and social framework, factors impacting the childbirth experience are highly interrelated, and there is not a theoretically prescribed number of components that would be 
presupposed. The identification of items that did not contribute to the maximum variance can be used to further refine the WECS.

Internal consistency of the WECS was assessed using Cronbach's alpha for the overall instrument, as well as components identified in PCA. Inter-item correlations and item to scale correlations are reported as part of the SPSS output for reliability analysis providing information about proper scoring of items and how well each item correlates to the overall score. Items with an item-score correlation less than .3 could be considered for elimination (Pallant, 2007). Testretest reliability was analyzed using paired t-tests. 


\section{CHAPTER 4}

\section{Results}

The following chapter presents the results from the administration of the WECS to 302 inpatient postpartum women between July 2013 and April 2014. The primary focus of the data analysis is the psychometric properties of the WECS. Descriptive statistics of the sample are also presented. Normality of the WECS scores, Cronbach's alpha coefficient, test-retest reliability, correlation of the WECS scores with the respondents' overall evaluation of the childbirth experience, and factor analysis were used to assess the reliability and validity of the WECS.

\section{Sample Description}

Descriptive analysis of the data is presented for demographic, obstetrical and neonatal characteristics. The mean age of the sample was 26.9 years $(\mathrm{SD}=5.5)$. The mean years of educational achievement were 14.34 years $(\mathrm{SD}=2.5)$. The majority of women in the sample entered prenatal care before 16 weeks gestation $(82.5 \%)$. There were more multiparas in the sample $(54.3 \%)$ than primiparas. The average length of labor for this sample was 9.9 hours (SD =6.5). Most women in the sample had never attended childbirth education classes (61.9\%). Immediate rooming in with the infant was begun for $83.4 \%$ of the mothers. Exclusive breastfeeding was the preference of $73.5 \%$ of mothers, with $81.3 \%$ of mothers being able to put the newborn to breast immediately following birth. One minute Apgar scores ranged from 1-9 with a mean score $=8(\mathrm{SD}=1.0)$. The majority of the women had the newborn $(85.4 \%)$ and family $(65.6 \%)$ in the room while completing the survey. The remaining characteristics of the sample are presented in Table 2. 
Table 2

Sample Demographics

\begin{tabular}{|c|c|c|c|}
\hline & $\mathrm{N}(\%)$ & $\begin{array}{l}\text { Minimum- } \\
\text { maximum }\end{array}$ & Mean (SD) \\
\hline Age & 299 & $18-43$ & $26.9(5.5)$ \\
\hline Educational Achievement (years) & 302 & $7-22$ & $14.3(2.5)$ \\
\hline Parity & 302 & $0-9$ & \\
\hline Entry to Prenatal Care (weeks) & 286 & $2-40$ & $11.2(5.7)$ \\
\hline Length of Labor (hours) & 296 & $.78-62$ & $9.9(6.5)$ \\
\hline \multicolumn{4}{|l|}{ Relationship Status } \\
\hline Married & $192(63.6)$ & & \\
\hline $\begin{array}{l}\text { Single committed to father of the baby } \\
\text { (FOB) }\end{array}$ & $82(27.2)$ & & \\
\hline Single not-committed to FOB & $15(5.0)$ & & \\
\hline Single committed to other than FOB & $5(1.7)$ & & \\
\hline Separated or divorced & $4(1.3)$ & & \\
\hline \multicolumn{4}{|l|}{ Income } \\
\hline Below $\$ 20,000$ & $23(7.6)$ & & \\
\hline$\$ 20,001-\$ 40,000$ & $44(14.6)$ & & \\
\hline$\$ 40,001-\$ 60,000$ & $64(21.2)$ & & \\
\hline$\$ 60,001-\$ 80,000$ & $43(14.2)$ & & \\
\hline Above $\$ 80,000$ & $75(24.8)$ & & \\
\hline Prefer not to say & $53(17.5)$ & & \\
\hline \multicolumn{4}{|l|}{ Race/Ethnicity } \\
\hline White/non-Hispanic & $270(89.4)$ & & \\
\hline Hispanic & $10(3.3)$ & & \\
\hline Black/non-Hispanic & $9(3.0)$ & & \\
\hline Self-reported mixed & $7(2.3)$ & & \\
\hline Asian/Pacific Islander & $2(0.7)$ & & \\
\hline Other & $1(0.3)$ & & \\
\hline \multicolumn{4}{|l|}{ Religious Affiliation } \\
\hline Protestant & $96(31.8)$ & & \\
\hline Other Christian & $44(14.6)$ & & \\
\hline Catholic & $40(13.2)$ & & \\
\hline Mormon & $6(2.0)$ & & \\
\hline Agnostic & $2(0.7)$ & & \\
\hline Orthodox & $1(0.3)$ & & \\
\hline
\end{tabular}


Table 2

Sample Demographics

\begin{tabular}{|c|c|c|c|}
\hline & $\mathrm{N}(\%)$ & $\begin{array}{l}\text { Minimum- } \\
\text { maximum }\end{array}$ & Mean (SD) \\
\hline Jehovah's Witness & $1(0.3)$ & & \\
\hline Jewish & $1(0.3)$ & & \\
\hline Buddhist & $1(0.3)$ & & \\
\hline Atheist & $1(0.3)$ & & \\
\hline Nothing in particular & $72(23.8)$ & & \\
\hline Prefer not to say & $37(12.3)$ & & \\
\hline \multicolumn{4}{|l|}{ Provider for Birth } \\
\hline Nurse Midwife & $21(7.0)$ & & \\
\hline Family Practice & $8(2.6)$ & & \\
\hline Obstetrician & $258(85.4)$ & & \\
\hline Staff nurse & $5(1.7)$ & & \\
\hline Resident Student & $10(3.3)$ & & \\
\hline Other & $1(0.3)$ & & \\
\hline \multicolumn{4}{|l|}{ Analgesia } \\
\hline None & $59(19.5)$ & & \\
\hline IV medication & $5(1.7)$ & & \\
\hline Local anesthesia & $6(2)$ & & \\
\hline Intermittent regional anesthesia & $1(0.3)$ & & \\
\hline Epidural & $231(76.5)$ & & \\
\hline \multicolumn{4}{|l|}{ Medical Interventions } \\
\hline No interventions & $81(26.8)$ & & \\
\hline Misoprostol & $30(9.9)$ & & \\
\hline Prostaglandin E2 & $23(7.6)$ & & \\
\hline Oxytocin & $153(50.7)$ & & \\
\hline Amniotomy & $137(45.4)$ & & \\
\hline Vacuum & $12(4.0)$ & & \\
\hline Forceps & $3(1.0)$ & & \\
\hline \multicolumn{4}{|l|}{ Fetal Monitoring } \\
\hline Intermittent external & $6(2.0)$ & & \\
\hline Continuous external & $270(89.4)$ & & \\
\hline Scalp electrode & $12(4.0)$ & & \\
\hline Intrauterine pressure catheter & $12(4.0)$ & & \\
\hline One Minute Apgar Scores & 300 & $1-9$ & $7.9(.98)$ \\
\hline \multicolumn{4}{|l|}{ Perineal Repair } \\
\hline No laceration or repair & $78(25.8)$ & & \\
\hline
\end{tabular}


Table 2

Sample Demographics

\begin{tabular}{|c|c|c|c|}
\hline & $\mathrm{N}(\%)$ & $\begin{array}{l}\text { Minimum- } \\
\text { maximum }\end{array}$ & Mean (SD) \\
\hline First degree laceration & $90(29.8)$ & & \\
\hline Second degree laceration & $115(38.1)$ & & \\
\hline Third degree laceration & $4(1.3)$ & & \\
\hline Episiotomy & $14(4.7)$ & & \\
\hline Episiotomy with third degree extension & $1(0.3)$ & & \\
\hline \multicolumn{4}{|l|}{ Support during labor } \\
\hline Total number of personal support & 302 & $0-6$ & $1.9(.99)$ \\
\hline Only nursing staff & $2(0.7)$ & & \\
\hline FOB if not married & $84(27.8)$ & & \\
\hline Spouse & $195(64.6)$ & & \\
\hline Mother & $131(43.4)$ & & \\
\hline Mother in Law & $43(14.2)$ & & \\
\hline Sister & $49(16.2)$ & & \\
\hline Friend & $23(7.6)$ & & \\
\hline Other & $46(15.2)$ & & \\
\hline
\end{tabular}

\section{Instrument Analysis 49-item WECS}

The distribution of the 49-item WECS scores ranged from 127 to 227 from a possible range of 49 to 245 . The mean score was $183.3(\mathrm{SD}=18.6)$. The distribution was slightly skewed to the left $(-.330, \mathrm{SE}=.14)$ with a moderate degree of kurtosis $(.54, \mathrm{SE}=.28)$. Internal consistency reliability of the 49 item WECS was measured with a Cronbach's alpha coefficient of .87 .

Factor analysis. Exploratory factor analysis using principal component extraction with Varimax rotation was performed on the 49 items of the WECS. The Kaiser-Meyer-Olkin value was .800 and Bartlett's Test of Sphericity was statistically significant $(\mathrm{p}<.001)$, providing evidence of the factorability of the correlation matrix. Inspection of the correlations identified several coefficients of .32 and above, indicating it was acceptable to perform factor analysis. 
The initial solution revealed the presence of 14 components with eigenvalues exceeding 1, explaining $61.34 \%$ of the variance. An inspection of the scree plot revealed a break after the fourth component. This was consistent with the theoretical organization of the instrument. A forced four factor solution with Varimax rotation accounted for $33.33 \%$ of total variance. Seven items loaded on more than one factor. Any item that loaded onto more than one factor was assigned to the factor to which it was more highly correlated. Items 3, 20, 22, and 39 had factor loading less than .32 for all factors. Items with correlations less than .40 were reviewed. In review of instrument items, it was found that item 10 "I was excited to finally be starting labor" was more aligned to anticipation of labor than the actual experience during labor. Item 36 related to a connection with the participant's mother since giving birth and item 37 asked for a retrospective evaluation of her behavior during labor. These three items were not well aligned with the experience during childbirth and were eliminated from analysis, along with the previously mentioned items, resulting in a 42 item version of the WECS.

\section{Instrument Analysis 42-item WECS}

The distribution of the 42-item WECS scores ranged from 107 to 197 with a possible range of 42 to $210, \mathrm{M}=157.5$ ( $\mathrm{SD}=16.4)$. The distribution was skewed to the left $(-.370$, $\mathrm{SE}=.14)$ with a small degree of kurtosis $(.056, \mathrm{SE}=.28)$. The Cronbach's alpha coefficient for the 42-item WECS was .86.

The relationship between the continuous variables of age, education, parity, length of labor, entry to prenatal care, 1-minute Apgar scores, the overall childbirth experience and the 42item WECS was investigated using Pearson product-moment correlation coefficient. Two significant relationships were identified, the length of labor and the overall experience of labor. There was a small negative correlation between the length of labor and the 42 item WECS, $\mathrm{r}=-$ 
$.13, \mathrm{n}=296, \mathrm{p}=.026$, indicating a shorter labor is associated with a higher WECS score. The participants were asked to rate their overall childbirth experience using a 10-point visual analog scale (VAS), with 1 being the "worst experience in their life" and 10 being the "best experience in their life". Two hundred ninety seven women completed the VAS on the questionnaire. Responses ranged from 1 to $10, \mathrm{M}=8(\mathrm{SD}=2.0)$. There was a moderate correlation between the two variables, $r=.51, \mathrm{n}=297, \mathrm{p}<.01$, with a high overall evaluation of the childbirth experience associated with a high WECS score.

One-way analysis of variance (ANOVA) was conducted to explore the differences in mean 42-item WECS scores by the levels of several categorical variables, including medical interventions during labor, labor analgesia, health care provider, perineal repair, infant feeding preference, immediate rooming in, childbirth education, father of baby present for labor, female support during labor, baby or family in room while completing the questionnaire, race, relationship status, religion, and income level.

Prior to ANOVA testing, the levels of several categorical variables were combined because of low cell counts. Three variables (relationship status, religious affiliation, and income status) offered the participant an option "prefer not to say." When recoding these three variables for analysis the "prefer not to say" option was considered to be missing data and not included in the analysis. Relationship status was reduced to a dichotomous variable for being in a committed relationship or not. Similarly the religious affiliation category was recoded to a variable whether there was a stated affiliation or not. Race/ethnicity was reduced to a dichotomous variable of White and non-White because of low cell counts in all minority groups. Analgesia choice was reduced to whether or not epidural analgesia was used. Medical interventions were analyzed individually as dichotomous variables. Another medical intervention variable was created by 
totaling the number of interventions that were received during labor and assigning to one of three groups: no interventions, one intervention, and more than one intervention. Another intervention grouping combined vacuum extraction $(n=12)$ and forceps delivery $(n=3)$ into a group labeled "operative delivery". The support persons present were categorized in two ways. The first grouping was if the father of the baby (FOB) was present and there were female family or friends present during labor. Perineal injury was categorized into no injury, first degree injury, and any repair to the perineum. Significant findings are reported in Table 7. A significant difference was identified, demonstrating higher WECS scores for the group for which the FOB was present during childbirth. Also noted was a difference in WECS scores by type of birth. Women having a spontaneous vaginal birth had significantly higher scores as compared to those women having an operative delivery with either forceps or vacuum extraction. No other significant differences in 42-item WECS scores were identified.

Factor analysis. Confirmatory factor analysis using principal component extraction with Varimax rotation and a forced 4-factor solution was performed on the 42-item WECS, with the resulting factors accounting for $36.49 \%$ of total variance. Seven items loaded onto two factors. Any item that loaded onto more than one factor was assigned to the factor to which it was more highly correlated. In addition to a total score for the childbirth experience, the 42-item WECS instrument can be used to calculate four separate subscale scores corresponding to each of the factors. Subscale scores are calculated by summing the response values for each subscale item.

Factor 1 contained 16 items and was labeled "Support during Childbirth". Items and factor loadings for Support during Childbirth are listed in Table 4. 
Table 3

Significant ANOVA Results for 42-item WECS

\begin{tabular}{lrrrl}
\hline \multicolumn{1}{c}{ Characteristic } & M (SD) & $95 \%$ CI & F (df) & p value \\
\hline Support Persons & & & 7.461 & .007 \\
FOB present & $158.2(16.24)$ & $(156.28,160.10)$ & $(1,300)$ & \\
FOB absent & $148.6(16.30)$ & $(141.52,155.61)$ & & \\
& & & & \\
Medical Interventions & & & 6.27 & .013 \\
Operative delivery & $147.2(15.87)$ & $(138.4,155.99)$ & $(1,300)$ & \\
Spontaneous delivery & $157.9(16.29)$ & $(156.1,159.89)$ & & \\
\hline
\end{tabular}

Note: FOB means Father of Baby

Factor 2 contained 11 items and was labeled "Physical and Emotional Response to Childbirth". Items and factor loadings for the Physical and Emotional Response to Childbirth are listed in Table 5.

Factor 3 contained nine items and was labeled "Transformative Experiences in Childbirth". Items and factor loading for Transformative Experiences in Childbirth are listed in Table 6.

Factor 4 contained six items and was labeled "Handling Pain in Childbirth". Items and factor loading for Handling Pain in Childbirth are listed in Table 7.

Analysis of subscales. The Support during Childbirth subscale has a possible range 16 to 80 , and subscale scores in the sample ranged from $43-80, \mathrm{M}=68.7(\mathrm{SD}=6.9)$. The Cronbach's alpha coefficient for the Support during Childbirth subscale was .82 .

The Transformative Experiences in Childbirth subscale has a possible range 9-45, and subscale scores in the sample ranged from $15-44, \mathrm{M}=32.7(\mathrm{SD}=5.0)$. The Cronbach's alpha coefficient for the Transformative Experience in Labor subscale was .71. 
The Handling Pain in Childbirth subscale has a possible range 6 to 30, and subscale scores in the sample ranged from 6-29, $\mathrm{M}=17.9(\mathrm{SD}=4.2)$. The Cronbach's alpha coefficient for the Handling Pain in Childbirth subscale was .66.

Table 4

Items and Factor Loadings: Support during Childbirth

\begin{tabular}{llc}
\hline Item & Item & $\begin{array}{c}\text { Factor } \\
\text { loading }\end{array}$ \\
\hline 47 & $\begin{array}{l}\text { The doctors/midwives and nurses kept me informed of how labor was } \\
\text { progressing. }\end{array}$ & .702
\end{tabular}

44 The midwives/doctors and nurses helped me have the kind of birth experience I wanted.

7 The nurses helped me stay as comfortable as possible.

42 I was able to make decisions about what was happening to me. 605

16 I am glad I made the choice I did whether to use pain medication. 576

45 My friends and family who were with me helped me stay comfortable during labor.

12 My nurse helped me feel calm.

49 The nurses knew what I needed before I had to ask.

15 My choice about using pain medication let me enjoy childbirth.

48 My friends and family gave me strength and emotional support during labor.

43 The doctors/midwives and nurses took control of the birth away from me.

40 The people I wanted were with me during birth.

46 My family and friends spoke up to make sure I had the kind of birth experience I wanted.

41 My birth experience was as private as I wanted it to be.

13 I felt like the nurses did not pay attention to me as a person.

38 I was able to change positions or do things that made me more comfortable during labor.

The correlation between the continuous variables of age, educational achievement, parity, entry to care, length of labor, the number of support persons present, 1-minute Apgar scores, and the four subscale scores were explored using Pearson product-moment correlation coefficient. 
Support during childbirth was significantly correlated with age and parity. Physical and emotional response to childbirth was significantly correlated with parity, length of labor, and number of support persons. Transformative experiences in childbirth was significantly correlated with age and number of support persons. Handling pain in childbirth was significantly correlated with length of labor. Significant correlation results for each subscale are identified in Table 8 .

Table 5

Items and Factor Loadings: Physical and Emotional Response to Childbirth

\begin{tabular}{llc}
\hline Item & & $\begin{array}{c}\text { Factor } \\
\text { No. }\end{array}$ \\
\hline 8 & Item & .640 \\
19 & I was afraid of what was happening to me during childbirth. & .629 \\
18 & I was prepared for what childbirth would be like. & .614 \\
21 & I thought my labor was never going to end. & .598 \\
11 & I could not control my emotions during childbirth. & .531 \\
4 & Nausea, vomiting, or shaking chills kept me from being able to enjoy childbirth. & .513 \\
24 & Birth was so amazing--I would gladly do it again. & .502 \\
9 & I look back on the birth with great joy. & .486 \\
32 & The only positive thing about my experience is that I have a healthy baby. & .473 \\
5 & I felt like I could control my body during childbirth. & .461 \\
2 & I was physically worn out from giving birth. & .449 \\
\hline
\end{tabular}

Continuous variables that had a significant correlation with subscale scores were categorized to better identify differences between groups. Except for ages younger than 21 and older than 36, ages were divided by 5 year increments beginning at age 21 . Parity was categorized two ways. The first considered the two groups of primiparas and multiparas. The second divided parity into three groups consisting of primiparas, multiparas with one to four births, and grand multiparas with five or more births. The length of labor was similarly analyzed in two ways; the first analysis divided labor time into 12 hours or less and more than 12 hours. 
The second analysis used three groups: women with less than 3 hours of labor, more than 3 hours and up to 12 hours, and more than 12 hours of labor. The support persons present were categorized in two ways as previously described.

Table 6

Items and Factor Loadings: Transformative Experiences in Childbirth

\begin{tabular}{llr}
\hline Item & & $\begin{array}{c}\text { Factor } \\
\text { No. }\end{array}$ \\
\hline 34 & Item & .695 \\
33 & Giving birth made me see that I am a strong woman. & .667 \\
35 & I feel a deep sense of connection with all mothers in the world. & .638 \\
31 & Giving birth is the greatest thing I have ever done. & .561 \\
23 & I kept telling myself that every pain got me closer to holding my baby. & .504 \\
28 & I felt like I was a part of nature and the creative universe. & .445 \\
27 & I felt connected to a higher power or God when I gave birth. & .409 \\
30 & I could tell when I was working well with my contractions. & .395 \\
29 & I was so focused on my contractions I was not worried what anyone thought & .356 \\
& about how I was acting. & \\
\hline
\end{tabular}

One-way between groups analysis of variance was conducted to determine the differences in mean subscale scores by educational level, age groups, parity, entry to prenatal care, length of labor, interventions, analgesia, perineal repair, 1-minute Apgar scores, feeding preference, health care provider, labor support, race/ethnicity, relationship status, religion, and income. All statistically significant results ( $\alpha=.05$ level of significance) are reported below for each subscale. Post hoc comparisons used Tukey's HSD for groups with more than two variables with significant findings.

Scores for support during childbirth differed significantly between women using epidural analgesia and those who did not. Comparison of the two groups indicates that the epidural group had significantly higher support subscale scores than the non-epidural group $(\mathrm{p}=.001)$. 
Scores for support during childbirth significantly differed based on the presence or absence of the FOB. Comparison of the two groups indicates that the FOB present group had significantly higher support subscale scores than when the FOB was absent $(\mathrm{p}=.003)$. 
Table 7

Items and Factor 4 Handling Pain in Childbirth

\begin{tabular}{llr}
\hline $\begin{array}{l}\text { Item } \\
\text { No. }\end{array}$ & Item & $\begin{array}{c}\text { Factor } \\
\text { loadings }\end{array}$ \\
\hline 26 & I was better at handling the contractions as labor progressed. \\
25 & I discovered I had unknown ability to handle the labor pain. & .648 \\
1 & My labor pain was more than I could handle. & .561 \\
14 & I was able to control the pain without medication. & .554 \\
17 & I thought I could handle the pain better than I did. & .527 \\
6 & I worked better with my contractions when I stopped trying to fight the & .478 \\
& contractions. & .470 \\
\hline
\end{tabular}

There were similar findings comparing women in a committed relationship with those not in a committed relationship. The committed relationship group had significantly higher support subscale scores than the women not in a committed relationship $(\mathrm{p}=.016)$. The results are presented in Table 9.

The subscale scores for the physical and emotional responses to childbirth differed according to the degree of perineal injury $(\mathrm{p}=.001)$. Tukey post-hoc comparisons of the three groups indicate that the no perineal injury group had significantly higher scores than the first degree laceration group $(\mathrm{p}=.002)$ and the perineal repair group $(\mathrm{p}=.002)$.

There were significant differences in physical and emotional responses to childbirth subscale scores based on history of attending childbirth education classes. Post-hoc comparisons of the three groups indicated that the women who had never attended childbirth education had significantly lower scores than the women who had attended classes with a previous pregnancy $(\mathrm{p}=.010)$. The group attending childbirth classes with this pregnancy also had significantly lower scores than those attending childbirth with a previous pregnancy $(\mathrm{p}=.049)$. There was no 
significant difference between the group who never attended childbirth classes and those who attended with this pregnancy.

Table 8

Significant Correlation Results for Subscale Scores

\begin{tabular}{|c|c|c|c|c|c|}
\hline & & $\begin{array}{l}\text { Support during } \\
\text { childbirth }\end{array}$ & $\begin{array}{l}\text { Physical and } \\
\text { emotional } \\
\text { response to } \\
\text { childbirth }\end{array}$ & $\begin{array}{l}\text { Transformative } \\
\text { experiences in } \\
\text { childbirth }\end{array}$ & $\begin{array}{l}\text { Handling } \\
\text { pain in } \\
\text { childbirth }\end{array}$ \\
\hline \multirow[t]{3}{*}{ Age } & $\mathrm{r}$ & -.131 & & -.124 & \\
\hline & Sig. (2-tailed) & .024 & & .031 & \\
\hline & $\mathrm{N}$ & 299 & & 299 & \\
\hline \multirow[t]{3}{*}{ Parity } & $\mathrm{r}$ & -.138 & .204 & & \\
\hline & Sig. (2-tailed) & .017 & .000 & & \\
\hline & $\mathrm{N}$ & 302 & 302 & & \\
\hline \multirow{3}{*}{$\begin{array}{l}\text { Length of } \\
\text { labor }\end{array}$} & $\mathrm{r}$ & & -.182 & & -.166 \\
\hline & Sig. (2-tailed) & & .002 & & .004 \\
\hline & $\mathrm{N}$ & & 296 & & 296 \\
\hline \multirow{3}{*}{$\begin{array}{l}\text { Number of } \\
\text { support } \\
\text { persons } \\
\text { present }\end{array}$} & $\mathrm{r}$ & & -.128 & .177 & \\
\hline & Sig. (2-tailed) & & .027 & .002 & \\
\hline & $\mathrm{N}$ & & 302 & 302 & \\
\hline
\end{tabular}

A significant difference was identified between groups based on the presence of female support persons during labor. Women without female support present had significantly higher scores for this subscale than did women who had female support present $(p=.005)$.

There were significant differences in the Subscale 2 scores between women who identified with a religion and those who did not. Women who identified with a religion had significantly higher subscale scores than those who did not $(\mathrm{p}=.036)$. 
Women having an operative delivery, either using forceps or vacuum extraction, had significantly different Subscale 2 scores than women having a spontaneous vaginal birth (SVD). Those with an SVD had higher scores than women with an operative delivery $(\mathrm{p}=.011)$. 
Table 9

Significant ANOVA Results Support during Childbirth

\begin{tabular}{lrrrr}
\hline \multicolumn{1}{c}{ Characteristic } & M (SD) & $95 \%$ CI & F (df) & p value \\
\hline Analgesia & & & 10.810 & .001 \\
Epidural analgesia & $69.41(6.40)$ & $(68.58,70.24)$ & $(1,300)$ & \\
No epidural analgesia & $66.38(7.91)$ & $(64.51,68.25)$ & & \\
& & & & \\
Support Persons & $69.03(6.80)$ & $(68.23,69.83)$ & $(1,300)$ & .003 \\
FOB present & $64.61(6.81)$ & $(61.66,67.56)$ & & \\
FOB absent & & & & \\
& & & 5.878 & .016 \\
Relationship Status & $68.89(6.83)$ & $(68.09,69.69)$ & $(1,296)$ & \\
$\quad \begin{array}{l}\text { Committed relationship } \\
\text { Not committed }\end{array}$ & $64.95(7.41)$ & $(61.38,68.52)$ & & \\
relationship & & & & \\
\hline
\end{tabular}

Note: FOB means Father of Baby

There were also significant differences in physical and emotional responses to childbirth scores for income groups. Post-hoc comparisons of the five groups indicate that the women reporting an annual income less than $\$ 20,000$ had significantly lower scores than the women who had an annual income between $\$ 60,000$ and $\$ 80,000(\mathrm{p}=.046)$.. There were no significant differences between the other income groups. The results are presented in Table 10.

The type of analgesia used affected the transformative experience subscore. Women using epidural analgesia had significantly lower scores than women who did not use epidural analgesia $(\mathrm{p}=.006)$.

The presence of female support persons during labor significantly affected the transformative experience scores. Women who had female support during labor had significantly higher scores than women who did not have female support persons present $(\mathrm{p}=$ $.002)$. 
Table 10

Significant ANOVA Results Physical and Emotional Responses to Childbirth

\begin{tabular}{|c|c|c|c|c|}
\hline Characteristic & $\mathrm{M}(\mathrm{SD})$ & $95 \% \mathrm{CI}$ & $F(d f)$ & $\mathrm{p}$ value \\
\hline $\begin{array}{l}\text { Perineal Injury } \\
\text { None } \\
\text { First degree laceration } \\
\text { Second degree or repair of } \\
\text { laceration }\end{array}$ & $\begin{array}{l}40.74(7.07) \\
36.96(6.95) \\
37.33(7.14)\end{array}$ & $\begin{array}{l}(39.15,42.34) \\
(35.49,38.41) \\
(36.11,38.55)\end{array}$ & $\begin{array}{l}7.436 \\
(2,298)\end{array}$ & .001 \\
\hline $\begin{array}{l}\text { Childbirth Education } \\
\text { Never } \\
\text { With this pregnancy } \\
\text { With previous pregnancy }\end{array}$ & $\begin{array}{l}37.42(7.43) \\
36.95(6.32) \\
40.24(6.75)\end{array}$ & $\begin{array}{l}(36.35,38.49) \\
(34.90,38.99) \\
(38.72,41.81)\end{array}$ & $\begin{array}{l}4.864 \\
(2,299)\end{array}$ & .008 \\
\hline $\begin{array}{l}\text { Support Persons } \\
\text { Female support present } \\
\text { No female support present }\end{array}$ & $\begin{array}{l}36.989(6.95) \\
39.31(7.34)\end{array}$ & $\begin{array}{l}(35.91,38.69) \\
(38.09,40.54)\end{array}$ & $\begin{array}{l}7.974 \\
(1,300)\end{array}$ & .005 \\
\hline $\begin{array}{l}\text { Religious Identity } \\
\text { Identifies with a religion } \\
\text { Does not identify with a } \\
\text { religion }\end{array}$ & $\begin{array}{l}38.84(7.38) \\
36.783(6.57)\end{array}$ & $\begin{array}{l}(37.79,39.90) \\
(35.28,38.30)\end{array}$ & $\begin{array}{l}4.427 \\
(1,263)\end{array}$ & .036 \\
\hline $\begin{array}{l}\text { Medical Interventions } \\
\text { Operative delivery } \\
\text { Spontaneous delivery }\end{array}$ & $\begin{array}{l}33.47(7.15) \\
38.31(7.15)\end{array}$ & $\begin{array}{l}(29.51,37.43) \\
37.48,39.15)\end{array}$ & $\begin{array}{l}6.544 \\
(1,300)\end{array}$ & .011 \\
\hline $\begin{array}{l}\text { Annual income } \\
<\$ 20,000 \\
\$ 20,001-\$ 40,000 \\
\$ 40,001-\$ 60,000 \\
\$ 60,001-\$ 80,000 \\
>\$ 80,001\end{array}$ & $\begin{array}{l}35.44(8.36) \\
37.86(6.69) \\
37.64(7.15) \\
40.56(6.25) \\
39.23(7.29)\end{array}$ & $\begin{array}{l}(31.82,39.48) \\
(35.83,39.89) \\
(35.85,39.43) \\
(38.51,42.61) \\
(37.55,39.36)\end{array}$ & $\begin{array}{l}2.459 \\
(4,244)\end{array}$ & .046 \\
\hline
\end{tabular}

The use of forceps or vacuum extraction for birth significantly affected the

Transformative Experience scores. Women having a SVD had significantly higher Subscale 4 scores than those women having an operative birth $(\mathrm{p}=.012)$. The results are presented in Table 11. 
Table 11

Significant ANOVA Results 3 Transformative Experiences in Childbirth

\begin{tabular}{lrrrr}
\hline \multicolumn{1}{c}{ Characteristic } & $\mathrm{M}(\mathrm{SD})$ & $95 \% \mathrm{CI}$ & $\mathrm{F}(\mathrm{df})$ & $\mathrm{p}$ value \\
\hline Analgesia & & & 7.641 & .006 \\
$\quad$ Epidural analgesia & $32.31(4.96)$ & $(31.67,32.96)$ & $(1,300)$ & \\
No epidural analgesia & $34.17(4.91)$ & $(33.01,35.33)$ & & \\
& & & & \\
Support Persons & & & 7.641 & .002 \\
Female support present & $33.57(4.89)$ & $(32.81,34.33)$ & $(1,300)$ & \\
No female support present & $31.82(4.52)$ & $(30.98,32.65)$ & & \\
& & & & \\
Medical Interventions & & & & \\
$\quad$ Operative delivery & $29.60(5.71)$ & $(26.44,32.76)$ & $(1,300)$ & \\
Spontaneous delivery & $32.91(4.92)$ & $(32.34,33.49)$ & & \\
\hline
\end{tabular}

The number of medical interventions during labor significantly affected the ability to handle pain scores $(\mathrm{p}=.006)$. Women who did not have any interventions during labor had significantly higher subscale scores than women who had one intervention $(\mathrm{p}=.046)$ or more than one intervention $(\mathrm{p}=.005)$. There was not a significant difference in Subscale 4 scores between women having one intervention and more than one intervention. Women having oxytocin administered during labor had significantly lower Subscale 4 scores than did women not having oxytocin $(\mathrm{p}=.004)$. Likewise, women having an operative birth had significantly lower scores than those having a spontaneous vaginal birth $(\mathrm{p}=.035)$.

Significant differences were identified between the use of epidural analgesia and the ability to handle pain scores. Women who did not use epidural analgesia had significantly higher Subscale 4 scores than did women who used epidural analgesia $(\mathrm{p}<.001)$. 
There were significant differences in the subscale 4 scores between women who identified with a religion and those who did not. Women who identified with a religion had a significantly higher score than those who did not $(\mathrm{p}=.008)$.

There were significant differences in handling pain in childbirth scores by income groups $(\mathrm{p}=.004)$. Post-hoc comparisons of the five groups indicate that the women reporting an annual income less than $\$ 20,000$ had significantly lower Subscale 4 scores than did women reporting incomes $>\$ 80,000$ annually $(\mathrm{p}=.025)$. There was also a significant difference between the two upper income levels. Women reporting $>\$ 80,000$ annually had significantly higher Subscale 4 scores than did the women reporting $\$ 60,000-\$ 80,000$ annually $(\mathrm{p}=.025)$. The results are presented in Table 12.

Test-retest reliability. A paired samples t-test was conducted to evaluate the difference between the 42-item WECS scores obtained in the hospital and 2 to 4 weeks after discharge. Two hundred forty-three of the participants agreed to receive the second questionnaire; 122 returned the second questionnaire (50.2\% return rate). There was no significant difference between overall WECS scores from inpatient time $(\mathrm{M}=159.5, \mathrm{SD}=1.56)$ and post discharge time $(\mathrm{M}=160.5, \mathrm{SD}=1.6), \mathrm{t}(121)=-1.304, \mathrm{p}=.195($ two tailed $)$.

Mean responses to 10 items on the second administration differed significantly from initial responses. The amount of physical fatigue, willingness to repeat the birth experience, a sense they were better able to handle the contractions, being connected to a higher power, having a sense they could accomplish anything, and being more connected to all mothers were rated significantly higher $(\mathrm{p}<.05)$ on the second administration. Nurses helping with comfort, being kept informed of their progress, being treated as an individual, and support from family and 
friends were rated significantly lower on the second administration $(\mathrm{p}<.05)$. Table 13 presents the test-retest information for the 42-item WECS.

Paired samples t-tests were also conducted to evaluate the differences between subscale scores obtained in the hospital and 2 to 4 weeks after discharge. Statistically significant differences were identified for three subscales. The differences in subscale scores over time are presented in Table 14. The subscale scores for support during childbirth and physical and emotional response to childbirth were significantly lower on the second evaluation. The subscale score for transformative experience was significantly higher on the second evaluation.

Table 12

Significant ANOVA Results Ability to Handle Pain

\begin{tabular}{|c|c|c|c|c|}
\hline Characteristic & $\mathrm{M}(\mathrm{SD})$ & $95 \% \mathrm{CI}$ & $F(d f)$ & $\mathrm{p}$ value \\
\hline $\begin{array}{l}\text { Medical Interventions } \\
\text { No interventions } \\
\text { One intervention } \\
\text { More than one intervention }\end{array}$ & $\begin{array}{l}19.16(4.33) \\
17.73(4.36) \\
17.26(6.63)\end{array}$ & $\begin{array}{l}(18.20,20.12) \\
(16.90,18.55) \\
(16.58,17.94)\end{array}$ & $\begin{array}{l}5.264 \\
(2,299)\end{array}$ & .006 \\
\hline $\begin{array}{l}\text { Oxytocin Administration } \\
\text { Yes } \\
\text { No }\end{array}$ & $\begin{array}{l}17.26(3.91) \\
18.64(4.30)\end{array}$ & $\begin{array}{l}(16.37,17.89) \\
(17.94,19.33)\end{array}$ & $\begin{array}{l}8.486 \\
(1,300)\end{array}$ & .004 \\
\hline $\begin{array}{l}\text { Medical Interventions } \\
\text { Operative delivery } \\
\text { Spontaneous delivery }\end{array}$ & $\begin{array}{l}15.73(3.17) \\
18.06(4.17)\end{array}$ & $\begin{array}{l}(13.98,17.49) \\
(17.57,18.54)\end{array}$ & $\begin{array}{l}4.505 \\
(1,300)\end{array}$ & .035 \\
\hline $\begin{array}{l}\text { Analgesia } \\
\text { Epidural analgesia } \\
\text { No epidural analgesia }\end{array}$ & $\begin{array}{l}16.99(3.78) \\
21.01(3.86)\end{array}$ & $\begin{array}{l}(16.51,17.49) \\
(20.00,21.93)\end{array}$ & $\begin{array}{l}60.899 \\
(1,300)\end{array}$ & $<.000$ \\
\hline $\begin{array}{l}\text { Religious Identity } \\
\text { Identifies with a religion } \\
\text { Does not identify with a } \\
\text { religion }\end{array}$ & $\begin{array}{l}18.44(4.13) \\
16.93(4.17)\end{array}$ & $\begin{array}{l}(17.85,19.03) \\
(15.97,17.89)\end{array}$ & $\begin{array}{l}7.133 \\
(1,263)\end{array}$ & \\
\hline $\begin{array}{l}\text { Annual income } \\
<\$ 20,000\end{array}$ & $16.17(4.14)$ & $(14.43,17.92)$ & $\begin{array}{l}3.902 \\
(4,244)\end{array}$ & .004 \\
\hline
\end{tabular}




$\begin{array}{lll}\$ 20,001-\$ 40,000 & 18.75(4.13) & (17.50,20.01) \\ \$ 40,001-\$ 60,000 & 17.80(3.85) & (15.42,18.07) \\ \$ 60,001-\$ 80,000 & 16.74(4.29) & (15.43,18.07) \\ >\$ 80,001 & 19.09(4.17) & (18.13,20.05)\end{array}$

Table 13

Test-Retest Results

\begin{tabular}{|c|c|c|c|c|c|}
\hline & & $\begin{array}{l}\text { Time } 1 \\
\text { mean } \\
(\mathrm{SD})\end{array}$ & $\begin{array}{c}\text { Time } 2 \\
\text { mean } \\
(\mathrm{SD})\end{array}$ & $\begin{array}{c}\mathrm{t} \\
\mathrm{df} \\
121\end{array}$ & $\mathrm{p}$ value \\
\hline 1 & My labor pain was more than I could handle. & $\begin{array}{l}3.11 \\
(1.23)\end{array}$ & $\begin{array}{l}3.20 \\
(1.16)\end{array}$ & -1.064 & .289 \\
\hline 2 & I was physically worn out from giving birth. & $\begin{array}{l}2.62 \\
(1.20)\end{array}$ & $\begin{array}{l}2.86 \\
(1.25)\end{array}$ & -2.552 & .012 \\
\hline 4 & $\begin{array}{l}\text { Nausea, vomiting, or shaking chills kept me } \\
\text { from being able to enjoy childbirth. }\end{array}$ & $\begin{array}{l}3.94 \\
(1.11)\end{array}$ & $\begin{array}{l}3.93 \\
(1.12)\end{array}$ & 199 & .842 \\
\hline 5 & $\begin{array}{l}\text { I felt like I could control my body during } \\
\text { childbirth. }\end{array}$ & $\begin{array}{l}3.16 \\
(1.13)\end{array}$ & $\begin{array}{l}3.29 \\
(1.07)\end{array}$ & -1.249 & .214 \\
\hline 6 & $\begin{array}{l}\text { I worked better with my contractions when I } \\
\text { stopped trying to fight the contractions. }\end{array}$ & $\begin{array}{l}3.77 \\
(1.4)\end{array}$ & $\begin{array}{l}3.79 \\
(.98)\end{array}$ & -.190 & .85 \\
\hline 7 & $\begin{array}{l}\text { The nurses helped me stay as comfortable as } \\
\text { possible. }\end{array}$ & $\begin{array}{l}4.66 \\
(.68)\end{array}$ & $\begin{array}{l}4.50 \\
(.74)\end{array}$ & 2.142 & .034 \\
\hline 8 & $\begin{array}{l}\text { I was afraid of what was happening to me } \\
\text { during childbirth. }\end{array}$ & $\begin{array}{l}3.62 \\
(1.26)\end{array}$ & $\begin{array}{l}3.80 \\
(1.11)\end{array}$ & -1.784 & .077 \\
\hline 9 & I look back on the birth with great joy. & $\begin{array}{l}4.15 \\
(.96)\end{array}$ & $\begin{array}{l}4.17 \\
(.95)\end{array}$ & -.366 & .737 \\
\hline 11 & $\begin{array}{l}\text { I could not control my emotions during } \\
\text { childbirth. }\end{array}$ & $\begin{array}{l}3.43 \\
(1.25)\end{array}$ & $\begin{array}{l}3.43 \\
(1.21)\end{array}$ & .000 & 1.000 \\
\hline 12 & My nurse helped me feel calm. & $\begin{array}{l}4.39 \\
(.77)\end{array}$ & $\begin{array}{l}4.27 \\
(.72)\end{array}$ & 1.548 & .124 \\
\hline 13 & $\begin{array}{l}\text { I felt like the nurses did not pay attention to me } \\
\text { as a person. }\end{array}$ & $\begin{array}{l}4.66 \\
(.85)\end{array}$ & $\begin{array}{l}4.48 \\
(.96)\end{array}$ & 2.618 & .010 \\
\hline 14 & $\begin{array}{l}\text { I was able to control the pain without } \\
\text { medication. }\end{array}$ & $\begin{array}{l}2.40 \\
(1.42)\end{array}$ & $\begin{array}{l}2.51 \\
(1.43)\end{array}$ & -1.248 & .214 \\
\hline 15 & $\begin{array}{l}\text { My choice about using pain medication let me } \\
\text { enjoy childbirth. }\end{array}$ & $\begin{array}{l}3.98 \\
(1.13)\end{array}$ & $\begin{array}{l}4.07 \\
(1.01)\end{array}$ & -1.291 & .199 \\
\hline 16 & $\begin{array}{l}\text { I am glad I made the choice I did whether to use } \\
\text { pain medication. }\end{array}$ & $\begin{array}{l}4.46 \\
(.83)\end{array}$ & $\begin{array}{l}4.48 \\
(.76)\end{array}$ & -.220 & .826 \\
\hline 17 & I thought I could handle the pain better than I & 3.20 & 3.06 & 1.517 & 132 \\
\hline
\end{tabular}


Table 13

Test-Retest Results

\begin{tabular}{|c|c|c|c|c|c|}
\hline & & $\begin{array}{l}\text { Time } 1 \\
\text { mean } \\
(\mathrm{SD})\end{array}$ & $\begin{array}{l}\text { Time } 2 \\
\text { mean } \\
(\mathrm{SD})\end{array}$ & $\begin{array}{c}\mathrm{t} \\
\mathrm{df} \\
121\end{array}$ & $\mathrm{p}$ value \\
\hline & did. & $(1.19)$ & $(1.14)$ & & \\
\hline 18 & $\begin{array}{l}\text { I was prepared for what childbirth would be } \\
\text { like. }\end{array}$ & $\begin{array}{l}3.56 \\
(1.15)\end{array}$ & $\begin{array}{l}3.70 \\
(1.04)\end{array}$ & -1.840 & .068 \\
\hline 19 & $\begin{array}{l}\text { I had no clue what I was in for during } \\
\text { childbirth. }\end{array}$ & $\begin{array}{l}3.95 \\
(1.10)\end{array}$ & $\begin{array}{l}3.91 \\
(1.04)\end{array}$ & .423 & .673 \\
\hline 21 & I thought my labor was never going to end. & $\begin{array}{l}3.52 \\
(1.02)\end{array}$ & $\begin{array}{l}3.44 \\
(1.14)\end{array}$ & .679 & .499 \\
\hline 23 & $\begin{array}{l}\text { I kept telling myself that every pain got me } \\
\text { closer to holding my baby. }\end{array}$ & $\begin{array}{l}3.91 \\
(.97)\end{array}$ & $\begin{array}{l}3.83 \\
(.97)\end{array}$ & 1.134 & .259 \\
\hline 24 & $\begin{array}{l}\text { Birth was so amazing--I would gladly do it } \\
\text { again. }\end{array}$ & $\begin{array}{l}3.47 \\
(1.02)\end{array}$ & $\begin{array}{l}3.70 \\
(1.08)\end{array}$ & -3.251 & .001 \\
\hline 25 & $\begin{array}{l}\text { I discovered I had unknown ability to handle } \\
\text { the labor pain. }\end{array}$ & $\begin{array}{l}3.24 \\
(1.14)\end{array}$ & $\begin{array}{l}3.34 \\
(1.12)\end{array}$ & -1.125 & .263 \\
\hline 26 & $\begin{array}{l}\text { I was better at handling the contractions as } \\
\text { labor progressed. }\end{array}$ & $\begin{array}{l}2.70 \\
(1.11)\end{array}$ & $\begin{array}{l}2.92 \\
(1.11)\end{array}$ & -2.264 & .025 \\
\hline 27 & $\begin{array}{l}\text { I felt connected to a higher power or God when } \\
\text { I gave birth. }\end{array}$ & $\begin{array}{l}3.05 \\
(1.25)\end{array}$ & $\begin{array}{l}3.21 \\
(1.23)\end{array}$ & -2.336 & .021 \\
\hline 28 & $\begin{array}{l}\text { I felt like I was a part of nature and the creative } \\
\text { universe. }\end{array}$ & $\begin{array}{l}2.91 \\
(1.01)\end{array}$ & $\begin{array}{l}2.88 \\
(1.147)\end{array}$ & .377 & .707 \\
\hline 29 & $\begin{array}{l}\text { I was so focused on my contractions I was not } \\
\text { worried what anyone thought about how I was } \\
\text { acting. }\end{array}$ & $\begin{array}{l}3.78 \\
(1.09)\end{array}$ & $\begin{array}{l}3.74 \\
(1.10)\end{array}$ & .432 & .666 \\
\hline 30 & $\begin{array}{l}\text { I could tell when I was working well with my } \\
\text { contractions. }\end{array}$ & $\begin{array}{l}3.85 \\
(.92)\end{array}$ & $\begin{array}{l}3.94 \\
(.90)\end{array}$ & -1.225 & .223 \\
\hline 31 & $\begin{array}{l}\text { Giving birth is the greatest thing I have ever } \\
\text { done. }\end{array}$ & $\begin{array}{l}4.24 \\
(.95)\end{array}$ & $\begin{array}{l}4.26 \\
(.98)\end{array}$ & -.345 & .731 \\
\hline 32 & $\begin{array}{l}\text { The only positive thing about my experience is } \\
\text { that I have a healthy baby. }\end{array}$ & $\begin{array}{l}3.71 \\
(1.12)\end{array}$ & $\begin{array}{l}3.67 \\
(1.18)\end{array}$ & .420 & .675 \\
\hline 33 & $\begin{array}{l}\text { Giving birth made me see that I am a strong } \\
\text { woman. }\end{array}$ & $\begin{array}{l}4.11 \\
(.87)\end{array}$ & $\begin{array}{l}4.20 \\
(.81)\end{array}$ & -1.464 & .146 \\
\hline 34 & $\begin{array}{l}\text { I believe I can accomplish anything since } \\
\text { giving birth. }\end{array}$ & $\begin{array}{l}3.49 \\
(.97)\end{array}$ & $\begin{array}{l}3.73 \\
(.98)\end{array}$ & -3.552 & .001 \\
\hline 35 & $\begin{array}{l}\text { I feel a deep sense of connection with all } \\
\text { mothers in the world. }\end{array}$ & $\begin{array}{l}3.25 \\
(1.001)\end{array}$ & $\begin{array}{l}3.47 \\
(.97)\end{array}$ & -2.851 & .005 \\
\hline 38 & $\begin{array}{l}\text { I was able to change positions or do things that } \\
\text { made me more comfortable during labor. }\end{array}$ & $\begin{array}{l}3.74 \\
(1.07)\end{array}$ & $\begin{array}{l}3.73 \\
(.99)\end{array}$ & .088 & .930 \\
\hline
\end{tabular}


Table 13

Test-Retest Results

\begin{tabular}{|c|c|c|c|c|c|}
\hline & & $\begin{array}{c}\text { Time } 1 \\
\text { mean } \\
(\mathrm{SD})\end{array}$ & $\begin{array}{c}\text { Time } 2 \\
\text { mean } \\
(\mathrm{SD})\end{array}$ & $\begin{array}{c}\mathrm{t} \\
\mathrm{df} \\
121\end{array}$ & $\mathrm{p}$ value \\
\hline 40 & The people I wanted were with me during birth. & $\begin{array}{l}4.67 \\
(.62)\end{array}$ & $\begin{array}{l}4.67 \\
(.58)\end{array}$ & .000 & 1.000 \\
\hline 41 & $\begin{array}{l}\text { My birth experience was as private as I wanted } \\
\text { it to be. }\end{array}$ & $\begin{array}{l}4.34 \\
(.79)\end{array}$ & $\begin{array}{l}4.38 \\
(.79)\end{array}$ & -.425 & .672 \\
\hline 42 & $\begin{array}{l}\text { I was able to make decisions about what was } \\
\text { happening to me. }\end{array}$ & $\begin{array}{l}4.37 \\
(.76)\end{array}$ & $\begin{array}{l}4.40 \\
(.71)\end{array}$ & -.491 & .624 \\
\hline 43 & $\begin{array}{l}\text { The doctors/midwives and nurses took control } \\
\text { of the birth away from me. }\end{array}$ & $\begin{array}{l}4.47 \\
(.73)\end{array}$ & $\begin{array}{l}4.33 \\
(.87)\end{array}$ & 1.778 & .078 \\
\hline 44 & $\begin{array}{l}\text { The midwives/doctors and nurses helped me } \\
\text { have the kind of birth experience I wanted. }\end{array}$ & $\begin{array}{l}4.27 \\
(.88)\end{array}$ & $\begin{array}{l}4.25 \\
(.78)\end{array}$ & .383 & .703 \\
\hline 45 & $\begin{array}{l}\text { My friends and family who were with me } \\
\text { helped me stay comfortable during labor. }\end{array}$ & $\begin{array}{l}4.47 \\
(.62)\end{array}$ & $\begin{array}{l}4.45 \\
(.64)\end{array}$ & .323 & .747 \\
\hline 46 & $\begin{array}{l}\text { My family and friends spoke up to make sure I } \\
\text { had the kind of birth experience I wanted. }\end{array}$ & $\begin{array}{l}3.99 \\
(.895)\end{array}$ & $\begin{array}{l}3.89 \\
(.91)\end{array}$ & 1.248 & .214 \\
\hline 47 & $\begin{array}{l}\text { The doctors/midwives and nurses kept me } \\
\text { informed of how labor was progressing. }\end{array}$ & $\begin{array}{l}4.51 \\
(.695)\end{array}$ & $\begin{array}{l}4.39 \\
(.64)\end{array}$ & 2.223 & .028 \\
\hline 48 & $\begin{array}{l}\text { My friends and family gave me strength and } \\
\text { emotional support during labor. }\end{array}$ & $\begin{array}{l}4.61 \\
(.57)\end{array}$ & $\begin{array}{l}4.50 \\
(.62)\end{array}$ & 2.047 & .043 \\
\hline 49 & $\begin{array}{l}\text { The nurses knew what I needed before I had to } \\
\text { ask. }\end{array}$ & $\begin{array}{l}3.73 \\
(.84)\end{array}$ & $\begin{array}{l}3.74 \\
(.78)\end{array}$ & -.115 & .909 \\
\hline
\end{tabular}

Note: Significant results are in boldface. 
Table 14

Paired t-test Results for Subscales Scores

\begin{tabular}{lcccc}
\hline & $\begin{array}{c}\text { Time 1 } \\
\text { Mean (SD) }\end{array}$ & $\begin{array}{c}\text { Time 2 } \\
\text { Mean (SD) }\end{array}$ & $\begin{array}{c}\mathrm{t} \\
\text { (df 121) }\end{array}$ & Sig. \\
\hline $\begin{array}{l}\text { Support during } \\
\text { Childbirth }\end{array}$ & $69.32(6.82)$ & $68.51(6.74)$ & 2.050 & .043 \\
$\begin{array}{l}\text { Physical and } \\
\begin{array}{l}\text { Emotional } \\
\text { Responses to } \\
\text { Childbirth }\end{array}\end{array}$ & $39.13(7.16)$ & $36.46(6.70)$ & 7.306 & .000 \\
$\begin{array}{l}\text { Transformative } \\
\begin{array}{l}\text { Experiences in } \\
\text { Childbirth }\end{array}\end{array}$ & $32.60(5.28)$ & & & \\
$\begin{array}{l}\text { Handling Pain } \\
\text { in Childbirth }\end{array}$ & $18.42(4.68)$ & $33.26(5.71)$ & -2.186 & .031 \\
\hline
\end{tabular}




\section{CHAPTER 5}

\section{Discussion}

The purpose of this study was to develop and test an instrument to measure a woman's perception of her childbirth experience. Previous analysis of existing instruments had not identified any that would span the entire spectrum of the childbirth experience, as it was reflected in literature. The desired instrument should capture a birth experience from the worst experience of a woman's life to a transcendent event. The WECS was developed using a framework incorporating aspects from transition theory, extant literature, and feedback from participants in pilot studies. Specific research questions in this study focused on identifying the validity and reliability of the WECS. Results from this study indicate the 42-item WECS and the associated four subscales demonstrate adequate validity and reliability to suggest that further development and research is indicated.

\section{Validity}

Content and construct validity methods used in the study contribute to the evidence that the WECS is a valid measure of a woman's perception of the childbirth experience. The validity measures for the WECS included content expert validation, cognitive interviewing, use of a theoretical framework, comparison of scores to similar measures and external variables, and factor analysis. Content expert validation and cognitive interviewing findings were discussed previously in Chapter Three.

Construct validity was demonstrated by the use of a conceptual framework with four aspects of the childbirth experience: physical, emotional, cognitive, and social. Factor analysis identified four subscales that were similar to the framework. The subscale labeled "Support during Childbirth" was the same as the social aspects identified for the framework and included 
items for support from friends and family as well as health care professionals. The physical and emotional aspects identified in the framework were combined into the second subscale labeled "Physical and Emotional Response to Childbirth". The cognitive aspect of the framework included items intended to measure a flow consciousness and other cognitive coping strategies aligned with the subscale labeled "Transformative Experiences in Childbirth". The identification of a factor relating to a transformative experience is a new finding that was anticipated in midwifery literature (Humenick, 1998; Walsh, 2008). This is the first time flow consciousness in childbirth has been identified. The fourth subscale labeled "Handling Pain in Childbirth" combined items originally designed to be in the physical or emotional aspects of the framework. In the framework, pain and pain management strategies were assigned to the physical aspect of childbirth. Salmon (1990) noted that satisfaction with labor is not dependent on the perception of pain. The separation of pain and pain management into a separate factor would support those assumptions.

While the conceptual framework was closely aligned with the derived factors, seven items were removed from analysis in this study. Three of the items had lower correlations within subscales and were removed from the analysis. These items concerned being excited about starting labor, appreciating their own mother, and not liking the woman's own behavior during childbirth. The excitement to start labor was thought to reflect anticipation more than the experience in labor. The other two appeared to be a post birth analysis rather than what occurred during childbirth.

Four items did not load onto any factor. Two of the items were somewhat redundant in that another item questioned the same aspect but in a negative manner. Item 3 was concerned with adequate rest between contractions and reflected the perceived work of labor; the contrary 
item that did load concerned being physically worn out. Item 20 addressed time passing quickly during labor; the contrary item that was retained asked if labor was never-ending. It could be that the negative wording elicited a stronger response by the participants. Item 22 concerned strategies to keep her mind off of the pain may have been affected by the high epidural rate in this sample. Women in these clinical settings could receive epidural analgesia as soon as they began to get uncomfortable and thus may not have needed to use distraction techniques as a pain management strategy. Item 39 related to a sense of being tied to monitoring equipment. Being tied to the equipment could be reworded to being able to move about as desired during labor. With only $39 \%$ of the women attending childbirth education, there may not have been an expectation that changing position during labor could provide comfort and delay the use of analgesics. One purpose of factor analysis is to reduce the number of items from an instrument that do not contribute to the underlying structure of the concept (Tabachnick \& Fidell, 2007). Additional review and rewording of the items would be considered before permanently removing these seven items from future analysis.

Factor analysis with four factors accounted for only $36.4 \%$ of variance and does not provide overwhelming support for construct validation. This may be a result of the sample characteristics, especially race/ethnicity and use of analgesia, and the need to repair the previously mentioned items for a subsequent study with a more diverse sample. It has also been noted by previous authors (Callister, 1995; Parratt \& Fahy, 2003; Larkin et al., 2009) that the childbirth experience is complex and interrelated, with women experiencing apparently conflicting experiences at the same time or at different times during childbirth. This type of situation could result in difficulty extracting significant differences between and within the sample. 
Support for the validity of the WECS was evidenced by a significant correlation $(\mathrm{r}=.51$, $\mathrm{p}<.01$ ) between the total WECS score and the woman's own rating of the childbirth experience using a 10-point visual analog score. It was anticipated that there would be at least a moderate correlation between the two scores. However, as noted previously, using a 10-point VAS does not substitute for a multidimensional instrument such as the WECS.

Additional support for the validity of the WECS is provided by comparing demographic and obstetrical variables that have been identified in the research as associated with the perception of the childbirth experience. Shorter labors have been related to higher satisfaction with the childbirth experience (Seguin et al, 1989; Waldenstrom et al, 1996; Waldenstrom, 1999), a finding echoed by this study. A shorter labor was correlated with an overall higher WECS score, as well as higher subscale scores for "Physical and Emotional Response to Childbirth" and "Handling Pain in Childbirth".

Medical interventions have been reported to decrease satisfaction with the childbirth experience (Creedy et al., 2000; Green, 1990; Waldenstrom et al., 2004; Waldenstrom et al., 1996). In this study, specific medical interventions related to medication for induction and augmentation of labor, operative delivery, analgesia, and perineal repair were analyzed, with significant evidence that fewer medical interventions are associated with a more positive birth experience. Women with operative births had lower overall WECS scores, and women with spontaneous births had higher subscale scores for "Physical and Emotional Responses to Childbirth", "Transformative Experiences in Childbirth" and "Handling Pain in Childbirth". In addition, women who did not have any interventions during childbirth and those who did not have oxytocin during labor had higher subscale scores for "Handling Pain in Childbirth". 
The use of epidural analgesia affected specific aspects of the childbirth experience. Women using epidural analgesia had higher subscale scores for "Support during Childbirth." This is an interesting finding in light that support during childbirth has traditionally been identified with less analgesia and epidural use (Hodnett et al., 2013). This may be related to the feedback obtained in the first pilot study for the WECS, where several women discussed birth with an epidural as a celebratory event with friends and family rather than a time of needing support for the mother. Another consideration may be the community hospital environment where this study took place. The staff nurses may have had a lower patient work load and were more available for support. Further evaluation of the types of support provided by both health care providers and social support persons is indicated.

Women not using epidural analgesia had higher subscale scores for "Transformative Experiences in Childbirth" and Handling Pain in Childbirth". The higher "Transformative Experience" score would be expected in an un-medicated birth if the woman has the ability to become fully engaged with childbirth in the face of strong pain. This type of situation lends itself to flow consciousness and an increased sense of being able to handle the pain. Flow consciousness involves complete engagement with challenging tasks beyond the normal everyday capacity of the body (Csikentmihalyi, 1990). It is likely that not using medication would result in a higher rating of her ability to handle pain. Women using epidural analgesia may experience ambivalent feelings about this choice despite having successful analgesia (Hidaka \& Callister, 2012).

Any perineal injury whether it was repaired or not was associated with a lower subscale score for "Physical and Emotional Responses to Childbirth". This appears contrary to current birth practices of allowing perineal tears to occur rather than performing routine episiotomy, 
which has been shown to negatively affect maternal infant interactions, emotional recovery, and resumption of sexual relations (Perry et al., 2010). Research concerning perineal repair has been primarily focused on optimal healing and long term medical complications (Fleming, Hagen, \& Niven, 2003); the maternal perception of perineal trauma was not measured in the study.

Support during childbirth has been shown to increase women's satisfaction with the experience and decrease the need for medical interventions during labor (Hodnett et al., 2007). This study analyzed the specific type and number of support persons during labor. Previously published instruments focus on care by health care providers, support using Lamaze method, or do not assess support persons directly. The presence of the father of the baby resulted in a higher WECS score and subscale score for "Support during Childbirth". The presence of female support persons resulted in higher subscale scores for "Transformative Experiences in Childbirth" but lower subscale scores for "Physical and Emotional Responses to Childbirth". It is not clear why these opposing effects occurred. The majority of the literature concerning support during childbirth identified that a non-related woman providing support is associated with positive birth outcomes (Hodnett et al., 2013). In this study only three women reported a doula being present; the majority of women in attendance were family members. The number of persons present during childbirth influenced subscale scores in differing ways. The fewer the number present, the higher the subscale score for "Physical and Emotional Responses to Childbirth", while the more persons present the higher the "Transformative Experience in Childbirth" subscale score. The data collected in this study used maternal recall of those present; it did not clarify the roles played by those persons. These results indicate a need for more understanding of the support roles played by family and friends during labor and considering mediating and moderating effects of different support persons on the WECS scores. 
The women in this study had higher subscale scores for "Physical and Emotional Responses to Childbirth" if they had attended childbirth classes with a previous pregnancy than if they never had attended or if they attended with this pregnancy. The research is not consistent about the effect of childbirth education and perception of the birth experience (Gagnon and Sandall, 2007). The results in this study seem to indicate that parity has more of an association with the subscale score than does the childbirth class. Multiple types of childbirth education are available (Walker et al., 2009). The type and content of the childbirth education was not recorded as part of this study. In future studies it would be helpful to know the type of class that was attended, whether a specific method of coping with labor was presented or if the class was focused on preparation for/orientation to the hospital birthing environment. Other educational preparation such as the use of printed materials or consulting internet resources should be considered in the type of childbirth preparation.

Demographic characteristics of age, parity, religious identity, and income levels have been associated with varying satisfaction with the childbirth experience. Most studies have reported older, multiparas are more satisfied with childbirth (Ayers \& Pickering, 2005; Baston, Rijnders, Green, \& Buitendijk, 2008; Waldenstrom, 1999). In this study there was a small negative correlation between the total WECS score and age, and subscale scores "Support during Childbirth" and "Transformative Experiences in Childbirth" were higher for younger women. Further analysis will be needed in future studies to determine if this is a persistent finding or the result of a confounding variable.

In this study, parity was correlated with higher scores on the "Physical and Emotional Responses to Childbirth" subscale. This could be the relationship identified in the literature indicating multiparas having higher satisfaction levels with childbirth since items from 
"Transformative Experiences in Childbirth" were not included in previous instruments.

However, there was a negative correlation between the number of births and the subscale score for "Support during Childbirth". It is not clear why this occurred and results indicate a need for more understanding of the roles of support persons during childbirth. It is possible the multiparas have higher expectations from their support persons.

As in most healthcare research, income is a significant variable affecting many aspects of health as well as the perception of well-being in pregnancy (Zachariah, 2009). Low income women in this study had lower subscale scores for "Physical and Emotional Responses to Childbirth" and "Handling Pain in Childbirth".

While there were not sufficient numbers in all identified religious groups, identity with a religion was associated with higher subscale scores for "Physical and Emotional Responses to Childbirth" and "Handling Pain in Childbirth". Specific religious identity has not always been reported in childbirth literature; however Bennington (2010) identified a relationship between spirituality and a positive birth experience. Qualitative studies of cultural and religious influences indicate there is an association between religious and cultural identity and positive outcomes for the new mother (Callister, 1995). This study would support that premise.

\section{Reliability}

Reliability of the WECS and associated subscales was analyzed by internal consistency and test-retest reliability. The WECs and factor scores demonstrated an adequate internal consistency as measured by the Cronbach's alpha coefficients for the total score $(\alpha=.86)$ and the first three subscales $(\alpha=.82, .78, .71)$. For the subscale labeled "Handling Pain in Childbirth" the coefficient was lower $(\alpha=.66)$. This may be as a result of having only six items in the subscale. The addition of items related to handling pain may improve this coefficient. Lowe 
(1989) found that maternal self-confidence, childbirth preparation, and frequency of contractions in women not using epidural analgesia were significant predictors of the woman's response to pain during labor. This supports the previous discussion about retaining the items from the 49item WECS for study with a more diverse sample.

The test-retest reliability between the WECS administered during the inpatient postpartum period and that completed at home at least 2 weeks following birth found no statistically significant difference in the overall WECS scores. However, some individual items did change between the two time periods, and there were statistically significant differences for three of the subscales. While the subscale score for handling pain did not change significantly, one item on the subscale concerning ability to handle contractions as labor progressed increased a significant amount by the second time frame. The subscale scores for support and the physical and emotional responses were lower at the second time interval; the transformative subscale scores were higher. Items related to support during labor, specifically the nursing care related to comfort, being treated as an individual, kept informed and emotional support from friends and family decreased significantly. In contrast, the woman's sense of her own accomplishment for managing pain, feeling empowered, closer to other mothers, and glad to repeat the experience may indicate the positive transition to the new role (Meleis et al., 2010). The statistical significance of this difference is probably not clinically significant. However, further validation of the effect of time difference on scores is required in light of previous studies that indicate the perception of the birth experience can be stable years following the event (Simkin, 1991;

Waldenstrom, 2003). 


\section{Limitations}

This study was conducted in a rural region of Virginia that is adjacent to Appalachia. At least $10 \%$ of the sample was definitely born in Appalachia. The sample was predominately White (89.4\%) and did not represent the number of Black and Hispanic women that would be found in the region. Census data for the study region reports a Black population of between 4.6\% and 10.9\%, and Hispanic population between $4 \%$ and $15.1 \%$ (U.S. Census Bureau, 2014). The result of this study may not be generalizable to women in other regions that have a different racial and ethnic population. This limitation could be offset by a change of research methodology that would use internet-based data collection. Being able to obtain a more diverse study sample would improve generalizability.

While more than $98 \%$ of US births occur in hospitals, the rate of out of hospital births is rising, and these women are not included in hospital based studies. Large scale studies of the perceptions of women giving birth outside of the U.S. hospital environment have not been performed. It is known there are significant socio-economic differences between women who choose an in-hospital and an out-of-hospital birth (MacDorman, Declerq, \& Mathews, 2013). An internet survey would be able to include women giving birth at home or in free-standing birthing centers as well as in hospitals, and could contribute to an understanding about differences in birth experiences between groups.

Several concerns arose during this study that indicated changes for methodology. Missing responses on the instrument were a concern. While an overall small percent of items were not answered $(0.4 \%)$, three cases were eliminated from the study and the remaining missing responses were imputed using the participant's mean score per item. It was not apparent whether these missing responses were intentionally not answered or if the woman was distracted and 
skipped a line on the paper. At the least, a response option "I choose not to answer" should be added to the paper version of the instrument. The use of a computer-based survey methodology could flag missing fields for attention and should result in less missing data.

Even for women giving birth in hospitals, data collection during the very short inpatient period is challenging. During data collection for this study, mothers may have been tired and sleepy, trying to initiate breastfeeding, or may have had multiple visitors including other children in the room. This could result in less than thoughtful responses to questions. An internet survey available to women outside of the hospital setting would not only capture women from a larger area with different characteristics, it would allow women to attend to their immediate postpartum needs without the distraction of completing a questionnaire.

This study sample was relatively homogenous for variables such as health care provider (primarily obstetrician) and analgesia (primarily epidural). Hospitals were initially selected for the study because of diverse health care providers offering obstetrical care, as well as adequate numbers of annual births. As the data collection progressed, the only nurse midwife in the region changed practice location. It was discovered after data collection began that she was on call for the obstetrical practice, and the women she assisted may not have been her individual patients. Similarly, the hospital that was chosen in order to include Family Practice physicians as birth attendants did not have a large group count. The low income women using that facility were often referred to obstetricians for complications and the overall birth rate was not high enough to account for a large enough cell count.

The study included a large percentage of women using epidural analgesia. It was not always clear if this was the desired choice for all women, or if they had planned for an unmedicated birth but decided to accept the epidural as labor progressed. The mis-match between 
expectations for an un-medicated birth and the actual experience could negatively affect the woman's perception of herself. Because the use of epidural was associated with lower subscale scores for "Transformative Experiences in Childbirth" and "Handling Pain in Childbirth" in this study, future studies should include a variable for the woman's analgesia plans. Specifically women should be asked what they initially planned for analgesia, if they were able to receive what they wanted, if they received analgesia that was not planned, during what part of labor they received analgesia, and whether the analgesia had the anticipated effect. A goal of data collection had been to record the cervical dilation of women just prior to receiving epidural analgesia. However, many provider orders are to provide an epidural on demand and the cervical dilation was often not recorded in a way that could be directly associated with the epidural request.

Another limitation is that the WECS is available only for English speaking women. Given the high numbers of Spanish speaking women giving birth (Kochanek, Kirmeyer, Martin, Strobino \& Guyer, 2012), and their low representation in this sample, future plans for development include a Spanish version of the WECS. A Spanish version would require more than translation of the existing items. Discussion of the childbirth experience with Hispanic women would be needed, to determine if their perceptions are congruent with items in the WECS.

This study focused on healthy women having normal pregnancies and vaginal births. The exclusion criteria eliminated women with high risk pregnancies, primary cesarean births, repeat or planned cesarean births, and vaginal birth after cesarean (VBAC). The original research for the QMAALD instrument focused on comparing women having a vaginal birth and those having a cesarean birth, since significant differences have been found between those groups (Marut \& 
Mercer, 1979). The QMAALD had a perioperative version. Further research is needed in order to ensure that the WECS, which was designed according to literature relating to a vaginal birth, could be used for mothers having a cesarean birth. Several mothers were identified during enrollment for this study that experienced a VBAC with this pregnancy. Casual interviewing with them found they were very pleased with the VBAC experience. This group of women should be included in future studies using the WECS.

High risk pregnancies were used as an exclusion criteria based on the premise that the mother's expectations affect her perception of the birth experience. The two most prevalent high risk problems identified during data collection were gestational diabetes mellitus (GDM) and maternal drug use. Anecdotally, when verifying eligibility for inclusion in the study, if the mother was asked if she had any complications with pregnancy or high risk factors, she would answer "no." However, when this was followed by a list of exclusion factors, she would respond that she was diagnosed with GDM but she did not see this as a complication. Future studies using the WECS should include women with all levels of medical risk.

\section{Implications for Research}

The initial validity and reliability of the WECS and associated subscales is adequate to indicate further development and research. Given the homogeneous nature of the study sample, retention of the original 49 items is recommended until further analysis with a more diverse group could be accomplished. Additional studies using an internet sampling to include women giving birth in other regions, alternative birthing sites, and using pain management strategies other than epidural analgesia would provide a better understanding of the psychometric properties of the WECS among women having vaginal births. This method would include antenatal enrollment into the study and provide the ability to contact the woman after the 
anticipated date of birth to complete the instrument. Additional information about intended analgesia and childbirth education could be obtained at the time of enrollment to divide the response burden into multiple segments.

Convergent validity analysis should be considered in future research. If valid and reliable instruments were available to measure the constructs of the four subscales, it would be possible to test the subscales for convergent validity (Polit \& Beck, 2008). There are numerous instruments measuring known aspects of childbirth and its outcomes, such as support and control, self-efficacy in childbirth, and post-partum depression that could be used to test convergent validity.

Development of a Spanish version of the WECS would include the largest growing segment of birthing women in the US and provide insight into the labor needs and perceptions of this significant minority group. As mentioned previously, this would require translation to Spanish and further assessment of the suitability of the instrument for this population. The ongoing development of a valid and reliable instrument to measure the childbirth experience could provide a means of testing transition theory. Using Meleis' model of transitions, variables thought to affect the perception of childbirth, such as expectations, existing level of knowledge and coping skills, planning for the transition, and physical and emotional well-being could be studied. Meleis also proposes that the perception of a positive transition experience can result in role mastery and positive health, while a negative experience can result in poor health and unhealthy coping mechanisms.

In the history of childbirth research, numerous studies were not able to demonstrate significant relationships between the childbirth experience and maternal/infant outcome variables such as the NCAST Feeding Score (Bryanton et al., 2009) or spirituality and maternal-infant 
bonding (Bennington, 2010). Replication of those studies using the WECS would seem to be indicated, once reliability and validity testing has progressed further.

\section{Implications for Practice}

Because the WECS is still in development, it will be sometime before definitive clinical inferences could be made from the results. Future studies using the WECS could identify predictors of optimal birth experiences in the four subscales. The WECS would offer a single tool and scoring method to identify the different aspects of the birth experience and their relationship to the overall experience, for both positive and negative birth experiences. Patient care could be customized to enhance the type of experience the woman desires.

Use of the WECS could also identify childbirth experience scores that are associated with risk to the mother. If the WECS was administered in the postpartum period, women at high risk for post-traumatic stress disorder or post-partum depression on the basis the birth experience could be identified and provided preventative interventions. If the instrument is used with women of all risk levels and characteristics, differing care may be indicated to help the higher risk mothers achieve a positive experience and outcomes.

Hospital policy changes that would determine the number and roles of non-professional support persons that contribute to a positive birth experience could result from using the WECS. Most U.S. hospitals allow the father of the baby to be present, however the number of additional persons allowed during childbirth varies significantly. Care could again be individualized to meet the needs of different women.

\section{Conclusion}

The evidence from this study indicates the WECS is a sufficiently valid and reliable instrument to allow for further research and development. The development of the WECS is a 
step in returning to a more woman-focused childbirth experience through study of the complex experience of childbirth and its effect on the transition of becoming a mother. Giving birth is an important event in a woman's life. While the safe birth of a health newborn is desirable, the effect of the mother's perception of that experience requires nursing's due consideration. The four subscales identified in this study are a reflection of nursing's focus on the holistic and multidimensional woman. The WECS may be able to provide a diverse and individual understanding of the spectrum of birth experiences and support the study of interventions to enhance the birth experience for many women. 


\section{References}

Alfirevic, Z., Devane, D., \& Gyte, G. M. (2006). Continuous cardiotocography (CTG) as a form of electronic fetal monitoring (EFM) for fetal assessment during labour. Cochrane Database of Systematic Reviews,(3, Art. No.: CD006066). doi:10.1002/14651858.CD006066

American Educational Research Association. (1999). Standards for educational and psychological testing. Washington, DC: American Educational Research Association.

Avasarala, S., \& Mahendran, M. (2009). A survey of women's experiences following instrumental vaginal delivery. Journal of Obstetrics \& Gynaecology, 29(6), 504-506. doi: $10.1080 / 01443610903003217$

Ayers, S. (2007). Thoughts and emotions during traumatic birth: A qualitative study. Birth, 34(3), 253-263. doi: 10.1111/j.1523-536X.2007.00178.x

Ayers, S., \& Pickering, A. D. (2005). Women's expectations and experience of birth. Psychology and Health, 20(1), 79-92. doi: 10.1080/0887044042000272912

Baston, H., Rijnders, M., Green, J. M., \& Buitendijk, S. (2008). Looking back on birth three years later: factors associated with a negative appraisal in England and in the Netherlands. Journal of Reproductive \& Infant Psychology, 26(4), 323-339. doi: 10.1080/02646830802408480

Beck, C. T. (1983). Parturients' temporal experiences during the phases of labor. Western Journal of Nursing Research, 5(4), 283-295.

Beck, C. T. (2004a). Birth trauma: In the eye of the beholder. Nursing Research, 53(1), 28-35.

Beck, C. T. (2004b). Post-traumatic stress disorder due to childbirth. Nursing Research, 53(4), 216-234. 
Bennington, L. (2010). The relationship among maternal infant bonding, spirituality, and maternal perception of childbirth experience. UMI Dissertations Publishing, (UMI Number 3418421).

Bowers, B. B. (2002). Mother's experiences of labor support: exploration of qualitative research. Journal of Obstetric, Gynecologic, \& Neonatal Nursing, 31(6), 742-752. doi: $10.1177 / 0884217502239218$

Bruggemann, O. M., Parpinelli, M. A., Osis, M. J. D., Cecatti, J. G., \& Carvalhinho N.A.S. (2007). Support to woman by a companion of her choice during childbirth: a randomized controlled trial. Reproductive Health, 4(1), 1-7. doi: 10.1186/1742-4755-4-5

Bryanton, J., Gagnon, A.J., Hatem, M., \& Johnston, C. (2008a). Predictors of early parenting self-efficacy. Nursing Research, 57(4), 252-259. doi:

10.1097/01.NNR.0000313490.56788.cd

Bryanton, J., Gagnon, A. J., Johnston, C., \& Hatem, M. (2008b). Predictors of women's perceptions of the childbirth experience. JOGNN: Journal of Obstetric, Gynecologic \& Neonatal Nursing, 37(1), 24-34. doi: 10.1111/j.1552-6909.2007.00203.x

Bryanton, J., Gagnon, A. J., Hatem, M., \& Johnston, C. (2009). Does perception of the childbirth experience predict women's early parenting behaviors? Research in Nursing \& Health, 32(2), 191-203. doi: 10:1002/nur.20314

Burgess, A. (2014). An evolutionary concept analysis of labor support. International Journal of Childbirth Education, 29(2), 64-72.

Burke, V., \& Greenberg, D. (2010). Determining readability: how to select and apply easy-to-use readability formulas to assess the difficulty of adult literacy materials. Adult Basic Education and Literacy Journal, 4(1), 34-42. 
Callister, L.C. (1995). Cultural meanings of childbirth. JOGNN: Journal of Obstetric, Gynecologic \& Neonatal Nursing, 24(4), 327-331.

Callister, L. C. (2006). The meaning of giving birth and mastery of the experience. International Journal of Childbirth Education, 21(3), 7-8.

Callister, L. C., Khalaf, I., Semenic, S., Kartchner, R., \& Vehvilainen-Julkunen, K. (2003). The pain of childbirth: perceptions of culturally diverse women. Pain Management Nursing, 4(4), 145-154. doi:10.1016/S1524-9042(03)00028-6

Centers for Disease Control. (2010). Average length of stay in nonfederal short-stay hospitals, by sex,age, and selected first-listed diagnosis: United States, selected years 1990 through 2008-2009. http://www.cdc.gov/nchs/data/hus/2010/102.pdf.

Cranley, M. S., Hedahl, K. J., \& Pegg, S. H. (1983). Women's perceptions of vaginal and cesarean deliveries. Nursing Research, 32(1), 10-15.

Creedy, D., Shochet, I. M., \& Horsfall, J. (2000). Childbirth and the development of acute trauma symptoms: incidence and contributing factors. Birth, 27(2), 104-111. doi: 10.1046/j.1523-536x.2000.00104.x

Csikzentmihalyi, M. (1990). Flow: the psychology of optimal experience. New York, NY: Harper \& Row.

Csikszentmihalyi, M. \& LeFever, J. (1989). Optimal experience in work and leisure. Journal of Personality and Social Psychology, 56(5), 815-822.

Davies, J., Slade, P., Wright, I., \& Stewart, P. (2008). Posttraumatic stress symptoms following childbirth and mothers' perceptions of their infants. Infant Mental Health Journal, 29(6), 537-554. doi:10.1016/j.janxdis.2010.12.006 
Dencker, A., Taft, C., Bergqvist, L., Lilja, H., \& Berg, M. (2010). Childbirth Experience Questionnaire (CEQ): development and evaluation of a multidimensional instrument. Pregnancy and Childbirth, 10, 1471. doi: 10.1186/1471-2393-10-81

Delpierre, C., Lauwers-Cances, V., Datta, G. D., Lang, T., \& Berkman, L. (2009). Using selfrated health for analyzing social inequalities in health: a risk for underestimating the gap between socioeconomic groups? Journal of Epidemiology and Community Health, 63, 426-432.

DiMatteo, M. R., Kahn, K., \& Berry, S. (1993). Narratives of birth and the postpartum: analysis of the focus group responses of new mothers. Birth, 20(4), 204-211.

Fairbrother, N., \& Woody, S. R. (2007). Fear of childbirth and obstetrical events as predictors of postnatal symptoms of depression and post-traumatic stress disorder. Journal of Psychosomatic Obstetrics \& Gynecology, 28(4), 239-242.

doi: $10.1080 / 01674820701495065$

Fawcett, J., \& Knauth, D. (1996). The factor structure of the Perception of Birth Scale. Nursing Research, 45(2), 83-86.

Fawcett, J., Pollio, N., \& Tully, A. (1992). Women's perceptions of cesarean and vaginal delivery: another look. Research in Nursing \& Health, 15, 439-446.

Fawcett, J., \& Weiss, M. E. (1993). Cross-cultural adaptation to cesarean birth. Western Journal of Nursing Research, 15(3), 281-287.

Fenwick, J., Hauck, Y., Downie, J., \& Butt, J. (2005). The childbirth expectations of a selfselected cohort of Western Australian women. Midwifery, 21, 23-35. doi: 10.1016/j.midw.2006.02.002 
Fleming, V.E.M., Hagen, S., \& Niven, C. (2003). Does perineal suturing make a difference? The SUNS trial. BJOG: an International Journal of Obstetrics and Gynaecology, 110, 684689.

Ford, E., Ayers, S., \& Wright, D. B. (2009). Measurement of maternal perceptions of support and control in birth (SCIB). Journal of Women's Health, 18, 245-252.

doi: 10.1089/jwh.2008.0882

Gagnon, A. J. \& Sandall, J. (2007). Individual or group antenatal education for childbirth or parenthood, or both. Cochrane Database of Systematic Reviews, Issue 3, Art. No. CD002869. doi: 10.1002/14651858.CD002869.pub2

Goodman, P., Mackey, M. C., \& Tavakoli, A. S. (2004). Factors related to childbirth satisfaction. Journal of Advanced Nursing, 46(2), 212-219. doi: 10.1111/j.1365-2648.2003.02981.x

Gottvall, K., \& Waldenstrom, U. (2002). Does a traumatic birth experience have an impact on future reproduction? British Journal of Obstetrics and Gynecology, 109, 254-260. doi: 10.1111/j.1471-0528.2002.01200.x

Green, J. M., \& Baston, H. A. (2003). Feeling in control during labor: oncepts, correlates, and consequences. Birth, 30(4), 235-247. doi: 10.1046/j.1523-536X.2003.00253.x

Green, J. M., Coupland, V. A., \& Kitzinger, J. V. (1990). Expectations, experiences, and psychological outcomes of childbirth: a prospective study of 825 women. Birth, 17(1), $15-24$.

Gungor, I. \& Beji, N. K. (2007). Effects of father's attendance to labor and delivery experience of childbirth in Turkey. Western Journal of Nursing Research, 29(2), 213-228. doi: $10.1177 / 0193945906292538$ 
Halldorsdottir, S., \& Karlsdottir, S. I. (1996a). Journeying through labour and delivery: perceptions of women who have given birth. Midwifery, 12, 48-61.

Halldorsdottir, S., \& Karlsdottir, S. I. (1996b). Empowerment or discouragement: women's experience of caring and uncaring encounters during childbirth. Health Care for Women International, 17, 361-379.

Hidaka, R. \& Callister, L.C. (2012). Giving birth with epidural analgesia: experience of firsttime mothers. The Journal of Perinatal Education, 21(1), 24-35. doi: 10.1891/10581243.21.1.24

Hodnett, E. D. (2002). Pain and satisfaction with the experience of childbirth: a systematic review. American Journal of Obstetrics and Gynecology, 186(5), S160-S172. doi: 10.1067/mob.2002.121141

Hodnett, E. D., Edwards, N., \& Walsh, D. (2005). Home-like versus conventional settings for birth. Cochrane Database of Systematic Reviews, 3 (CD003766), 1-68. doi:10.1002/14651858.CD000012.pub2.

Hodnett, E. D., Gates, S., Hofmeyr, G. J., \& Sakala, C. (2013). Continuous support for women during childbirth. Cochrane Database of Systematic Reviews, Issue 7, Art. No CD003766. 1-68. doi:10.1002/14651858.CD003766.pub5

Hodnett, E. D., Lowe, N. K., Hannah, M. E., Willan, A. R., Stevens, B., Weston, J. A., \& Stremler, R. (2002). Effectiveness of nurses as providers of birth labor support in North American hospitals. JAMA: Journal of the American Medical Association, 288(11), 1373-1381. doi:10.1001/jama.288.11.1373

Humenick, S. S. (1998). Flow, flow, flow a birth: pathway to an optimal experience. Journal of Perinatal Education, 7(1), v-vii. 
Humenick, S. S. (2006). The life-changing significance of normal birth. Journal of Perinatal Education, 15(4), 1-3. 1-3 doi: 10.1624/105812406X15

Jackson, S., \& Marsh, H. W. (1996). Development and validation of a scale to measure optimal experience: the flow state scale. Journal of Sport \& Exercise Psychology, 18, 17-35.

Jones, L., Othman, M., Dowswell, T., Alfirevic, Z., Gates, S. Newburn, M., Jordan, S., Lavender, T. \& Neilson, J.P. (2012). Pain management for women in labor: an overview of systematic reviews. Cochrane Database of Systematic Reviews, Issue 3, Art No. CD009234. doi: 10.1002/14651858.CD009234.pub2

Jordan, B. (1993). Birth in Four Cultures (4th ed.). Long Grove, IL: Waveland Press, Inc.

Kochanek, K.D., Kirmeyer, S. E., Martin, J.A., Strobino, D. M. \& Guyer, B. (2012). Annual summary of vital statistics. Pediatrics, 2012(129), 338. DOI: 10.1542/peds.2011-3435

Koume, J. B. (2010). Using readability tests to improve the accuracy of evaluation documents intended for low-literate participants. Jounal of Multidisciplinary Evaluation, 6(14), 132139.

Larkin, P., Begley, C. M., \& Devane, D. (2009). Women's experiences of labour and birth: an evolutionary concept analysis. Midwifery, 25, e49-e59. http://dx.doi.org.www.libproxy.wvu.edu/10.1016/j.midw.2007.07.010

Lavender, T., Walkinshaw, S. A., \& Walton, I. (1999). A prosective study of women's views of factors contributing to a positive birth experience. Midwifery, 15, 40-46.

Leeds, L., \& Hargreaves, I. (2008). The psychological consequences of childbirth. Journal of Reproductive \& Infant Psychology, 26(2), 108-122. doi: 10.1080/02646830701688299 
Lemola, S., Stadlmayr, W., \& Grob, A. (2007). Maternal adjustment five months after birth: the impact of the subjective experience of childbirth and emotional support from the partner. Journal of Reproductive \& Infant Psychology, 25(3), 190-202.

doi: 10.1080/02646830701467231

Lietz, P. (2010). Research into questionnaire design. A summary of the literature. International Journal of Market Research, 52 (2), 249-272. doi: 10.2501/S147078530920120X

Lowe, N. K. (1989). Explaining the pain of active labor: the importance of maternal confidence. Research in Nursing \& Health, 12(4), 237-245.

Lowe, N. K. (1993). Maternal confidence for labor: development of the Childbirth Self-Efficacy Inventory. Research in Nursing \& Health, 16, 141-149.

Lowe, N. K. (1996). The pain and discomfort of labor and birth. JOGNN: Journal of Obstetric, Gynecologic \& Neonatal Nursing, 25(1), 82-91.

Lundgren, I. (2004). Releasing and relieving encounters: experiences of pregnancy and childbirth. Scandinavian Journal of Caring Sciences, 18, 368-375. doi: 10.1111/j.1471-6712.2004.00300.x

MacDorman, M.F. Declerq, E., Mathews, T.J. (2013). Recent trends in out-of-hospital births in the United States. Journal of Midwifery and Women's Health, 58(5), 494-501. doi: 10.1111/jmwh.12092

Mackey, M. C. (1995). Women's evaluation of their childbirth performance. Maternal-Child Nursing Journal, 23(2), 57-72.

Maher, J. M. (2008). Progressing through labour and delivery: birth time and women's experiences. Women's Studies International Forum, 31(2), 129-137. doi: 10.1016/j.wsif.2008.03.005 
Marut, J. S. (1978). The special needs of the cesarean mother. MCN: The American Journal of Maternal Child Nursing, 3, 202- 206.

Marut, J. S., \& Mercer, R. T. (1979). Comparison of primimparas' perceptions of vaginal and cesarean births. Nursing Research, 28(5), 260-266.

McCool, W. F., \& Simeone, S. A. (2002). Birth in the United States; an overview of trends past and present. Nursing Clinics of North America, 37, 735-746.

Meleis, A. I., Sawyer, L. M., Im, E., Messias, D. K. H., \& Schumaker, K. (2010). Transition Theory. In A.I. Meleis (Ed.), Transition Theory (pp. 52-83). New York, NY: Springer Publishing Company.

Mercer, R. T. (1985). Relationship of the birth experience to later mothering behaviors. Journal of Nurse-Midwifery, 30(4), 204-211.

Mercer, R. T. (2004). Becoming a mother versus maternal role attainment. Journal of Nursing Scholarship, 36(3), 226-232. doi: 10.1111/j.1547-5069.2004.04042.x

Mercer, R. T., Hackley, K. C., \& Bostrom, A. G. (1983). Relationship of psychosocial and perinatal variables to perception of childbirth. Nursing Research, 32(4), 202-207.

Nilsson, C., \& Lundgren, I. (2009). Women's lived experience of fear in childbirth. Midwifery, 25, e1-e9. doi: 10.1016/j.midw.2007.01.017

Niven, C. A., \& Murphy-Black, T. (2000). Memory for labor pain: a review of the literature. Birth: Issues in Perinatal Care, 27(4), 244-253. doi: 10.1046/j.1523-536x.2000.00244.x

Noriko, O., Megumi, M., Hanako, M., \& Yasuko, M. (2007). Birth experience and postnatal depression: women's negative evaluation as a risk factor. Asian Journal of Nursing, 10, 257-264. 
O'Hare, J., \& Fallon, A. (2011). Women's experience of control in labour and birth. British Journal of Midwifery, 19(3), 164-169.

Osgood, C. E., Suci, G. J., \& Tannenbaum, P. H. (1957). The Measurement of Meaning. Urbana, IL: University of Illinois Press.

Pallant, J. (2007). SPSS Survival Manual (3 ed.). New York, NY: Open University Press.

Parratt, J., \& Fahy, K. (2003). Trusting enough to be out of control: a pilot study of women's sense of self during childbirth. Australian Midwifery Journal, 16(1), 15-22.

Peirce, A. G. (1994). Cognitive appraisal of stress events: measuring the personal schema of childbirth. Journal of Nursing Measurement, 2(2), 117-127.

Perry, S. E., Hockenberry, M. J., Lowdermilk, D. L., \& Wilson, D. (2010). Maternal child nursing $\left(4^{\text {th }}\right.$ ed.). Maryland Heights, MO: Mosby.

Polit, D. F., \& Beck, C. T. Nursing research generating and assessing evidence for nursing practice ( $8^{\text {th }}$ edition). Philadelphia, PA: Wolters-Kluwer.

Polomeno, V. (1998). Labor and birth: supporting a couple's intimacy, part 1. International Journal of Childbirth Education, 13(2), 18-24, 184-191.

Price, S., Noseworthy, J. \& Thornton, J. (2007). Women's experience with social presence during childbirth. Maternal Child Nursing, 32(3),

Pridham, K. F., Lytton, D., Chang, A. S., \& Rutledge, D. (1991). Early postpartum transition: progress in maternal identity and role attainment. Research in Nursing \& Health, 14, 2131.

Salmon, P., \& Drew, N. C. (1992). Multidimensional assessment of women's experience of childbirth: relationship to obstetric procedure, antenatal preparation and obstetric history. Journal of Psychosomatic Research, 36(4), 317-327. 
Salmon, P., Miller, R., \& Drew, N. C. (1990). Women's anticipation and experience of childbirth: the independence of fulfillment, unpleasantness and pain. British Journal of Medical Psychology, 63, 255-259.

Samko, M. R., \& Schoenfeld, L. S. (1975). Hypnotic susceptibility and the Lamaze childbirth experience. American Journal of Obstetrics \& Gynecology, 121, 631-636.

Sauls, D. J. (2004). The Labor Support Questionnaire: development and psychometric analysis. Journal of Nursing Measurement, 12(2), 123-132.

Schneider, D. (2009). Beyond the baby: women's narratives of childbirth, change, and power. UMI Dissertations Publishing, (UMI Number 3416170).

Seguin, L., Therrien, R., Champagne, F., \& Larouche, D. (1989). The components of women's satisfaction with maternity care. Birth, 16(3), 109-113.

Simkin, P. (1991). Just another day in a woman's life? Women's long-term perceptions of their first birth experience. Part I. Birth, 18(4), 203-210.

Soderquist, J., Wijma, B., Thorbert, G., \& Wijma, K. (2009). Risk factors in pregnancy for posttraumatic stress and depression after childbirth. BJOG An International Journal of Obstetrics and Gynecology, 116, 672- 680. doi: 10.1111/j.1471-0528.2008.02083.x

Soet, J. E., Brack, G. A., \& Dilorio, C. (2003). Prevalence and predictors of women's experience of psychological trauma during childbirth. Birth, 30(1), 36-46.

doi: 10.1046/j.1523-536X.2003.00215.x

Solms, M., \& Turnbull, O. (2002). The Brain and the Inner World. New York, NY: Other Press.

Stadlmayr, W., Amsler, F., Lemola, S., Stein, S., Alt, M., \& Burgin, D. (2006). Memory of childbirth in the second year: the long term effect of a negative birth experience and its 
modulation by the perceived intranatal relationship with caregivers. Journal of Psychosomatic Obstetrics \& Gynecology, 27(4), 211-224.

doi: $10.1080 / 01674820600804276$

Stadlmayr, W., Bitzer, J., Hosli, I., Amsler, F., Leupold, J., Schwendke-Kliem, A. ...Burgin, D. (2001). Birth as a multidimensional experience: comparison of the English and German language versions of Salmon's Item List. Journal of Psychosomatic Obstetrics \& Gynecology, 22, 205-214.

Stadlmayr, W., Schneider, H., Amsler, F., Burgin, D., \& Bitzer, J. (2004). How do obstetric variables influence the dimensions of the birth experience as assessed by Salmon's item list (SIL-Ger)? European Journal of Obstetrics \& Gynecology \& Reproductive Biology, 115(1), 43-50. doi: 10.1016/j.ejogrb.2003.12.015

Sticht, T. (1975). Reading for working: a functional literacy anthology. Alexandria, VA: Human Resources Research Organization.

Streiner, D. L., \& Norman, G. R. (2008). Health measurement scales a practical guide to their development and use. Oxford, UK: Oxford University Press.

Tabachnick, B.G. and Fidell, L.S. (2007). Using multivariate statistics $\left(5^{\text {th }}\right.$ ed). Boston, MA: Pearson Education, Inc.

Tucker, M.J., Berg, C.J., Callaghan, W.M., \& Hsia, J. (2007). The black-white disparity in pregnancy-related mortality from 5 conditions: differences in prevalence and case-fatality rates. American Journal of Public Health, 97(2), 247-51.

VandeVusse, L. (1999). The essential forces of labor revisited: 13 Ps reported in women's stories. MCN: The American Journal of Maternal Child Nursing, 24(4), 176-184. 
U.S. Department of Health and Human Services. (2014). Maternal, infant and child health. Healthy People 2020. Retrieved from http://www.healthypeople.gov/2020/topicsobjectives/topic/maternal-infant-and-child-health.

U.S. Census Bureau. (2014). State and county quick facts. Retrieved from http://quickfacts.census.gov/qfd/states/51000.html

Waldenstrom, U. (1999). Experience of labor and birth in 1111 women. Journal of Psychosomatic Research, 47(5), 471-482.

Waldenstrom, U. (2003). Women's memory of childbirth at two months and one year after the birth. Birth, 30(4), 248-254. doi: 10.1046/j.1523-536X.2003.00254.x

Waldenstrom, U., Borg, I., Olsson, B., Skold, M., \& Wall, S. (1996). The childbirth experience: a study of 295 new mothers. Birth, 23(1), 144-153.

Waldenstrom, U., Hildingsson, I., Rubertsson, C., \& Radestad, I. (2004). A negative birth experience: prevalence and risk factors in a national sample. Birth, 31(1), 17-27. doi: 10.1111/j.0730-7659.2004.0270.x

Waldenstrom, U., Rudman, A., \& Hildingsson, I. (2006). Intrapartum and postpartum care in Sweden: women's opinions and risk factors for not being satisfied. Acta Obstetricia et Gyncecologica, 85, 551-560.

Walker, D. S., Visger, J. M., \& Rossie, D. (2009). Contemporary childbirth education models. Journal of Midwifery \& Women's Health, 54(6), 469-476. doi:

10.1016/jmwh.2009.02.013

Walsh, D. (2008). Birthwrite: The experience of flow and physiological birth. British Journal of Midwifery, 16(5), 278. 
Waltz, C. F., Strickland, O. L., \& Lenz, E. R. (2005). Measurement in nursing and health research (3rd ed.). New York: Springer Publishing Company, Inc.

Weisman, O., Granat, A., Gilboa-Schechtman, E., Singer, M., Gordon, I., Azulay, H. et al. (2010). The experience of labor, maternal perception of the infant, and the mother's postpartum mood in a low-risk community cohort. Archives of Women's Mental Health, 13(6), 505-513. doi: 10.1007/s00737-010-0169-z

Willis, G. B. (2004). Cognitive interviewing revisited: a useful technique, in theory? In S. Presser, J. M. Rothgeb, M. P. Couper, J. T. Lessler, E. Martin, J. A. Martin, \& E. Singer (Eds.), Methods for testing and evaluating survey questionnaires (pp. 23-43). Hoboken, NJ: John Wiley \& Sons, Inc.

Wright, M. E., Mccrea, H., Stringer, M., \& Murphy-Black, T. (2000). Personal control in pain relief during labor. Journal of Advanced Nursing, 32(5), 1168-1177. doi: $10.1046 / j .1365-2648.2000 .01587 . x$

Zachariah, R. (2009). Social support, life stress, and anxiety as predictors of pregnancy complications in low-income women. Research in Nursing \& Health, 32, 391-404. doi: 10.1002/nur.20335 


\section{Appendix A: Comparison of Existing Instruments}

\begin{tabular}{|c|c|c|c|c|}
\hline & QMAALD & SIL & CSS & CEQ \\
\hline Purpose of instrument & $\begin{array}{l}\text { To assess the difference } \\
\text { in birth experience for } \\
\text { women having vaginal } \\
\text { birth or cesarean section }\end{array}$ & $\begin{array}{l}\text { To assess the } \\
\text { multidimensional } \\
\text { nature of the } \\
\text { childbirth } \\
\text { experience }\end{array}$ & $\begin{array}{l}\text { Assess cognitive } \\
\text { construction of the } \\
\text { stress event of } \\
\text { childbirth }\end{array}$ & $\begin{array}{l}\text { Measure the different } \\
\text { dimensions of the childbirth } \\
\text { experience for first time } \\
\text { mothers, part of a larger } \\
\text { study of labor progress and } \\
\text { oxytocin augmentation }\end{array}$ \\
\hline $\begin{array}{l}\text { Populations sampled } \\
\text { Primipara } \\
\text { Multipara } \\
\text { Vaginal Birth } \\
\text { Emergency Cesarean Section } \\
\text { Planned Cesarean Section }\end{array}$ & $\begin{array}{l}\mathrm{US} \\
\mathrm{X} \\
\mathrm{X} \\
\mathrm{X} \\
\mathrm{X} \\
\mathrm{X}\end{array}$ & $\begin{array}{c}\text { Great Britain } \\
\text { X } \\
\text { X } \\
\text { X } \\
\text { X }\end{array}$ & $\begin{array}{l}\text { US } \\
\mathrm{X} \\
\mathrm{X} \\
\mathrm{X}\end{array}$ & $\begin{array}{c}\text { Sweden } \\
\text { X } \\
\\
\text { X } \\
\text { X }\end{array}$ \\
\hline Factors & $\begin{array}{l}\text { Delivery } \\
\text { Labor } \\
\text { Delivery outcome, } \\
\text { Partner participation, } \\
\text { Awareness }\end{array}$ & $\begin{array}{l}\text { Fulfillment/delight } \\
\text { Distress } \\
\text { Difficulty }\end{array}$ & $\begin{array}{l}\text { Emotions of } \\
\text { outcome } \\
\text { Sensations of work } \\
\text { Time } \\
\text { Preparation for } \\
\text { control }\end{array}$ & $\begin{array}{l}\text { Own capacity } \\
\text { Professional support } \\
\text { Perceived safety } \\
\text { Participation }\end{array}$ \\
\hline
\end{tabular}




\begin{tabular}{|l|l|l|l|l|}
\hline & QMAALD & SIL & CSS & CEQ \\
\hline Reliability $\alpha$ & $.76-.87$ overall & Fulfillment/delight & .73 overall & Own capacity .82 \\
& Delivery .87 & .83 & Emotions .73 & Professional support .88 \\
& Labor .79 & Distress .54 & Sensations .70 & Perceived safety .78 \\
& Delivery outcome .68 & Difficulty .64 & Time .84 & Participation .62 \\
& Partner participation .62 & & Preparation .65 & \\
& Awareness .59 & & & \\
\hline
\end{tabular}


Appendix B: Comparison of Existing Instruments to Conceptual Framework

\begin{tabular}{|c|c|c|c|c|}
\hline Aspect & QMAALD & SIL & CSS & CEQ \\
\hline \multicolumn{5}{|l|}{ Physical Dimension } \\
\hline Pain & $\begin{array}{l}\text { Do you remember your labor as } \\
\text { painful? } \\
\text { Do you remember your delivery as } \\
\text { painful? }\end{array}$ & Painful & $\begin{array}{l}\text { Painful/not painful } \\
\text { Pleasurable/ uncomfortable }\end{array}$ & $\begin{array}{l}\text { Experienced level of pain in } \\
\text { dilation stage (VAS) Anchors" } \\
\text { no pain/worst imaginable }\end{array}$ \\
\hline $\begin{array}{l}\text { Able to manage } \\
\text { pain }\end{array}$ & & & & $\begin{array}{l}\text { I felt I could choose which pain } \\
\text { method to use }\end{array}$ \\
\hline $\begin{array}{l}\text { Pain self- } \\
\text { confidence }\end{array}$ & $\begin{array}{l}\text { How confident were you during } \\
\text { labor? }\end{array}$ & Confident & & $\begin{array}{l}\text { I felt I handled the situation } \\
\text { well }\end{array}$ \\
\hline Work of labor & & $\begin{array}{l}\text { Easy } \\
\text { Exhausted }\end{array}$ & Easy/Hard work & I felt tired \\
\hline \multicolumn{5}{|l|}{$\begin{array}{l}\text { Rhythm and timing } \\
\text { of contraction }\end{array}$} \\
\hline \multicolumn{5}{|l|}{$\begin{array}{l}\text { Unpleasant physical } \\
\text { sensation }\end{array}$} \\
\hline & & & Relieving/ burdening & \\
\hline $\begin{array}{l}\text { Professional } \\
\text { support-comforted }\end{array}$ & & & & $\begin{array}{l}\text { I felt very well taken care of by } \\
\text { the midwife } \\
\text { My midwife devoted enough } \\
\text { time to me }\end{array}$ \\
\hline \multicolumn{5}{|c|}{ Emotional Dimension } \\
\hline Emotions/labiality & $\begin{array}{l}\text { How pleasant or satisfying was the } \\
\text { feeling state you experienced } \\
\text { during delivery? } \\
\text { How unpleasant was the feeling } \\
\text { state you experienced during }\end{array}$ & $\begin{array}{l}\text { Enthusiastic } \\
\text { Delighted } \\
\text { Depressed } \\
\text { Happy } \\
\text { Anxious }\end{array}$ & $\begin{array}{l}\text { Not scary/scary } \\
\text { Not anxiety } \\
\text { producing/anxiety } \\
\text { producing } \\
\text { Exciting/not exciting }\end{array}$ & $\begin{array}{l}\text { I felt happy } \\
\text { Some of my memories from the } \\
\text { labor process make me feel } \\
\text { depressed } \\
\text { I felt scared }\end{array}$ \\
\hline
\end{tabular}




\begin{tabular}{|c|c|c|c|c|}
\hline Aspect & QMAALD & SIL & CSS & CEQ \\
\hline & $\begin{array}{l}\text { delivery? } \\
\text { How scared were you during } \\
\text { delivery? } \\
\text { Did you worry about your baby's } \\
\text { condition during labor? } \\
\text { Did you worry about your baby's } \\
\text { condition during delivery? }\end{array}$ & & & \\
\hline $\begin{array}{l}\text { Control of self: } \\
\text { emotions }\end{array}$ & & & $\begin{array}{l}\text { Controllable/not } \\
\text { controllable }\end{array}$ & \\
\hline $\begin{array}{l}\text { Professional } \\
\text { support-emotional } \\
\text { support }\end{array}$ & & & & $\begin{array}{l}\text { My midwife understood my } \\
\text { needs }\end{array}$ \\
\hline \multicolumn{5}{|l|}{ Cognitive Dimension } \\
\hline Time differences & & $\begin{array}{l}\text { Time going } \\
\text { slowly }\end{array}$ & $\begin{array}{l}\text { Fast/long } \\
\text { Short wait/ long time } \\
\text { coming }\end{array}$ & \\
\hline $\begin{array}{l}\text { Cognitive strategy } \\
\text { for coping }\end{array}$ & $\begin{array}{l}\text { How successful were you in using } \\
\text { the breathing or relaxation methods } \\
\text { to help with contractions? } \\
\text { How relaxed were you during } \\
\text { labor? } \\
\text { How relaxed were you during } \\
\text { delivery? }\end{array}$ & $\begin{array}{l}\text { Coped } \\
\text { Relaxed }\end{array}$ & & \\
\hline $\begin{array}{l}\text { Flow intrinsically } \\
\text { rewarding }\end{array}$ & & Enjoyable & $\begin{array}{l}\text { Rewarding/not rewarding } \\
\text { Satisfying/not satisfying }\end{array}$ & \\
\hline $\begin{array}{l}\text { Flow-ability meet to } \\
\text { challenge }\end{array}$ & & & & \\
\hline
\end{tabular}




\begin{tabular}{|c|c|c|c|c|}
\hline Aspect & QMAALD & SIL & CSS & CEQ \\
\hline \multicolumn{5}{|l|}{$\begin{array}{l}\text { Flow sense of } \\
\text { mastery (transition } \\
\text { outcome) }\end{array}$} \\
\hline \multicolumn{5}{|l|}{$\begin{array}{l}\text { Flow being at one } \\
\text { with universe }\end{array}$} \\
\hline \multicolumn{5}{|l|}{$\begin{array}{l}\text { Flow loss of } \\
\text { awareness of self }\end{array}$} \\
\hline \multicolumn{5}{|l|}{$\begin{array}{l}\text { Flow unambiguous } \\
\text { feedback about how } \\
\text { well coping }\end{array}$} \\
\hline $\begin{array}{l}\text { Expectations of } \\
\text { experience }\end{array}$ & $\begin{array}{l}\text { To what extent did your experience } \\
\text { of having a baby go along with the } \\
\text { expectation you had before labor } \\
\text { began? }\end{array}$ & $\begin{array}{l}\text { Disappointed } \\
\text { Satisfied } \\
\text { Good } \\
\text { Experience } \\
\text { Cheated }\end{array}$ & $\begin{array}{l}\text { Prepared/Not prepared } \\
\text { Known/unknown }\end{array}$ & $\begin{array}{l}\text { The labour process went as I } \\
\text { had expected }\end{array}$ \\
\hline $\begin{array}{l}\text { Control of self: } \\
\text { behaviors }\end{array}$ & $\begin{array}{l}\text { How well in control were you } \\
\text { during labor? } \\
\text { How well in control were you } \\
\text { during delivery? }\end{array}$ & In control & & $\begin{array}{l}\text { Experienced level of control } \\
\text { (VAS) Anchors no } \\
\text { control/complete control }\end{array}$ \\
\hline $\begin{array}{l}\text { Birth defining } \\
\text { moment in life }\end{array}$ & & Fulfilled & Beautiful/awful & \\
\hline \multicolumn{5}{|l|}{$\begin{array}{l}\text { Enhanced sense of } \\
\text { self }\end{array}$} \\
\hline $\begin{array}{l}\text { New awareness of } \\
\text { strength }\end{array}$ & & & & $\begin{array}{l}\text { I felt strong } \\
\text { I felt capable }\end{array}$ \\
\hline \multicolumn{5}{|l|}{$\begin{array}{l}\text { Connection to } \\
\text { mother(s) }\end{array}$} \\
\hline Social Dimension & & & & \\
\hline
\end{tabular}




\begin{tabular}{|c|c|c|c|c|}
\hline Aspect & QMAALD & SIL & CSS & CEQ \\
\hline $\begin{array}{l}\text { Control of } \\
\text { environment- } \\
\text { position }\end{array}$ & & & & $\begin{array}{l}\text { I felt I could choose whether I } \\
\text { should be up and moving or lie } \\
\text { down } \\
\text { I felt I could choose the } \\
\text { delivery position }\end{array}$ \\
\hline \multicolumn{5}{|l|}{$\begin{array}{l}\text { Control of who was } \\
\text { present }\end{array}$} \\
\hline $\begin{array}{l}\text { Control of decision- } \\
\text { making }\end{array}$ & $\begin{array}{l}\text { Did you have choices about } \\
\text { intervention, i.e., examinations or } \\
\text { treatments during labor? }\end{array}$ & & & \\
\hline \multicolumn{5}{|l|}{$\begin{array}{l}\text { Trusted care } \\
\text { providers to make } \\
\text { decisions }\end{array}$} \\
\hline $\begin{array}{l}\text { Cultural } \\
\text { expectations power } \\
\text { holder }\end{array}$ & $\begin{array}{l}\text { To what extent do you consider } \\
\text { yourself to have been a useful and } \\
\text { cooperative member of the } \\
\text { obstetric team? }\end{array}$ & & & \\
\hline $\begin{array}{l}\text { Personal support } \\
\text { physical comfort }\end{array}$ & $\begin{array}{l}\text { How useful was your partner in } \\
\text { helping you through delivery? How } \\
\text { useful was your partner in helping } \\
\text { you through your labor? }\end{array}$ & & & \\
\hline \multicolumn{5}{|l|}{$\begin{array}{l}\text { Personal support } \\
\text { trusted }\end{array}$} \\
\hline $\begin{array}{l}\text { Professional } \\
\text { support gave } \\
\text { information about } \\
\text { progress }\end{array}$ & & & & $\begin{array}{l}\text { My midwife kept me informed } \\
\text { about what was happening } \\
\text { during labour and birth }\end{array}$ \\
\hline $\begin{array}{l}\text { Personal support } \\
\text { emotional support }\end{array}$ & & & Shared/lonely & \\
\hline $\begin{array}{l}\text { Professional } \\
\text { support competent }\end{array}$ & $\begin{array}{l}\text { Did the equipment used during } \\
\text { labor bother you? }\end{array}$ & & & $\begin{array}{l}\text { Experience level of sense of } \\
\text { security (VAS) Anchors: no }\end{array}$ \\
\hline
\end{tabular}




\begin{tabular}{|l|l|l|l|l|}
\hline \multicolumn{1}{|c|}{ Aspect } & \multicolumn{1}{|c|}{ QMAALD } & SIL & \multicolumn{1}{|c|}{ CSS } & \multicolumn{1}{c|}{ CEQ } \\
\hline & & & $\begin{array}{l}\text { sense of security/feel totally } \\
\text { secure } \\
\text { My impression of the medical } \\
\text { competence made me feel } \\
\text { secure }\end{array}$ \\
\hline $\begin{array}{l}\text { Unable to assign to } \\
\text { matrix }\end{array}$ & $\begin{array}{l}\text { To what degree were you aware of } \\
\text { events during labor? } \\
\text { To what degree were you aware of } \\
\text { events during delivery? } \\
\text { Was the delivery experience } \\
\text { realistic as opposed to dream-like? } \\
\text { Were you pleased with how your } \\
\text { delivery turned out? } \\
\text { Were you able to enjoy holding } \\
\text { your baby for the first time? } \\
\text { Did your partner (or other person) } \\
\text { review your labor experience with } \\
\text { you? } \\
\text { Did you feel better after reviewing } \\
\text { the labor and delivery experience? }\end{array}$ & & & $\begin{array}{l}\text { My midwife also devoted } \\
\text { enough time to my partner } \\
\text { I have many negative memories } \\
\text { from the labour process } \\
\text { I have many positive memories } \\
\text { from the labour process }\end{array}$ \\
& & & & \\
\hline
\end{tabular}




\section{Appendix C: WECS Phase 1 Content Validity Scores}

\begin{tabular}{|c|c|c|c|}
\hline & 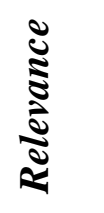 & 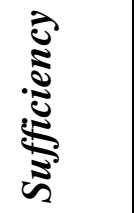 & $\frac{\vec{E}}{\mathbb{E}}$ \\
\hline \multicolumn{4}{|l|}{ Example: I learned as much about childbirth as I could. } \\
\hline $\begin{array}{l}\text { 1. I did everything medically required to ensure a good birth } \\
\text { experience. }\end{array}$ & 2 & 1.5 & 1.5 \\
\hline $\begin{array}{l}\text { 2. I trusted the doctors and nurses to make decisions that would be } \\
\text { best for me. }\end{array}$ & 3 & 3 & 3 \\
\hline $\begin{array}{l}\text { 3. It is important to me to experience the least amount of pain during } \\
\text { childbirth. }\end{array}$ & 4 & 3 & 4 \\
\hline 4. The process of giving birth prepared me for being a mother. & 2.5 & 2.5 & 3 \\
\hline I learned as much about childbirth as I could. & 5 & 3.5 & 5 \\
\hline Giving birth is hard physical work. & 4.5 & 4.5 & 4.5 \\
\hline I felt like my individual needs were attended to during childbirth. & 5 & 5 & 5 \\
\hline $\begin{array}{l}8 . \quad \text { I had a personal relationship with the person who delivered my } \\
\text { baby. }\end{array}$ & 2 & 2 & 2 \\
\hline 9. I had time to rest between contractions. & 4 & 4 & 3 \\
\hline $\begin{array}{l}\text { 10. I feel a stronger bond with those who were with me during the } \\
\text { labor and birth. }\end{array}$ & 5 & 5 & 5 \\
\hline $\begin{array}{l}\text { 11. During labor and birth I was sometimes experienced opposite } \\
\text { emotions at the same time. }\end{array}$ & 4 & 2 & 2 \\
\hline $\begin{array}{l}\text { 12. I could change the labor room and equipment to help me be } \\
\text { comfortable. }\end{array}$ & 4 & 2.5 & 2.5 \\
\hline 13. Giving birth is a significant event in my life. & 5 & 5 & 5 \\
\hline 14. I feel like my birth was private and dignified. & 5 & 5 & 5 \\
\hline 15. Each phase of labor and birth brought different challenges for me. & 4 & 3.5 & 3.5 \\
\hline 16. Giving birth is emotionally challenging. & 4.5 & 4.5 & 4.5 \\
\hline 17. I feel like my contractions had a predictable and increasing rhythm. & 3 & 2.5 & 3 \\
\hline $\begin{array}{l}\text { 18. I was able to make decisions about what was happening to me } \\
\text { during labor and birth. }\end{array}$ & 4.5 & 4.5 & 4.5 \\
\hline $\begin{array}{l}\text { 19. I was confident of my ability to cope with the challenges of labor } \\
\text { and birth. }\end{array}$ & 4 & 4 & \\
\hline 20. I have a changed sense of myself since because of giving birth. & 4.5 & 4.5 & 4.5 \\
\hline 21. I think the pain during labor has a purpose. & 2.5 & 3 & 3 \\
\hline 22. I felt like I had control of my body during labor and birth. & 4 & 4 & 4 \\
\hline 23. I believed childbirth would be a happy experience. & 4 & 4 & 4 \\
\hline $\begin{array}{l}\text { 24. When I did things like walking, showering, changing positions, } \\
\text { sitting on the ball it helped me feel more comfortable. }\end{array}$ & 4.5 & 4.5 & 4.5 \\
\hline $\begin{array}{l}\text { 25. The kindness and caring of those around me during labor and birth } \\
\text { gave me needed support. }\end{array}$ & 4.5 & 4.5 & 4.5 \\
\hline
\end{tabular}


26. I was able to manage the pain during labor.

27. The medical equipment such as fetal monitor and IV's gave me a sense of security during childbirth.

28. My dread and worry about labor and birth were not realized.

29. The pain control method I chose was the best decision for me.

\begin{tabular}{|r|r|r|r|} 
& 4 & 4 & 4 \\
\hline$a$ & & & \\
& 4 & 4 & 4 \\
\hline & 2.5 & 2.5 & 2 \\
\hline & 4 & 2.5 & 3 \\
\hline
\end{tabular}


Appendix D: Progression of Item Development for WECS

\begin{tabular}{|c|c|c|c|c|c|}
\hline Original Items & Current Items & $\begin{array}{l}\text { Literature } \\
\text { Review }\end{array}$ & $\begin{array}{l}\text { Existing } \\
\text { Instruments }\end{array}$ & $\begin{array}{l}\text { Participant } \\
\text { feedback- } \\
\text { cognitive } \\
\text { interview }\end{array}$ & $\begin{array}{l}\text { Content } \\
\text { experts } \\
\text { indicate } \\
\text { need for } \\
\text { revision }\end{array}$ \\
\hline \multicolumn{6}{|l|}{ Physical Aspects } \\
\hline $\begin{array}{l}\text { The pain in labor was } \\
\text { overwhelming to me }\end{array}$ & $\begin{array}{l}\text { My labor pain was more than I could } \\
\text { handle. }\end{array}$ & $X$ & $X$ & $X$ & $X$ \\
\hline \multicolumn{6}{|l|}{$\begin{array}{l}\text { The labor pains were worse than } \\
\text { I expected }\end{array}$} \\
\hline & $\begin{array}{l}\text { I was physically worn out from giving } \\
\text { birth. }\end{array}$ & $X$ & & $X$ & $X$ \\
\hline \multirow[t]{2}{*}{$\begin{array}{l}\text { I felt like labor occurred like a } \\
\text { predictable rhythm }\end{array}$} & $\begin{array}{l}\text { I had enough time to rest between } \\
\text { contractions. }\end{array}$ & $X$ & & $X$ & \\
\hline & $\begin{array}{l}\text { Nausea, vomiting, or shaking chills } \\
\text { kept me from being able to enjoy } \\
\text { childbirth. }\end{array}$ & & & $X$ & $X$ \\
\hline \multirow{3}{*}{$\begin{array}{l}\text { I felt like I had control of labor } \\
\text { by letting my body do what it } \\
\text { needed to do to give birth. }\end{array}$} & $\begin{array}{l}\text { I felt like I could control my body } \\
\text { during childbirth. }\end{array}$ & $X$ & & $X$ & \\
\hline & $\begin{array}{l}\text { I worked better with my contractions } \\
\text { when I stopped trying to fight the } \\
\text { contractions. }\end{array}$ & $\mathrm{X}$ & $\mathrm{X}$ & & \\
\hline & $\begin{array}{l}\text { The nurses helped me stay as } \\
\text { comfortable as possible. }\end{array}$ & $X$ & $\mathrm{X}$ & & \\
\hline
\end{tabular}


Original Items

\section{Emotional Aspects}

I feel conflicting emotions about my labor and birth

The first minutes with my child were precious to me

I feel conflicting emotions about
my labor and birth

I was excited about finally starting

labor.

I could not control my emotions during childbirth.

My nurse helped me feel calm.

\section{Cognitive Aspects}

I felt like the nurses did not pay attention to me as a person.

I was able to control the pain without medication.

I am glad I made the choice I did about pain medication during childbirth

My choice about using pain medication let me enjoy childbirth.

I am glad I made the choice I did whether to use pain medication.

I felt like I could separate myself I thought I could handle the pain better from the pain in labor than I did.

\section{Content}

Participant feedbackcognitive

\section{Review}

Existing

interview

experts

indicate

need for

revision

$\mathrm{X}$

X

X

X

X

X

X

X

X

X

X

X

X

X

X

X

X

X

X

X

X 


\section{Original Items}

I felt like I was prepared for

what would happen to me during childbirth

There were times when I

thought I might die during

childbirth

I was not always aware of the

time it was taking during labor and birth.

The way time passed seemed to be different from normal

I felt like I was alone within myself during labor and birth.

I was internally focused during labor and birth

Some aspects of childbirth are pleasurable

Some aspects of childbirth are erotic.

\section{Current Items}

I was prepared for what childbirth

would be like.

I had no clue what I was in for during childbirth.

Time passed very quickly during labor.

I worked hard to keep my mind off the pain.

I kept telling myself that every pain got me closer to holding my baby.

Birth was so amazing--I would gladly do it again (Flow)
X

$\mathrm{X}$

X

$\mathrm{X}$

Content

Participant experts

feedback- indicate

cognitive need for

revision

$\mathrm{X}$

X $\quad X$




\section{Original Items}

I don't think I can share all the sensations and experiences of birth with everyone

I loved the feeling of my

performance in labor and want to capture it again

I felt like I could accomplish anything after having my baby.

I felt like I could meet the challenges of labor

My attention was focused entirely on what I was doing

I could respond to my body in labor without thinking about it

When my baby was born, I

\section{Current Items}

I discovered I had unknown ability to handle the labor pain.(Flow)

I was better at handling the contractions as labor progressed.(Flow)

I felt connected to a higher power or God when I gave birth.(Flow)

I felt like I was a part of nature and the creative universe.(Flow)

I was so focused on my contractions I was not worried what anyone thought about how I was acting.(Flow)

I could tell when I was working well with my contractions.(Flow)

Giving birth is the greatest thing I have ever done.

The only positive thing about my
Content

Participant feedbackcognitive

Literatu

Existing

interview experts

indicate

need for

revision

$\begin{array}{ll}X & X \\ X & X\end{array}$

$\mathrm{X}$

$\mathrm{X}$
$\mathrm{X}$

X

X

X X 


\section{Original Items}

experience "love at first site"

I feel more womanly after

giving birth

I am more aware of my body since giving birth

I feel like labor and birth helped prepare me for motherhood.

I feel a deeper connection with other mothers since giving birth I feel a deeper connection with my own mother since giving birth

I felt comfortable enough with the people around me to lose my inhibitions during labor and

birth

\section{Social Aspects}

I could change my position to make myself more comfortable during labor

\section{Current Items}

experience is that I have a healthy baby.

Giving birth made me see that I am a strong woman.

I believe I can accomplish anything since giving birth.

I feel a deep sense of connection with all mothers in the world.

I appreciate my own mother more since giving birth.

I did not like the way I behaved during childbirth.

I was able to change positions or do things that made me more comfortable during labor.
X

X $\mathrm{X}$ $\mathrm{X}$

X

X

X

$\mathrm{X}$

$\mathrm{X}$

X
X $\quad$ X

\section{Content}

Participant

feedback-

cognitive

Literat
Review

Existing

interview

experts

indicate

need for

revision 


\section{Original Items}

I feel closer to my partner after sharing this birth experience with them.

I wish my birth experience could have been more private than it was.

I trusted the doctors and nurses to make decisions that would be best for my needs.

I trusted the doctors and nurses to make decisions that would be best for my baby.

I felt like the people around me during labor listened to my concerns

The people around me during labor offered suggestions about how to cope my contractions

I feel a strong bond with those who were present during the labor and birth.

\section{Current Items}

I felt tied to the equipment during labor.

The people I wanted were with me during birth.

My birth experience was as private as I wanted it to be.

I was able to make decisions about what was happening to me.

The doctors/midwives and nurses took control of the birth away from me.

The midwives/doctors and nurses helped me have the kind of birth experience I wanted.

My friends and family who were with me helped me stay comfortable during labor.

\section{Content}

Participant

feedback-

\section{cognitive \\ Literature \\ Existing \\ interview}

experts

indicate

need for

revision

$\mathrm{X}$

$\mathrm{X}$

X

X

X

X

X

X

X

X

X 


\section{Original Items}

The support I received from the people around me during childbirth gave me the confidence I needed to continue

I was overly sensitive to the people around me during childbirth

The kindness and caring of those around me during birth gave me strength to continue

I felt safe during childbirth

When I remember my birth experience, it runs in a steady stream like watching a movie

\section{Current Items}

My family and friends spoke up to make sure I had the kind of birth experience I wanted.

The doctors/midwives and nurses kept me informed of how labor was progressing.

My friends and family gave me strength and emotional support during labor.

The nurses knew what I needed before I had to ask.

\section{Content}

Participant

feedback-

cognitive

Literature

Review

Existing

Instruments

interview

$\mathrm{x}$

need for

revision
$\mathrm{X}$

$\mathrm{X}$

X

$\mathrm{X}$

X 


\section{Appendix E: WECS Phase 2 Content Validity Scores}

\begin{tabular}{|c|c|c|c|}
\hline & 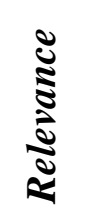 & 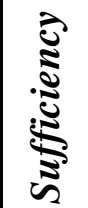 & \\
\hline My labor pain was more than I could handle & 4.8 & 4.0 & 3.8 \\
\hline I was worn out from giving birth & 3.5 & 3.5 & 3.3 \\
\hline I had enough time to rest between contractions & 4.3 & 4.5 & 4.5 \\
\hline $\begin{array}{l}\text { Nausea, vomiting, or shaking chills kept me from being able to enjoy } \\
\text { childbirth }\end{array}$ & 3.8 & 3.5 & 3.0 \\
\hline I felt like I could control my body during childbirth & 3.3 & 3.5 & 3.3 \\
\hline $\begin{array}{l}\text { I was so focused on my contractions that I could not pay attention to } \\
\text { anything else }\end{array}$ & 4.5 & 4.5 & 4.0 \\
\hline $\begin{array}{l}\text { I worked better with my contractions when I stopped trying to control } \\
\text { my body }\end{array}$ & 4.3 & 4.5 & 3.8 \\
\hline The nurses helped me stay as comfortable as possible & 4.3 & 4.3 & 3.8 \\
\hline I was afraid of what was happening to me & 4.0 & 4.5 & 4.0 \\
\hline I look back on the birth with great joy & 4.3 & 4.5 & 4.5 \\
\hline I was excited about beginning labor & 4.3 & 4.5 & 4.3 \\
\hline I could not control my emotions during childbirth & 4.8 & 4.3 & 4.3 \\
\hline My nurse helped me feel calm & 4.3 & 4.3 & 4.0 \\
\hline I felt like I was invisible to the nurses & 4.0 & 4.3 & 3.5 \\
\hline I was able to manage the labor pain & 4.3 & 4.5 & 4.0 \\
\hline The pain control method I used let me enjoy childbirth & 3.0 & 3.3 & 3.0 \\
\hline I am glad I made the choice I did about using pain medication & 4.0 & 4.0 & 3.8 \\
\hline I thought I could handle the pain better than I did & 3.5 & 3.5 & 3.3 \\
\hline I was prepared for what childbirth would be like & 4.5 & 4.5 & 4.5 \\
\hline I had no clue what I was in for & 4.0 & 4.3 & 3.8 \\
\hline Time passed very quickly during labor & 4.3 & 4.5 & 4.5 \\
\hline I thought my labor was never going to end & 4.3 & 4.5 & 4.5 \\
\hline I worked hard to keep my mind off the pain & 4.3 & 4.5 & 4.0 \\
\hline I kept telling myself that every pain got me closer to holding my baby & 4.5 & 4.3 & 4.0 \\
\hline Birth was so amazing--I would gladly do it again & 4.5 & 4.5 & 4.5 \\
\hline I discovered I was able to deal with the pain & 4.3 & 4.3 & 4.3 \\
\hline I got better at dealing with the contractions as labor progressed & 4.3 & 4.3 & 4.5 \\
\hline I felt connected to a higher power & 4.0 & 4.3 & 4.0 \\
\hline I felt like I was a part of nature and the creative universe & 3.8 & 4.3 & 3.5 \\
\hline $\begin{array}{l}\text { I was so focused on my contractions I was not worried what anyone } \\
\text { thought about how I was acting }\end{array}$ & 4.3 & 4.0 & 3.5 \\
\hline
\end{tabular}




\begin{tabular}{|l|l|l|l|}
\hline I could tell when I was working well with my contractions & 4.5 & 4.3 & 3.8 \\
\hline Giving birth is the greatest thing I have ever done & 4.3 & 4.5 & 4.3 \\
\hline At least the baby is healthy & 3.8 & 4.3 & 3.5 \\
\hline Giving birth made me see that I am a strong woman & 4.0 & 4.3 & 3.8 \\
\hline I believe I can accomplish anything since giving birth & 4.3 & 4.5 & 4.0 \\
\hline I feel a deep sense of connection with all mothers in the world & 4.0 & 4.3 & 3.8 \\
\hline I appreciate my own mother more since giving birth & 4.3 & 4.3 & 4.3 \\
\hline I did not like the way I behaved during childbirth & 4.5 & 4.3 & 4.3 \\
\hline I could change positions or do things that made me more comfortable & 4.5 & 4.5 & 3.8 \\
\hline I felt tied to the equipment & 4.5 & 4.8 & 4.3 \\
\hline The people I wanted were with me during birth & 4.5 & 4.8 & 4.5 \\
\hline My birth experience was as private as I wanted it to be & 4.3 & 4.5 & 4.3 \\
\hline I was able to make decisions about what was happening to me & 4.5 & 4.8 & 4.5 \\
\hline The doctors and nurses took control of the birth & 3.5 & 3.5 & 3.3 \\
\hline I put all my trust in the doctors and nurses to do what is best & 4.0 & 4.0 & 3.8 \\
\hline $\begin{array}{l}\text { My friends and family who were with me helped me stay } \\
\text { comfortable }\end{array}$ & 4.5 & 4.5 & 4.3 \\
\hline $\begin{array}{l}\text { I trusted my family and friends to help me have the birth experience I } \\
\text { wanted }\end{array}$ & 4.3 & 4.0 & 3.5 \\
\hline $\begin{array}{l}\text { The doctors and nurses kept me informed of how labor was } \\
\text { progressing }\end{array}$ & 4.3 & 4.3 & 4.5 \\
\hline My friends and family gave me strength and support & 4.3 & 4.3 & 4.3 \\
\hline The nurses knew what I needed before I had to ask & 4.3 & 4.3 & 4.3 \\
\hline
\end{tabular}




\section{Appendix F: Instrument and Data Collection Forms}

In the table below, please circle the number in the column that best describes how much you agree with each statement about being in labor and delivery.

When the term "midwives/doctors" is used, this refers to the person who delivered your baby. When the term "nurses" is used, it refers to the nurses who work in labor and delivery.

\begin{tabular}{|c|c|c|c|c|c|c|}
\hline & 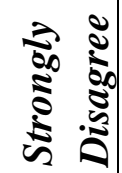 & 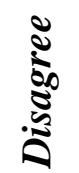 & 胥 & 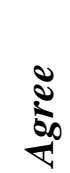 & 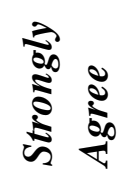 \\
\hline \multicolumn{2}{|r|}{ Example: I learned as much about childbirth as I could. } & 1 & 2 & (3) & 4 & 5 \\
\hline 1 & My labor pain was more than I could handle. & 1 & 2 & 3 & 4 & 5 \\
\hline 2 & I was physically worn out from giving birth. & 1 & 2 & 3 & 4 & 5 \\
\hline 3 & I had enough time to rest between contractions. & 1 & 2 & 3 & 4 & 5 \\
\hline 4 & $\begin{array}{l}\text { Nausea, vomiting, or shaking chills kept me from being able to } \\
\text { enjoy childbirth. }\end{array}$ & 1 & 2 & 3 & 4 & 5 \\
\hline 5 & I felt like I could control my body during childbirth. & 1 & 2 & 3 & 4 & 5 \\
\hline 6 & $\begin{array}{l}\text { I worked better with my contractions when I stopped trying to } \\
\text { fight the contractions. }\end{array}$ & 1 & 2 & 3 & 4 & 5 \\
\hline 7 & The nurses helped me stay as comfortable as possible. & 1 & 2 & 3 & 4 & 5 \\
\hline 8 & I was afraid of what was happening to me during childbirth. & 1 & 2 & 3 & 4 & 5 \\
\hline 9 & I look back on the birth with great joy. & 1 & 2 & 3 & 4 & 5 \\
\hline 10 & I was excited about finally starting labor. & 1 & 2 & 3 & 4 & 5 \\
\hline 11 & I could not control my emotions during childbirth. & 1 & 2 & 3 & 4 & 5 \\
\hline 12 & My nurse helped me feel calm. & 1 & 2 & 3 & 4 & 5 \\
\hline 13 & I felt like the nurses did not pay attention to me as a person. & 1 & 2 & 3 & 4 & 5 \\
\hline 14 & I was able to control the pain without medication. & 1 & 2 & 3 & 4 & 5 \\
\hline 15 & My choice about using pain medication let me enjoy childbirth. & 1 & 2 & 3 & 4 & 5 \\
\hline 16 & I am glad I made the choice I did whether to use pain medication. & 1 & 2 & 3 & 4 & 5 \\
\hline 17 & I thought I could handle the pain better than I did. & 1 & 2 & 3 & 4 & 5 \\
\hline 18 & I was prepared for what childbirth would be like. & 1 & 2 & 3 & 4 & 5 \\
\hline 19 & I had no clue what I was in for during childbirth. & 1 & 2 & 3 & 4 & 5 \\
\hline 20 & Time passed very quickly during labor. & 1 & 2 & 3 & 4 & 5 \\
\hline 21 & I thought my labor was never going to end. & 1 & 2 & 3 & 4 & 5 \\
\hline 22 & I worked hard to keep my mind off the pain. & 1 & 2 & 3 & 4 & 5 \\
\hline
\end{tabular}




\begin{tabular}{|c|c|c|c|c|c|c|}
\hline & & 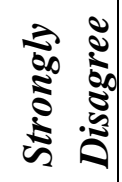 & 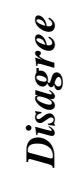 & $\begin{array}{l}\bar{\Xi} \\
\bar{\Xi} \\
z\end{array}$ & 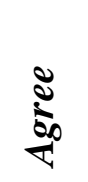 & 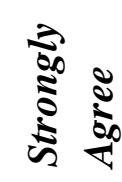 \\
\hline 23 & $\begin{array}{l}\text { I kept telling myself that every pain got me closer to holding } \\
\text { my baby. }\end{array}$ & 1 & 2 & 3 & 4 & 5 \\
\hline 24 & Birth was so amazing--I would gladly do it again. & 1 & 2 & 3 & 4 & 5 \\
\hline 25 & I discovered I had unknown ability to handle the labor pain. & 1 & 2 & 3 & 4 & 5 \\
\hline 26 & I was better at handling the contractions as labor progressed. & 1 & 2 & 3 & 4 & 5 \\
\hline 27 & I felt connected to a higher power or God when I gave birth. & 1 & 2 & 3 & 4 & 5 \\
\hline 28 & I felt like I was a part of nature and the creative universe. & 1 & 2 & 3 & 4 & 5 \\
\hline 29 & $\begin{array}{l}\text { I was so focused on my contractions I was not worried what } \\
\text { anyone thought about how I was acting. }\end{array}$ & 1 & 2 & 3 & 4 & 5 \\
\hline 30 & I could tell when I was working well with my contractions. & 1 & 2 & 3 & 4 & 5 \\
\hline 31 & Giving birth is the greatest thing I have ever done. & 1 & 2 & 3 & 4 & 5 \\
\hline 32 & $\begin{array}{l}\text { The only positive thing about my experience is that I have a } \\
\text { healthy baby. }\end{array}$ & 1 & 2 & 3 & 4 & 5 \\
\hline 33 & Giving birth made me see that I am a strong woman. & 1 & 2 & 3 & 4 & 5 \\
\hline 34 & I believe I can accomplish anything since giving birth. & 1 & 2 & 3 & 4 & 5 \\
\hline 35 & I feel a deep sense of connection with all mothers in the world. & 1 & 2 & 3 & 4 & 5 \\
\hline 36 & I appreciate my own mother more since giving birth. & 1 & 2 & 3 & 4 & 5 \\
\hline 37 & I did not like the way I behaved during childbirth. & 1 & 2 & 3 & 4 & 5 \\
\hline 38 & $\begin{array}{l}\text { I was able to change positions or do things that made me more } \\
\text { comfortable during labor. }\end{array}$ & 1 & 2 & 3 & 4 & 5 \\
\hline 39 & I felt tied to the equipment during labor. & 1 & 2 & 3 & 4 & 5 \\
\hline 40 & The people I wanted were with me during birth. & 1 & 2 & 3 & 4 & 5 \\
\hline 41 & My birth experience was as private as I wanted it to be. & 1 & 2 & 3 & 4 & 5 \\
\hline 42 & I was able to make decisions about what was happening to me. & 1 & 2 & 3 & 4 & 5 \\
\hline 43 & $\begin{array}{l}\text { The doctors/midwives and nurses took control of the birth away } \\
\text { from me. }\end{array}$ & 1 & 2 & 3 & 4 & 5 \\
\hline 44 & $\begin{array}{l}\text { The midwives/doctors and nurses helped me have the kind of } \\
\text { birth experience I wanted. }\end{array}$ & 1 & 2 & 3 & 4 & 5 \\
\hline 45 & $\begin{array}{l}\text { My friends and family who were with me helped me stay } \\
\text { comfortable during labor. }\end{array}$ & 1 & 2 & 3 & 4 & 5 \\
\hline 46 & My family and friends spoke up to make sure I had the kind of & 1 & 2 & 3 & 4 & 5 \\
\hline
\end{tabular}




\begin{tabular}{|c|c|c|c|c|c|c|}
\hline & & 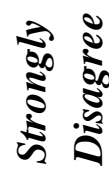 & 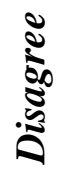 & 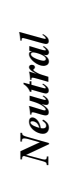 & 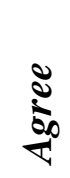 & 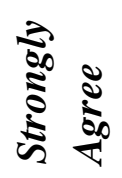 \\
\hline & birth experience I wanted. & & & & & \\
\hline 47 & $\begin{array}{l}\text { The doctors/midwives and nurses kept me informed of how labor } \\
\text { was progressing. }\end{array}$ & 1 & 2 & 3 & 4 & 5 \\
\hline 48 & $\begin{array}{l}\text { My friends and family gave me strength and emotional support } \\
\text { during labor. }\end{array}$ & 1 & 2 & 3 & 4 & 5 \\
\hline 49 & The nurses knew what I needed before I had to ask. & 1 & 2 & 3 & 4 & 5 \\
\hline
\end{tabular}

Please circle a number that corresponds with your overall birth experience

\section{$\begin{array}{lllllllllllll}\text { Worst experience of my life } & 1 & 2 & 3 & 4 & 5 & 6 & 7 & 8 & 9 & 10 & \text { Best experience of my life }\end{array}$}

Did you attend a childbirth class?

Yes with this pregnancy $\square$ No, but did with a previous pregnancy

$\square$ Never attended class

Who was with you for support during labor? Select all that apply

Just the nursing staff

Father of the baby

My mother in law/ partner's mother

Friend(s)

Others please list
Spouse/Partner

My mother

Sister(s)

Was the baby in the room with you when you were completing this survey?

Yes $\quad \square$ No

Was any family in the room with you when you were completing this survey?

Yes

No 
What do you consider your race/ethnicity to be? Select all that apply

Asian/Pacific Islander

Hispanic

White, Non-Hispanic

Other
Black, Non-Hispanic

Native American/Alaskan Native

\section{What country were you born in?}

If you were born in the United States, what state were you born in?

\section{What is your current relationship status?}

$\square$ Single, no committed relationship $\square$ Single, committed relationship with father of baby

Single, committed relationship with someone other than father of baby
Married
Divorced or separated
Widowed

Other

What is your preferred religion or spiritual practice? You may select from the list or write in your choice

Christian:

$\begin{array}{lll} & \square \text { Jewish } & \square \text { Agnostic } \\ \text { Catholic } & \square \text { Buddhist } & \square \text { Atheist } \\ \text { Orthodox } & \square \text { Muslim } & \square \text { Nothing in particular } \\ \text { Mormon } & \square \text { Hindu } & \square \text { Prefer not to say } \\ \text { Jehovah's Witness } & \square \text { Other faith: }\end{array}$


What is your household income?

$\square$ Below \$20,000

$\square$ Between $\$ 20,001$ and $\$ 40,000$

Between $\$ 40,001$ and $\$ 60,000$

$\square$ Between $\$ 60,001$ and $\$ 80,000$

$\square$ Above $\$ 80,000$

$\square$ Prefer not to say 


\section{Demographic and Obstetrical Information Form}

Please verify the following inclusion and exclusion criteria

Inclusion (all must be present to participate in study):

At least 18 years of age $\quad \square$ Able to read and write English

Full term pregnancy ( $\geq 37$ weeks) $\quad \square$ Singleton birth

Vaginal birth $\quad \square$ Living birth

Exclusion criteria - (if any responses are selected, participant is not eligible for inclusion)

Vaginal bleeding in $2^{\text {nd }}$ or 3rd trimesters (not including show with onset of labor)

History of previous fetal demise $\quad \square$ Previous cesarean section

Known fetal anomalies before labor $\quad \square \mathrm{PIH}$

Maternal diabetes (Type I, II, or Gestational) $\quad \square$ Positive maternal drug screen

Baby to be relinquished for adoption or Social Services

\section{Maternal Information}

Maternal Age

Highest Educational Achievement: (total years)

\section{Obstetrical Information}

Gravida

Full term

Pre-term

Aborted

Living

EDB (MM/DD/YYYY):

Week began prenatal care

Length of labor: (Hours \& minutes):

Interventions (check all that apply)

Misoprostol ${ }^{\circledR}$

Cervidil ${ }^{\circledR}$

Oxytocin prior to birth 
AROM

Vacuum extraction
Episiotomy

Forceps

Interventions continued

Other

Intrapartum fetal assessment (Select the highest level of intervention during labor)

$\square$ Intermittent External HR and TOCO

$\square$ Continuous External HR and TOCO

$\square$ Scalp electrode and Ext TOCO

$\square$ Scalp electrode and IUPC

Pain Medication Used (Select all that apply)

$\square$ No pain medication $\quad \square$ Local perineal anesthetic

Intermittent regional anesthetic (paracervical/pudendal block)

$\square$ Epidural analgesia

$\square$ IV analgesia Name of agent

Delivering professional

$\square$ Certified Nurse Midwife

OB-GYN

Medical Resident

Perineal repair

$\square$ None, no lac

Repair $2^{\circ}$ lac

Repair episiotomy
MD_Family Practice

L\&D Nursing Staff

Other

$\square$ None, $1^{\text {st } \circ}$ lac

Repair $3^{\circ}$ lac 
Repair episiotomy, $3^{\circ}$ extension $\quad \square$ Repair episiotomy, $4^{\circ}$ extension

\section{Newborn Information}

Gender: (Select one) $\square$ Female $\square$ Male

Gestational Age: by dates ___ Ballard Score, if available

APGAR 1 minute__ APGAR 5 minutes

$\square$ Breast feeding $\quad \square$ Bottle feeding $\quad \square$ Breast and bottle

$\square$ Baby to breast in delivery room $\quad \square$ Immediate rooming in 
Appendix G: IRB Approval 


\section{W. West VurginiaUniversity. \\ Office of Research Integrity and Compliance}

\section{Approval Letter Expedited}

To

From

Approval Period

Subject

Protocol Number

Title
Kari Sand-Jecklin

WVU Office of Research Integrity and Compliance

08/04/2014 Expiration Date 08/03/2015

Protocol Approval Letter

1305047700R001

Development and psychometric analysis of an instrument to measure a womans experience of childbirth

The above-referenced research study was reviewed by the West Virginia University Institutional Review Board IRB and was approved in accordance with 46 CFR 46.101b.

It has been determined that this study is of minimal risk and meets the criteria as defined by the expedited categorys listed below:

- Category 7. Research on individual or group characteristics or behavior including but not limited to research on perception cognition motivation identity language communication cultural beliefs or practices and social behavior or research employing survey interview oral history focus group program evaluation human factors evaluation or quality assurance methodologies. NOTE Some research in this category may be exempt from the DHHS regulations for the protection of human subjects. See Exempt Categories and 45 CFR $46.101 \mathrm{~b} 2$ and b3. This listing refers only to research that is not exempt.

Documents for use in this study have been approved and validated and are available in the WVUkc system in the Notes and Attachments section of your protocol.

Thank you.

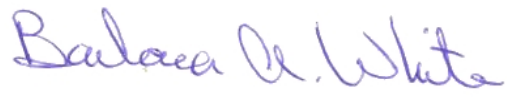

Board Designee Barbara White

Letter Sent By Barbara White on 08/04/2014 at 18:23:46-04:00 
Once you begin your human subject research, the following regulations apply:

1. Unanticipated or serious adverse events/side effects encountered in this research study must be reported to the IRB within five (5) days.

2. Any modifications to the study protocol or informed consent form must be reviewed and approved by the IRB prior to implementation.

3. You may not use a modified informed consent form until it has been approved and validated by the IRB. 
Appendix H: Permissions 


\section{BMDS meatalual \\ Database Services \\ Health and Psychosocial Instruments (HaPI)}

Director Eveiyn Perloff PhD

Behavioral Measurement

Database Services

HaPi Advisory Board

Aaron T. Beck. MD

University of Pennsyivania School of

Medicine

Timothy C. Brock, PhD

Ohio State University. Psychology

William C. Byham, PhD

Development Dimensions international

Nicholas A Cummings PhD

Foundation for Behavior Health

Donald Egolf PhD

University of Pittsburgh, Communication

Sandra J Frawley. PhD

Yale University School of Medicine

Medical Informatics

David F. Gillespie, PhD

George Warren Brown School of Social

Work, Washington University

Robert C. Uke. MD. MS

University of Medicine and Dentistry of

New Jersey

Robert Wood Johnson Medical School

Joseph D Matarazzo, PhD Oregon

Health Sciences University

Vickie M. Mays, PhD

University of Calfornia at

Los Angeles, Psychology

Kay Pool. President Pool

Heller \& Mine, inc

Ora Lea Strickland. PhD. RN. FAAN

Emory University Woodruff School of

Nursing

Gerald Zaitman, PhD

Harvard Unversity Graduate School of

Business Administration

Stephen J. Zyzanski. PhD

Case Western Reserve University

School of Medicine
Date: March 7, 2011

To: $\quad$ Ms. Elizabeth Viens Rini

From: Evelyn Perloff, PhD

Enclosed is the:

\section{Questionnaire Measuring Attitudes About Labor and Delivery Experience--Vaginal Delivery J. S. Marut and R. T. Mercer}

As I have indicated authors like to receive feedback on your study. All that is asked is that you provide a brief summary of your findings upon completion of your study/project. In addition, we encourage you to send a full report which we will consider for inclusion in Health and Psychosocial Instruments (HaPl) and which you may list on your vita/resume.

You have the author's permission to use the above instrument.

Please note that the instruments are for a single study only. It is, of course, necessary to provide the appropriate title and author credit in reproduced material and in your report. 


\section{Elizabeth Viens}

From:

Sent:

To:

Subject:
Anne Peirce [PEIRCE@adelphi.edu]

Friday, January 21, 2011 10:26 AM

Elizabeth Viens

Re: Birth Schema Instrument

I developed the instrument for my dissertation.. so you may use it. To develop it I interviewed 30+ (if my memory serves me right, the details are in my dissertation ) pregnant and post partum women and asked them to give me the words they words use to describe childbirth.. it had good reliability and validity... Iket me know what you find

Anne Griswold Peirce, RN, PhD

Associate Dean for Academic Affairs

Adelphi University School of Nursing

One South Main Street

Garden City, NY 11530-0701

Peirce@adelphi.edu

516-877-4746

$516-877-4558$ (Fax)

>>> "Elizabeth Viens" <elviens@comcast.net>1/20/2011 6:41 PM >>>

Dr. Peirce,

I am continuing my work on an instrument for women's birth experiences. This semester I am developing items and would like to include your instrument as part of cognitive interviewing about the birth experience. Do you hold the copyright? If you do, may I have permission to administer it in this pilot study?

Elizabeth Viens Rini

WVU School of Nursing 
From:

Sent:

To:

Subject:
Salmon, Peter [psalmon@liverpool.ac.uk]

Sunday, May 22, 2011 12:12 PM

Elizabeth Viens

RE: Salmon Inventory List

that's fine. I think that both questionnaires could be reconstructed from the information in the papers. But let me know if not and I will see if I have any copies.

Best wishes with your research

From: Elizabeth Viens [elviens@comcast.net]

Sent: 22 May 2011 14:38

To: Salmon, Peter

Subject: Salmon Inventory List

Dr. Salmon,

I am a doctoral student focusing on women's perceptions of their childbirth experience. I would like permission to use the instrument discussed in:

Salmon, P., Miller, R., \& Drew, N. C. (1990). Women's anticipation and experience of childbirth: the independence of fulfillment, unpleasantness and pain. British Journal of Medical Psychology, 63, 255-259.

and

Salmon, P. \& Drew, N. C. (1992). Multidimensional assessment of women's experience of childbirth: relationship to obstetric procedure, antenatal preparation and obstetric history. Journal of Psychosomatic Research, 36, 317-327.

Thank you for your consideration

Elizabeth Viens Rini 